\section{Pacific Northwest}

National Laboratory

Operated by Battelle for the

U.S. Department of Energy

\title{
Physical Property and Rheological Testing of Actual Transuranic Waste from Hanford Single-Shell Tanks
}

\author{
J. Tingey \\ J. Gao \\ C. Delegard \\ L. Bagaasen \\ B. Wells
}

August 2003

Prepared for the U.S. Department of Energy under Contract DE-AC06-76RL01830 


\title{
DISCLAIMER
}

This report was prepared as an account of work sponsored by an agency of the United States Government. Neither the United States Government nor any agency thereof, nor Battelle Memorial Institute, nor any of their employees, makes any warranty, express or implied, or assumes any legal liability or responsibility for the accuracy, completeness, or usefulness of any information, apparatus, product, or process disclosed, or represents that its use would not infringe privately owned rights. Reference herein to any specific commercial product, process, or service by trade name, trademark, manufacturer, or otherwise does not necessarily constitute or imply its endorsement, recommendation, or favoring by the United States Government or any agency thereof, or Battelle Memorial Institute. The views and opinions of authors expressed herein do not necessarily state or reflect those of the United States Government or any agency thereof.

\author{
PACIFIC NORTHWEST NATIONAL LABORATORY \\ operated by \\ BATTELLE \\ for the \\ UNITED STATES DEPARTMENT OF ENERGY \\ under Contract DE-AC06-76RL01830
}

This document was printed on recycled paper. 


\title{
Physical Property and Rheological Testing of Actual Transuranic Waste from Hanford Single-Shell Tanks
}

\author{
J. M. Tingey \\ J. Gao \\ C. H. Delegard \\ L. M. Bagaasen \\ B. E. Wells
}

August 2003

Prepared for the U.S. Department of Energy under Contract DE-AC06-76RL01830

Pacific Northwest National Laboratory

Richland, WA 99352 


\section{Executive Summary}

Composites of sludge from Hanford Tanks 241-B-203 (B-203), 241-T-203 (T-203), 241-T-204 (T-204), and 241-T-110 (T-110) were prepared at the Hanford 222-S Laboratory and transferred to the Radiochemical Processing Laboratory at the Pacific Northwest National Laboratory (PNNL) to measure the composites' physical properties. These tank composites were prepared from core samples retrieved from these tanks. These composites may not be representative of the entire contents of the tank, but they provide some indication of the properties of the waste in these underground storage tanks. Dilutions in water were also prepared from these composite samples. The measurements included paint filter tests, viscosity, direct measurement of shear strength with a rheometer, settling and centrifuging behavior, a qualitative test of stickiness, total solids concentration, sludge and supernatant liquor densities, $\mathrm{pH}$, and extrusion tests to estimate shear strength.

Three water dilutions were prepared from each of these homogenized samples (see Section 3.0 and Table 3.3). The first dilution was prepared to have a water concentration resulting in approximately 30 $\mathrm{wt} \%$ solids. The second dilution is a 1:1 dilution, and the third dilution is a 4:1 (water: sludge by mass) dilution. All of these dilutions were prepared with distilled water. Another dilution (DL1) was prepared for Tank T-110 to be more representative of the actual concentration when the sample was initially taken. Water was added to the Tank T-110 sample to form a sludge that would just meet the paint filter test. The solids content of this dilution was approximately $54 \mathrm{wt} \%$ solids. Solids content of all of the samples were measured by heating each sample in a drying oven at $105^{\circ} \mathrm{C}$.

The total solids concentration of the homogenized samples also was measured by thermogravimetric analysis. At $165^{\circ} \mathrm{C}$, the measured $\mathrm{wt} \%$ solids of the as-received Tank T-110 composite sample was approximately $70 \mathrm{wt} \%$. This is significantly higher than is reported in the data report for this core sample; therefore, it is assumed that samples from this tank lost substantial amounts of water prior to the composite being prepared. The wt $\%$ solids of the other composite samples (32 $\mathrm{wt} \%$ for $\mathrm{T}-204,41 \mathrm{wt} \%$ for B-203, and $34 \mathrm{wt} \%$ for T-203 as measured by oven drying) are similar to the data reported on the original core samples.

No clarified liquid was observed on any of the homogenized, as-received samples after a week of gravity settling. After centrifugation at $1000 \times \mathrm{g}(\sim 2300 \pm 100 \mathrm{rpm}$ with a radius of $16.2 \mathrm{~cm})$ for 15 minutes, the homogenized, as-received sample from Tank T-110 still had no separate liquid phase, but the samples from Tanks T-204, B-203, and T-203 had a small amount of clarified liquid ( $\approx 10 \mathrm{vol} \%)$ after centrifugation. The bulk density for these homogenized samples was $1.32 \mathrm{~g} / \mathrm{mL}$ for T-110, B-203, and T203 and $1.48 \mathrm{~g} / \mathrm{mL}$ for $\mathrm{T}-204$.

The 1:1 and 4:1 dilutions for all of the samples gravity settled to form clarified supernatant liquor. The $30 \mathrm{wt} \%$ solids dilutions did not form clarified supernatant during gravity settling for one week with the exception of the $30 \mathrm{wt} \%$ solids dilution from Tank T-110. No clarified supernatant was observed for the initial dilution (54 wt\% solids) for Tank T-110, but clarified supernatant was observed after centrifugation of this dilution. The vol\% centrifuged solids was measured after 15, 30, and 90 minutes of centrifugation. No significant additional compaction was observed after 15 minutes of centrifuging for the $1: 1$ and 4:1 dilutions. A small amount of additional compaction of the solids was observed for the $30-w t \%$ solids dilutions and the homogenized samples after 30 minutes of centrifuging. No significant 
changes in the vol\% centrifuged solids were observed between the 30 - and 90 -min measurements. The centrifuged solids volume is a linear function of the $\mathrm{wt} \%$ solids, but the slope is different for each tank.

The centrifuged solids densities of all the tested samples ranged from 1.29 to $1.61 \mathrm{~g} / \mathrm{mL}$, depending on the sample source. The solids in more diluted samples usually show slightly lower densities than less diluted samples. The centrifuged supernatant densities vary from 1.03 to $1.24 \mathrm{~g} / \mathrm{mL}$. The centrifuged supernatant densities of some of the composites are greater than the densities observed in tank liquid samples. The supernatant densities are higher than the density of water due to the dissolution of salts into the supernatant liquor. The supernatant liquor $\mathrm{pH}$ of all the tested tank composites do not vary significantly over the range of dilutions tested. The supernatant liquor $\mathrm{pH}$ was about $\mathrm{pH} 8$ for Tank T110 and about $\mathrm{pH} 11$ for Tanks T-204, B-203, and T-203.

Homogenized as-received samples from Tanks T-204, T-203, and B-203 were significantly stickier than the samples from Tank T-110. Stickiness was estimated by weighing the amount of sludge adhering to a metal probe that had been inserted into and then removed from the sludge. The stickiness of the samples decreased with decreasing solids contents. The 1:1 and 4:1 dilutions did not leave any significant residue on the metal cylinder placed in the sample. All other samples left significant residue on the metal cylinder after it was pushed into the sample except for the T-110 composite and 30-wt $\%$ solids dilution.

The shear strength of the homogenized samples from Tanks B-203, T-203, and T-204 was between 1500 and $4000 \mathrm{~Pa}$, and the shear strength of the $30-\mathrm{wt} \%$ solids dilutions from these tanks ranged from 60 to $850 \mathrm{~Pa}$. The shear strength of the T-110 dilution was much smaller than those observed for the other tank samples (20 Pa for the $54 \mathrm{wt} \%$ solids dilution). The dilutions of all of the tank samples exhibited Bingham Plastic behavior with yield stresses ranging from 0.03 to $40 \mathrm{~Pa}$. All of these dilutions exhibited thixotropic behavior.

Shear strengths for the homogenized samples and the 30 -wt $\%$ solids dilutions estimated from the small-scale (mini-) extrusion testing ranged from a lower bound of $390 \mathrm{~Pa}$ to an upper bound of $630 \mathrm{~Pa}$ for the B-203 sample, 260 to $720 \mathrm{~Pa}$ for the T-203 sample, and 310 to $1230 \mathrm{~Pa}$ for the T-204 sample. This range is similar to the shear strengths measured by the rheometer. Multiple measurements in T-203 and T-204 showed relatively good repeatability. In each case, the original core extrusions had median and maximum strengths two to four times greater than those determined from the present mini-extrusion tests. The prior shear strengths were estimated by analyzing the waste behavior during the original extrusion of the core samples. Possible explanations for this difference include the effects of sample handling or the smaller scale of the mini extrusions. The mini-extrusion results are generally bounded by the core extrusion results. 


\section{Acronyms}

\begin{tabular}{|c|c|}
\hline $\mathrm{BF}$ & extrusion length best fit \\
\hline $\mathrm{CS}$ & constant stress \\
\hline DSC & Differential Scanning Calorimeter \\
\hline DST & double-shell tank \\
\hline DTA & High-Temperature Differential Thermal Analyzer \\
\hline EPA & U.S. Environmental Protection Agency \\
\hline IEC & International Equipment Company \\
\hline LB & lower extrusion length bounds \\
\hline MAI & Mission Acceleration Initiative \\
\hline NIST & National Institute of Standards and Technology \\
\hline PNNL & Pacific Northwest National Laboratory \\
\hline PUREX & Plutonium Uranium Extraction (Plant) \\
\hline SST & single-shell tank \\
\hline $\mathrm{TC}$ & temperature controlled \\
\hline TG & Thermo-Gravimetric Analyzer \\
\hline TGA & thermogravimetric analysis \\
\hline TS & total solids concentration \\
\hline TRU & transuranic \\
\hline UB & upper extrusion length bounds \\
\hline WIPP & Waste Isolation Pilot Plant \\
\hline
\end{tabular}




\section{Contents}

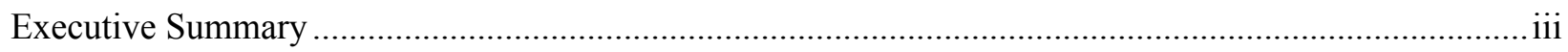

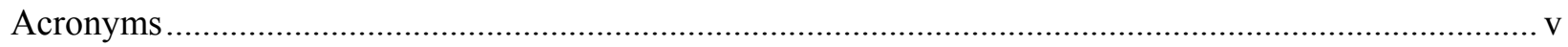

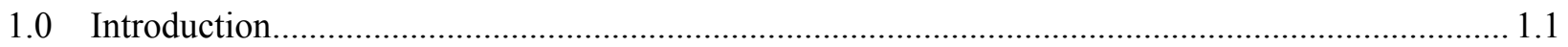

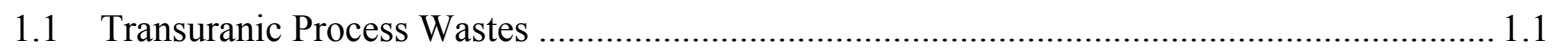

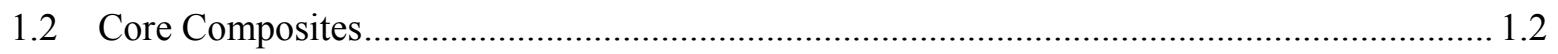

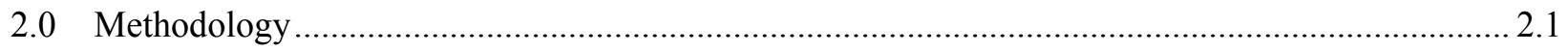

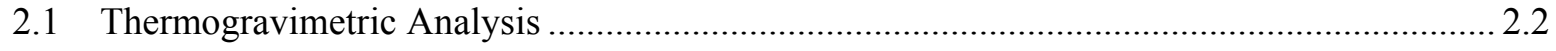

2.2 Total Solids Concentration by Oven Drying ….............................................................. 2.2

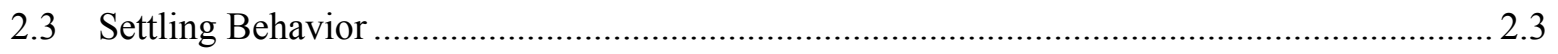

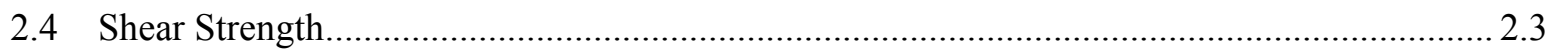

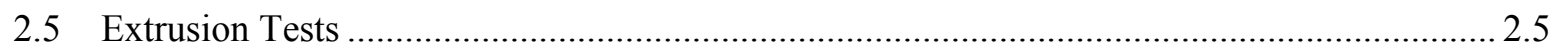

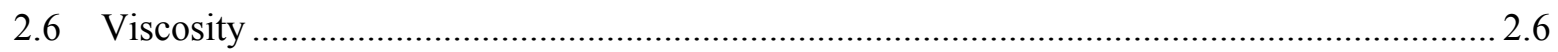

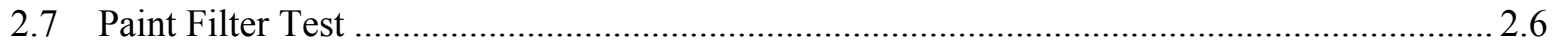

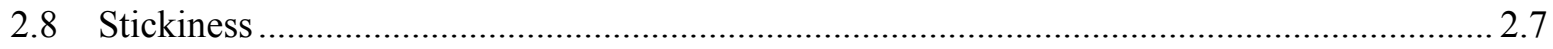

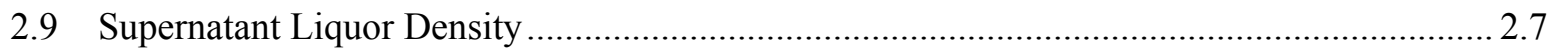

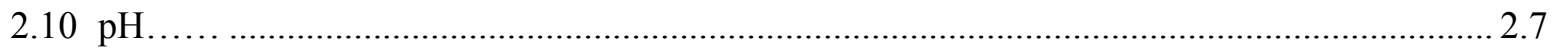

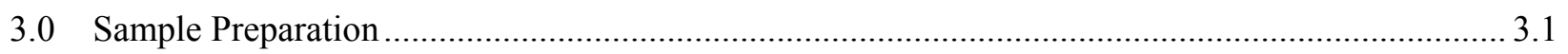

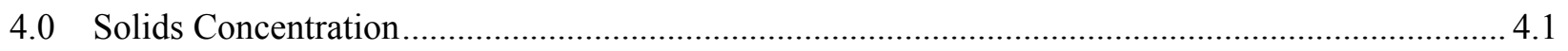

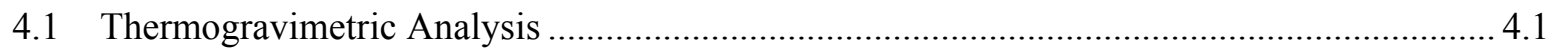

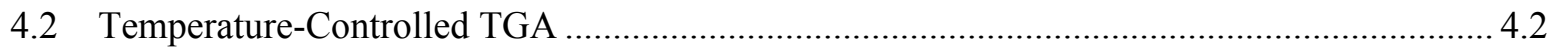

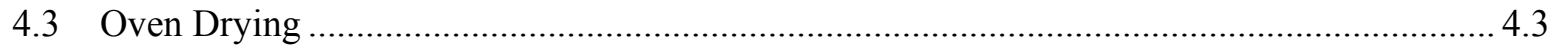

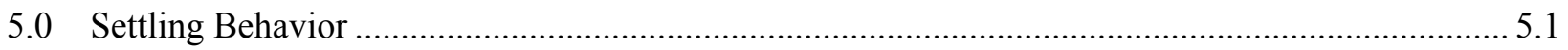

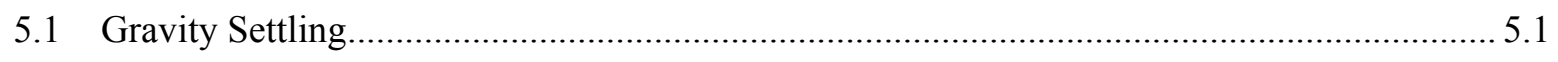




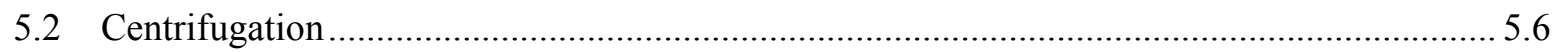

5.3 Centrifuged Solids and Supernatant Liquor Density ..................................................... 5.12

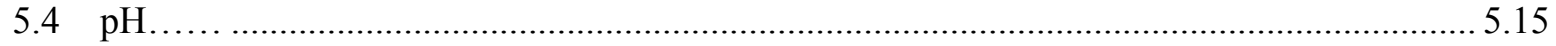

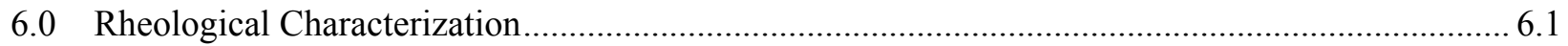

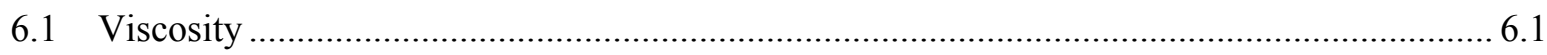

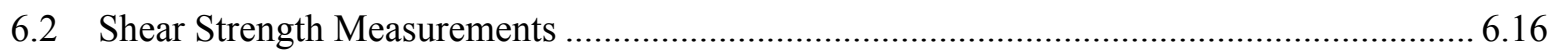

6.3 Shear Strength Estimates from Extrusion Length............................................................ 6.17

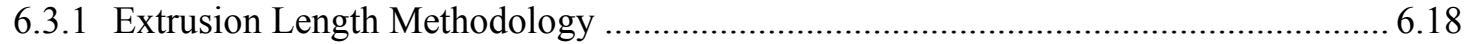

6.3.2 Mini-Extrusion Shear-Strength Results.................................................................... 6.18

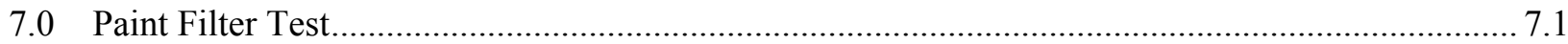

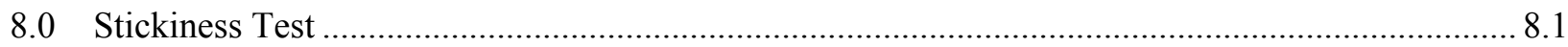

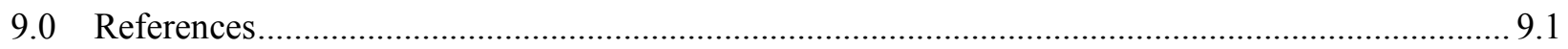

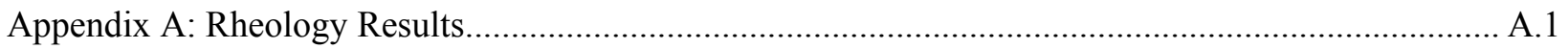




\section{Figures}

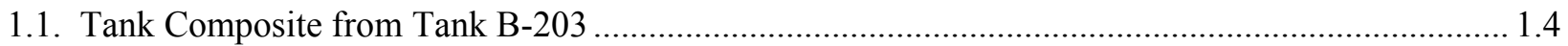

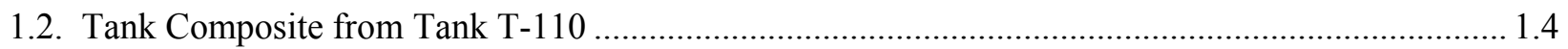

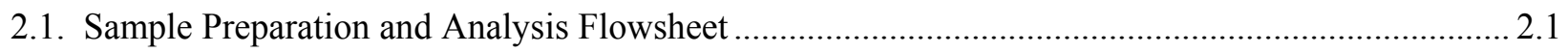

2.2. Typical Stress-Versus-Time Profile for a Shear Vane at Constant Shear Rate ............................... 2.4

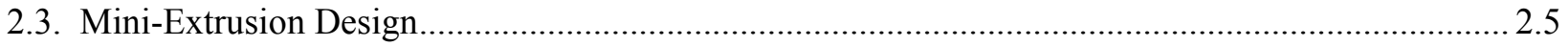

4.1. Thermogravimetric Analysis of Homogenized Tank Composites ................................................ 4.2

4.2. TC-TGA Curve for the Homogenized Composite from Tank B-203 ........................................... 4.2

4.3. Comparison of Total Solids Concentrations of Tank Composite Samples Analyzed by TGA

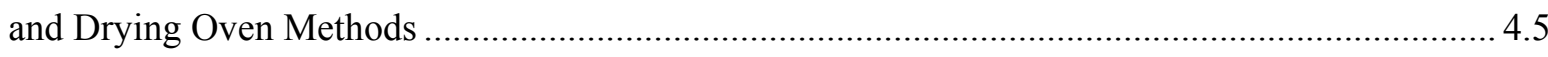

4.4. Comparison of Calculated and Measured Total Solids Concentrations of Tank Samples

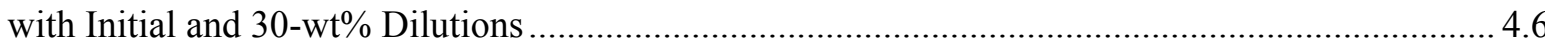

4.5. Comparison of Calculated and Measured Total Solids Concentrations of Tank Samples with 1:1 Dilution

4.6. Comparison of Calculated and Measured Total Solids Concentrations of Tank Samples with 4:1 Dilution

5.1. Settled Solids Volume Profiles of the 1:1 and 4:1 Dilutions of Tank T-204 ............................... 5.2

5.2. Settled Solids Volume Profiles of the 1:1 and 4:1 Dilutions of Tank B-203 ................................5.2

5.3. Settled Solid Volume Profiles of the 1:1 and 4:1 Dilutions of Tank T-203 ..................................5.3

5.4. Settled Solids Volume Profiles of the Dilutions of Tank T-110 ................................................. 5.4

5.5. Settled Solids Volume as a Function of Total Solids Content of Tank T-110 Dilutions .................. 5.5

5.6. Comparison of Sediment-Bed Volume Profiles of All Tested Tank Samples ................................ 5.5

5.7. Centrifuged Solids-Volume Profiles of T-110 Homogenized Composite and Dilutions.................. 5.8

5.8. Centrifuged Solids Volume Profiles of T-204 Homogenized Composite and Dilutions .................. 5.9

5.9. Centrifuged Solids Volume Profiles of B-203 Homogenized Composite and Dilutions................... 5.9

5.10. Centrifuged Solids-Volume Profiles of T-203 Homogenized Composite and Dilutions............... 5.10 
5.11. Centrifuged Sample Solids Volume Versus Total Solids Concentration. Linear stands for the linear regression curves for each individual sample.

5.12. Supernatant Liquor $\mathrm{pH}$ vs. Total Solids Concentration (wt $\%$ ) of Homogenized and Diluted Tank Composites in Tanks T-110, T-203, B-203, and T-203....

6.1. Viscosity Versus Shear Rate of Tank T-110 30-wt\% Solids Dilution............................................. 6.3

6.2. Viscosity Versus Shear Rate of the Tank T-110 1:1 Dilution ....................................................... 6.3

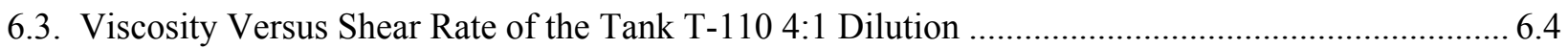

6.4. Viscosities Versus Shear Rate of the Tank T-204 1:1 Dilution ...................................................... 6.5

6.5. Viscosities Versus Shear Rate of the Tank T-204 4:1 Dilution ..................................................... 6.6

6.6. Viscosities Versus Shear Rate of the Tank B-203 30-wt\% Solids Dilution .................................... 6.8

6.7. Viscosities Versus Shear Rate of the Tank B-203 1:1 Dilution.................................................... 6.8

6.8. Viscosities Versus Shear Rate of the Tank B-203 4:1 Dilution ................................................... 6.9

6.9. Viscosities Versus Shear Rate of the Tank T-203 30-wt\% Solids Dilution................................... 6.11

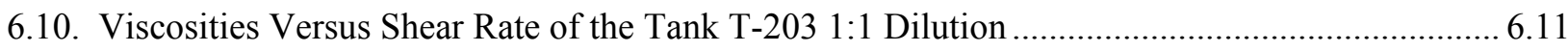

6.11. Viscosities Versus Shear Rate of the Tank T-203 4:1 Dilution ................................................... 6.12

6.12. Viscosity Versus Shear Rate of the 30 -wt\% Solids Dilutions ......................................................... 6.14

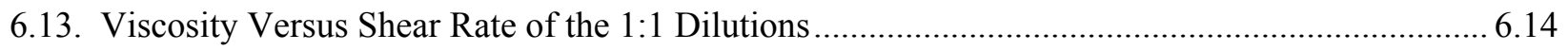

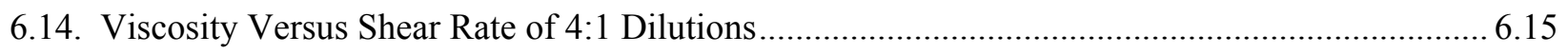

6.15. Shear-Strength Results for Tank T-110, T-204, B-203, and T-203 Samples.............................. 6.16 


\section{Tables}

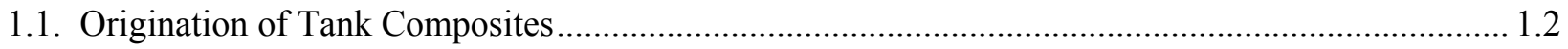

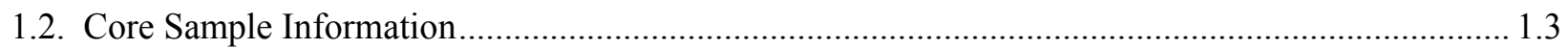

1.3. Water Concentrations of Original Core Samples and Archived Tank Composites ......................... 1.3

3.1. TRU Composite Sample Identification and Quantities........................................................... 3.1

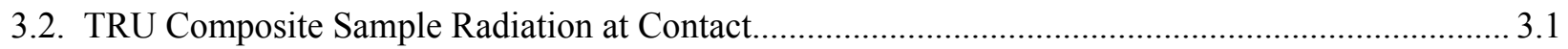

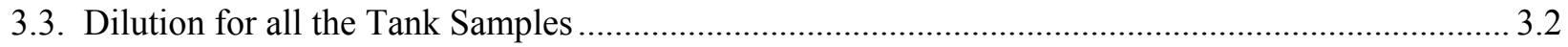

3.4. Densities of Original and Diluted Tank T-110 Samples .............................................................. 3.3

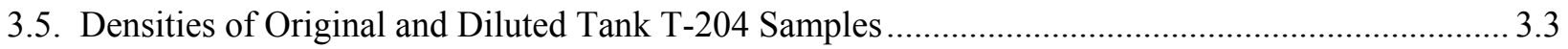

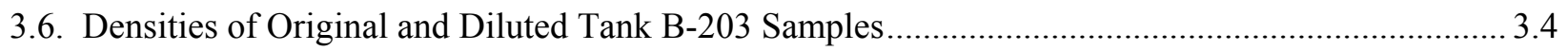

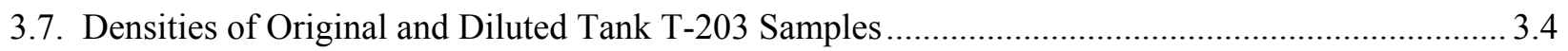

4.1. Total Solids Concentrations of Homogenized Tank Composites as Analyzed by TGA

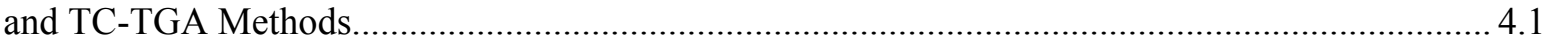

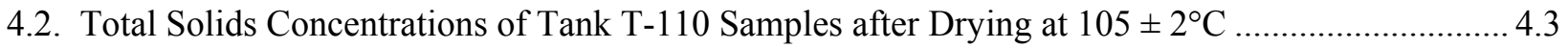

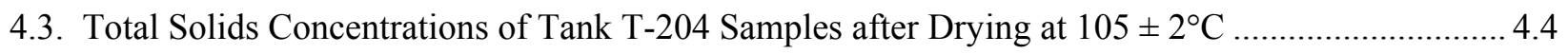

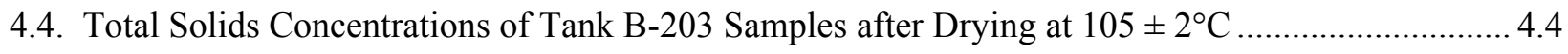

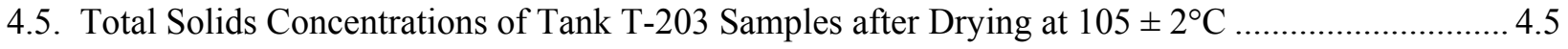

5.1. Completeness of the Gravity Settling Process Within the Testing Periods .................................... 5.6

5.2. Centrifuged Solids Volumes of All Tested Tank Samples after 90-min Centrifugation .................. 5.7

5.3. Linear Regression Results of Total Solids Concentration and Centrifuged Solids Volume........... 5.11

5.4. Densities of Centrifuged Solids of the Composite and Diluted Tank T-110 Samples.................... 5.12

5.5. Densities of Centrifuged Supernatant Liquor of the Composite and Diluted T-110 Samples ........5.13

5.6. Densities of Centrifuged Solids of Homogenized and Diluted Tank T-204 Samples.................... 5.13

5.7. Densities of Centrifuged Supernatant Liquor of Homogenized and Diluted T-204 Samples......... 5.13

5.8. Densities of Centrifuged Solids of Homogenized and Diluted Tank B-203 Samples ................... 5.14 
5.9. Densities of Centrifuged Supernatant Liquor of Homogenized and Diluted B-203 Samples........ 5.14

5.10. Densities of Centrifuged Solids of Homogenized and Diluted Tank T-203 Samples................... 5.14

5.11. Densities of Centrifuged Supernatant Liquor of Homogenized and Diluted T-203 Samples....... 5.15

5.12. $\mathrm{pH}$ Values of Diluted TRU Composite Supernatant liquors ...................................................... 5.16

6.1. Summary of Bingham Plastic Curve Fit Parameters of Tank T-110 Dilutions .............................. 6.4

6.2. Comparison of Different Curve Fits of Tank T-110 Samples........................................................ 6.5

6.3. Summary of Bingham Plastic Curve Fit Parameters of Tank T-204 Dilutions .............................. 6.6

6.4. Comparison of Different Curve Fits of Tank T-204 Samples......................................................... 6.7

6.5. Summary of Bingham Plastic Curve Fit Parameters of Tank B-203 Dilutions ............................ 6.10

6.6. Comparison of Different Curve Fits of Tank B-203 Samples ................................................... 6.10

6.7. Summary of Bingham Plastic Curve Fit Parameters of Tank T-203 Dilutions ............................. 6.13

6.8. Summary of Power Regression Model of the Shear Strengths for Tested Samples of

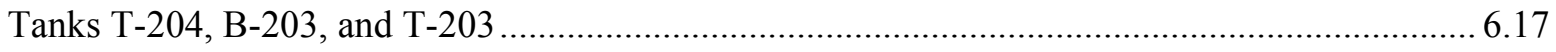

6.9. Comparison of Measured and Calculated Shear Strengths of Various Tank Samples ................... 6.17

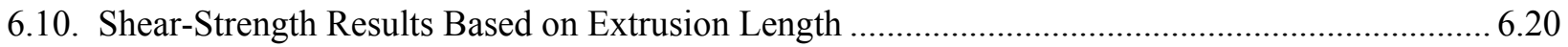

7.1. Paint Filter Test Results of Composites of Tanks T-110, T-204, B-203, T-203 and

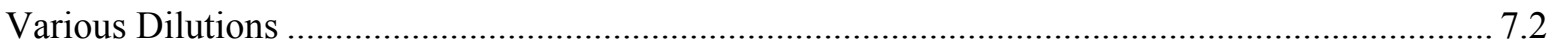

8.1. Stickiness Test Results of Tank T-110, T-204, B-203, and T-203 Samples.................................. 8.1 


\subsection{Introduction}

Supplemental technologies are being identified to accelerate the Hanford tank waste cleanup mission. Methods and equipment to package the transuranic (TRU) process wastes are part of the supplemental technologies being evaluated. The resulting TRU package and waste must be acceptable for disposal at the Waste Isolation Pilot Plant (WIPP).

A modified dry-retrieval process is proposed to remove the waste from these 10 Hanford SSTs. The sludge is removed from the tank using a vacuum. An aqueous stream flowing at approximately 1 to $5 \mathrm{gpm}$ will be added to the retrieved waste in the vacuum line to transfer the diluted waste to a storage vessel. A significant fraction of the liquid in this diluted waste stream must be removed to meet the WIPP disposal criteria; therefore, a dewatering process such as gravity settling, centrifugation, absorption, or drying will be added before packaging the waste. An absorbent may be added to the waste package to prevent the formation of free liquid during handling, transport, and storage of the package. Rheological and physical properties of the sludges during each step of the retrieval, transfer, dewatering, and packaging processes are needed to design the TRU waste disposal system.

\subsection{Transuranic Process Wastes}

To date, 13 Hanford waste tanks have been designated as potentially containing TRU process wastes, including three double-shell tanks (DSTs) (AW-103, AW-105, and SY-102) and 10 single-shell tanks (SSTs) (B-201 through B-204, T-201 through T-204, T-110 and T-111). Waste from Tank T-110 was initially classified as low-level waste (Gasper et al. 2002) but currently is considered a candidate for designation as potentially containing TRU process waste.

The sludge contained in DST SY-102 was produced in the Plutonium Finishing Plant. The sludges contained in DSTs AW-103 and AW-105 were produced from chemical dissolution of the cladding on irradiated nuclear fuel elements within the Plutonium Uranium Extraction (PUREX) Plant.

The waste contained in SSTs B-201 through B-204 and T-201 through T-204 was initially produced in the 224-B and 224-T Building operations as part of the plutonium concentration cycle in the Bismuth Phosphate Process (DuPont 1944, pp. 152-157). The waste contained in SSTs T-110 and T-111 also received waste from the 224-T Building as well as second plutonium decontamination cycle waste (2C) produced in the 221-T Plant as part of the Bismuth Phosphate Process (DuPont 1944, pp. 152-157). The 224-B/224-T Building waste and $2 \mathrm{C}$ waste comprised solid and supernatant fractions. The solids were settled in these tanks (Gasper et al. 2002; Anderson 1990). The bulk of the fission product and product activity settled out with precipitated phosphates and lanthanum fluoride. Fission-product activity of the supernatant fraction of these wastes was low enough $(<0.001 \%$ of that in the starting metal) to permit ground disposal.

The sludges present in the 10 SSTs are the topic of this report. Archived core samples from selected Hanford tanks (B-203, T-110, T-203, and T-204) were composited, homogenized, diluted, and analyzed to provide the rheological and physical properties needed to design the TRU waste-disposal system. The properties measured include the settling behavior based on gravity and centrifugation; the density of the 
slurries, sediments, and supernatant liquor; the supernatant liquor $\mathrm{pH}$; the total solids concentration (TS); the shear strength; the sludge viscosity; "stickiness"; and the sludge extrusion behavior. The results of these measurements are provided in this report.

Chemical and radiochemical analyses of similar composites from the same Hanford tanks (B-203, T-110, T-203, and T-204) are provided in a separate report (Cooke 2003). An assessment of the physical properties of the TRU process wastes has been published based on previous results obtained on Hanford tank core samples from the 10 SSTs considered to be TRU process waste tanks (Rassat et al. 2003a).

\subsection{Core Composites}

Four Hanford tank waste composites were prepared from core samples archived in the hot cells of the Hanford 222-S Laboratory. The tank, cores, and segments used to prepare these composites are listed in Table 1.1. All four of these tanks contained waste originating from the plutonium concentration cycle in the Bismuth Phosphate Process. Tank T-110 also contains waste originating from the second plutonium decontamination cycle (2C). The core composites were prepared in the 222-S Laboratory and transferred to the Radiochemical Processing Laboratory at Pacific Northwest National Laboratory (PNNL). A detailed description of the composite preparation is provided in a letter from G. A. Cooke. ${ }^{\text {(a) }}$

Table 1.1. Origination of Tank Composites

\begin{tabular}{|c|c|c|c|}
\hline Tank & Core & Segments & Mass \\
\hline $241-\mathrm{B}-203$ & 115 & 1 and $4-10$ & $559 \mathrm{~g}$ \\
\hline $241-\mathrm{T}-203$ & 190 & $1-9$ and $1 \mathrm{R}$ & $563 \mathrm{~g}$ \\
\hline $241-\mathrm{T}-204$ & 188 & 1 and $3-10$ & $555 \mathrm{~g}$ \\
\hline $241-\mathrm{T}-110$ & 180 & $1-4$ and $6-8$ & $260 \mathrm{~g}$ \\
\cline { 2 - 4 } & 181 & $1-8$ & $280 \mathrm{~g}$ \\
\hline
\end{tabular}

All the samples used to prepare the composite were obtained from the Hanford tanks by push-mode core sampling. The push-mode core sampler is based on a modified core drilling design that is similar to the thief-and-trier-type samplers described in SW-846 (EPA 1994). Stainless steel samplers are passed through risers on the top of the tank to withdraw 19 -in.-long and $7 / 8$-inch-diameter cylindrical segments. A spring-actuated rotary valve is used to capture the waste in the sampler. Enough 19-in. segments are taken through the riser to represent a full core sample for all but the bottom 1.5 inches of waste in the tank (Bell 1993). The segments are numbered consecutively starting from the top of the waste in the tank. An " $R$ " is used after the segment number if the sample is repeated from the same location. After the core samples are retrieved from the tanks, the samplers are transferred to a hot cell where the sample is extruded from the sampler by applying pressure to the sampler piston after opening the rotary valve. These extruded segments are placed in glass jars and archived for further characterization of the waste.

(a) Letter by GA Cooke. "Large Composite and Shipment: Mission Acceleration Initiative (MAI) Transuranic (TRU)Large Composite Preparation and Shipment to Pacific Northwest National Laboratory (PNNL)."

FH-0301349, Fluor Hanford Inc., Richland, WA (2003). 
The composites used in these tests for Tanks B-203, T-203, and T-204 were prepared from a single core sample. The composite for Tank T-110 was prepared from two different core samples retrieved from the tank on the same day but from different locations within the tank. The date these core samples were retrieved from the tank and the riser used to obtain these core samples are noted in Table 1.2.

Table 1.2. Core Sample Information

\begin{tabular}{|c|c|c|c||}
\hline Tank & Core & Riser & Date Retrieved \\
\hline $241-\mathrm{B}-203$ & 115 & 2 & November 1995 \\
\hline $241-\mathrm{T}-203$ & 190 & 3 & April 1997 \\
\hline $241-\mathrm{T}-204$ & 188 & 3 & March 1997 \\
\hline \multirow{2}{*}{$241-\mathrm{T}-110$} & 180 & 6 & January 1996 \\
\cline { 2 - 4 } & 181 & 2 & January 1996 \\
\hline
\end{tabular}

Water evaporated during handling and storage of these core samples, resulting in composites with water concentrations lower than initially observed for these materials. The original water concentrations of core samples from Tanks T-110, T-204, B-203, and T-203 range from 64 to $82 \mathrm{wt} \%$ (Rassat et al. 2003a). Table 1.3 summarizes the water concentrations of the original core samples and the corresponding archived samples based on the wt $\%$ solids measured after drying at $105^{\circ} \mathrm{C}$. Water losses during storage of between 4 and 22\%, 7 and $10 \%, 3$ and $11 \%$, and 35 and $42 \%$, respectively, were observed for Tanks B-203, T-203, T-204, and T-110. Original core sample data on weight percent water from cores 120 and 122 were used for the weight percent water from the original core from Tank B-203 because data were not available for Core 115. Composites from Tanks B-203, T-203, and T-204 maintained enough water to form a moist sludge (Figure 1.1). The composite from Tank T-110 contained some moisture, but the composite was dry and crumbly (Figure 1.2).

Table 1.3. Water Concentrations of Original Core Samples and Archived Tank Composites

\begin{tabular}{|c|c|c|c|}
\hline Tank & Core & $\begin{array}{c}\text { Water Concentrations of } \\
\text { Original Core Samples } \\
\mathbf{( w t \% )}\end{array}$ & $\begin{array}{c}\text { Water Concentrations of } \\
\text { Archived Tank Composites } \\
(\mathbf{w t} \%)\end{array}$ \\
\hline $241-\mathrm{B}-203$ & 120,122 & $64-82$ & 60 \\
\hline $241-\mathrm{T}-203$ & 190 & $73-76$ & 66 \\
\hline $241-\mathrm{T}-204$ & 188 & $72-80$ & 69 \\
\hline $241-\mathrm{T}-110$ & 180,181 & $73-80$ & 38 \\
\hline
\end{tabular}




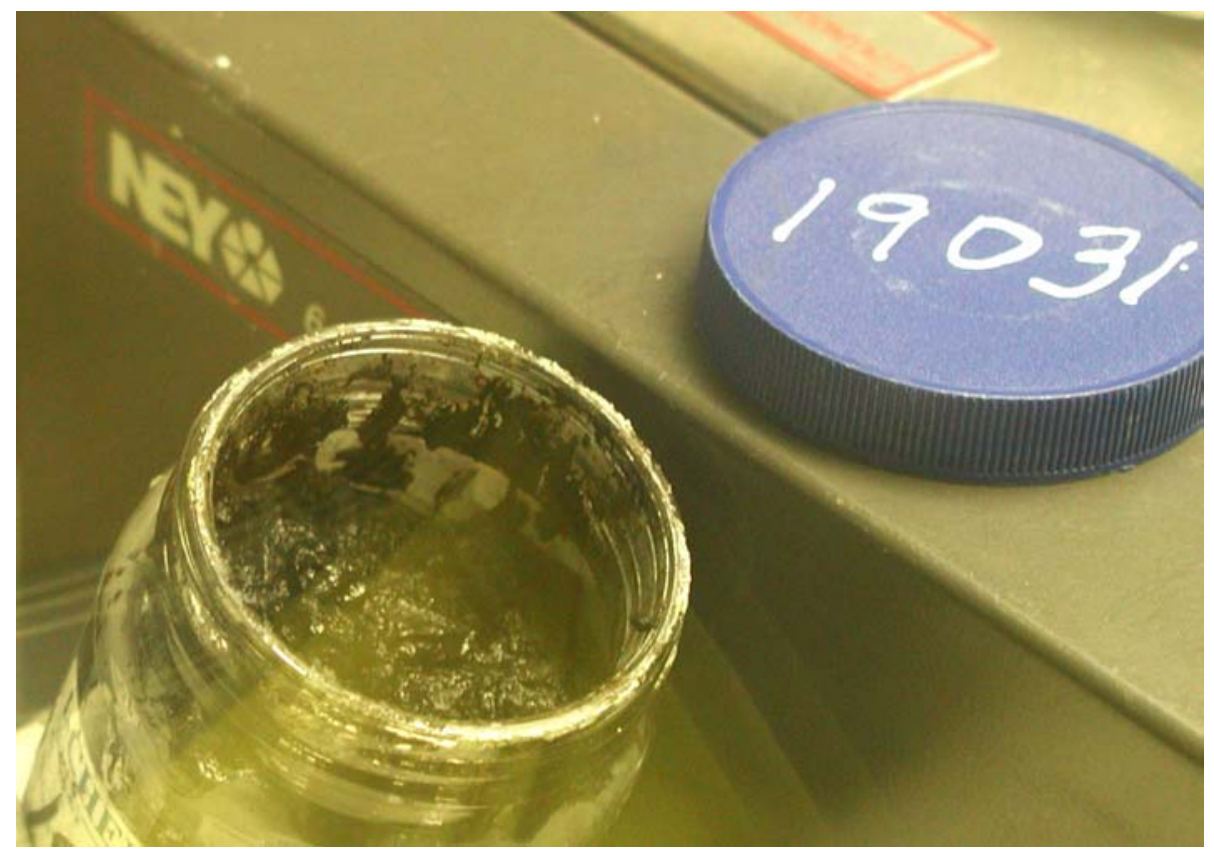

Figure 1.1. Tank Composite from Tank B-203

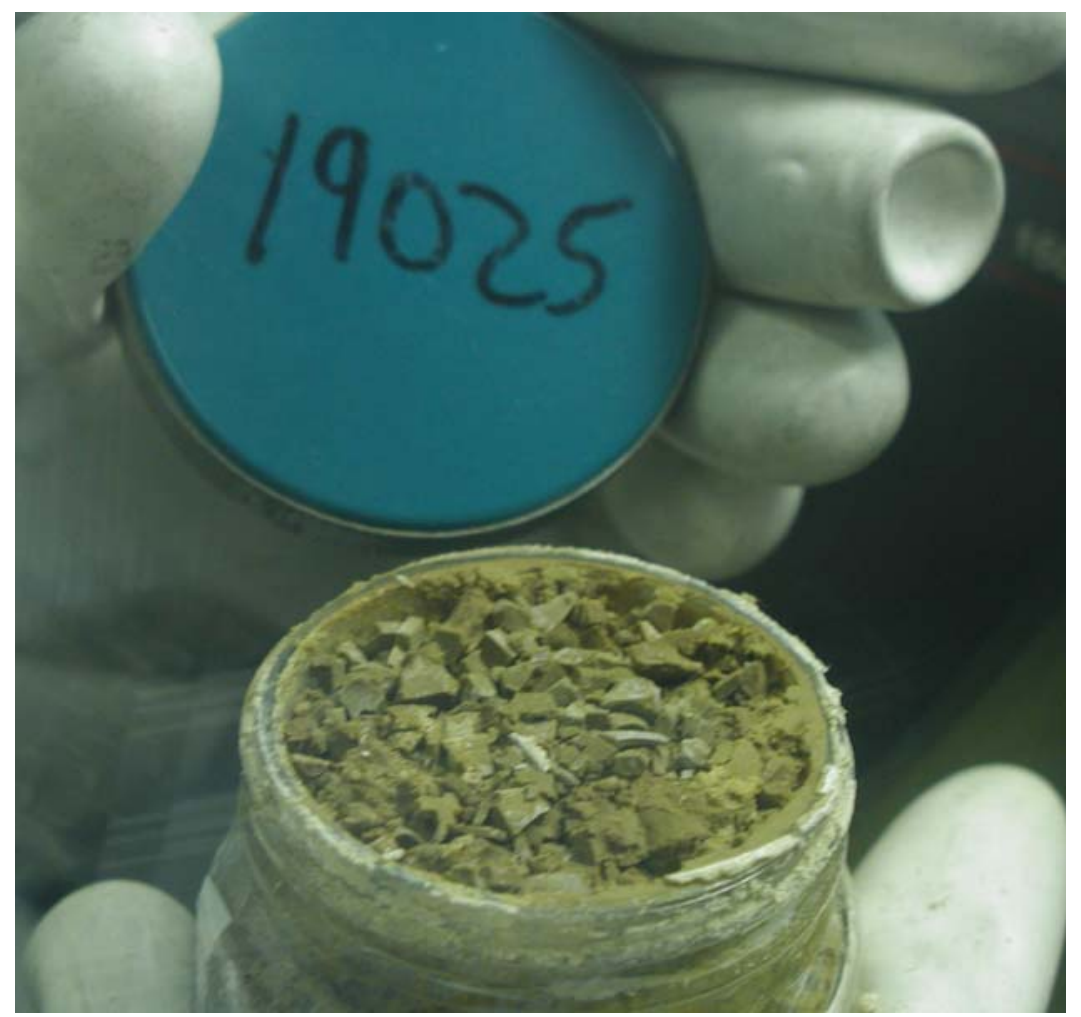

Figure 1.2. Tank Composite from Tank T-110 


\subsection{Methodology}

The flowsheet for preparing the samples and subsamples and the analyses performed on each subsample are presented in Figure 2.1. The tank composites were homogenized by transferring the sample into a larger jar and stirring with a plastic spatula. Large particles were broken by pressing the particles against the side of the jar with the spatula.

The initial dilution for Tank T-204 was prepared by slowly adding water and stirring until the resulting slurry had a consistency similar to a kaolin clay mixture with a shear strength of $450 \mathrm{~Pa}$. Based on the calculated solids concentration of this dilution (approximately $30 \mathrm{wt} \%$ solids), water was added to the composites from Tanks B-203 and T-203 to form slurries with solids concentrations of $30 \mathrm{wt} \%$. Two other dilutions were prepared by adding water at water-to-composite mass ratios of $1: 1$ and 4:1.

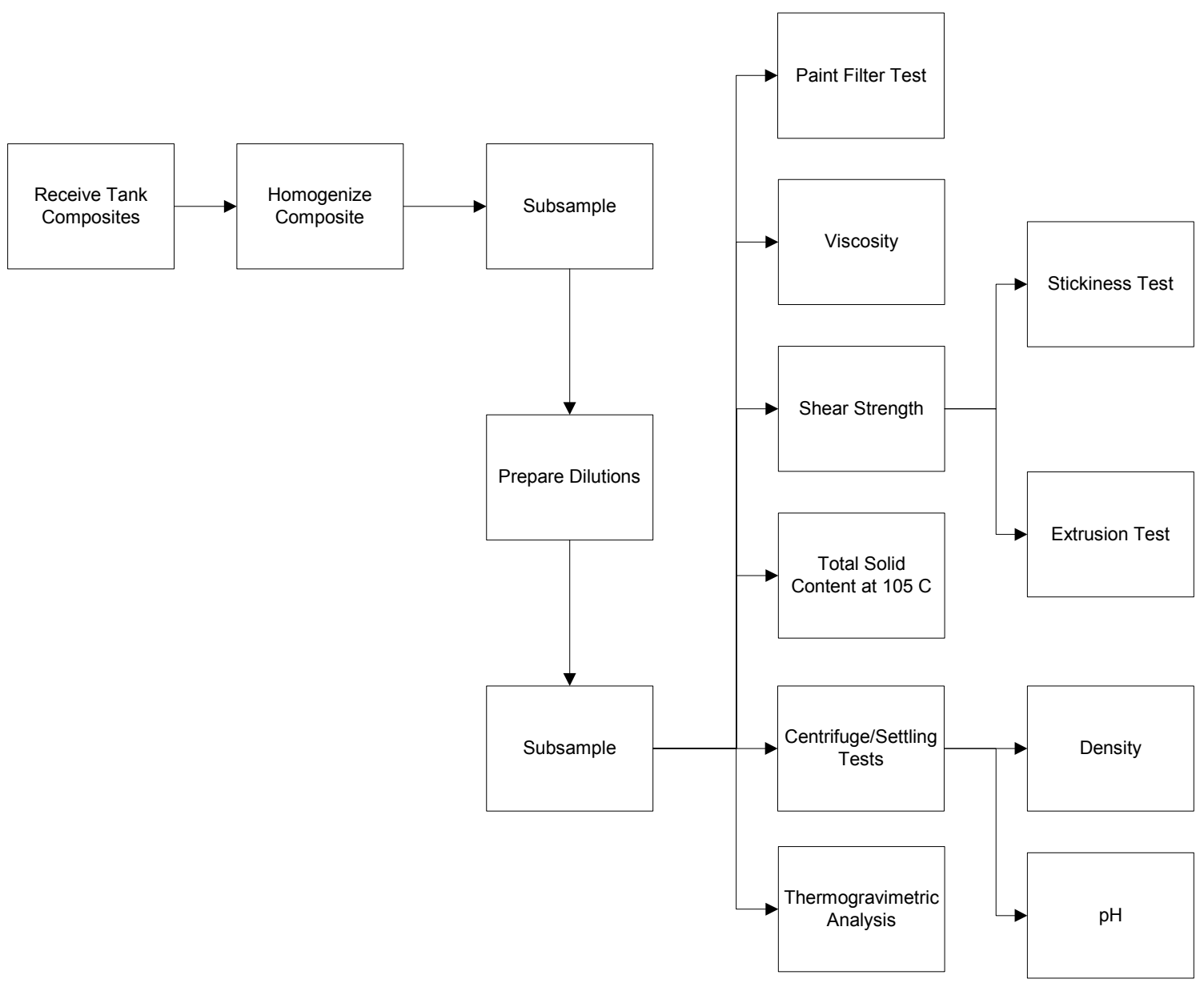

Figure 2.1. Sample Preparation and Analysis Flowsheet 
Because the water concentration of the composite from Tank T-110 was so much lower than that observed in the original core samples, and the slurry prepared at $30 \mathrm{wt} \%$ solids contained a significant amount of free liquid, an additional dilution at a solids concentration of $\sim 50 \mathrm{wt} \%$ was prepared from this tank composite. This initial dilution was prepared by adding water to the tank composite to obtain a slurry that would just pass the paint filter test. The third and fourth dilutions of the Tank T-110 composite were based on 1:1 and 4:1 mass ratios of water to a tank composite that would have a solids concentration equivalent to the average solids concentration of the core composites from the other three tanks as measured by thermogravimetric analysis (TGA) (37.6 wt \% solids).

\subsection{Thermogravimetric Analysis}

Analyses of the homogenized tank composites were conducted by TGA. The analyses were performed on Seiko Series 5200 and 6200 Thermal Analysis Systems according to PNNL technical procedure PNL-ALO-508, "Laboratory Procedure for Operation of the Differential Scanning Calorimeter (DSC), Thermo-Gravimetric Analyzer (TG), High-Temperature Differential Thermal Analyzer (DTA), and DSC," Revision 0.

Approximately $25 \mathrm{mg}$ of each sample were placed in a platinum pan, and the temperature of the sample was increased from ambient to approximately $550^{\circ} \mathrm{C}$ at a constant rate of $5^{\circ} \mathrm{C} /$ minute. The mass of the sample (TGA) and the change in the temperature of the sample (DTA) in relation to a reference sample (an empty platinum pan) were monitored as a function of temperature. These analyses were performed in a flowing helium atmosphere $(120 \mathrm{~mL} / \mathrm{min})$. The analysis was repeated on another subsample in a temperature-controlled mode. In this mode, the temperature was held constant during intervals experiencing a mass loss rate of greater than $100 \mu \mathrm{g} / \mathrm{min}$. Once the mass loss rate decreased below $20 \mu \mathrm{g} / \mathrm{min}$, the temperature ramp resumed at the specified rate $\left(5^{\circ} \mathrm{C} / \mathrm{min}\right)$.

The calibration of the thermal analysis system was checked with a lead or indium melting point standard and calibrated weights before each batch of measurements. The literature values for the onset temperature of indium and lead melting are 156.6 and $327.4^{\circ} \mathrm{C}$, respectively. The measured values for the onset temperature were 158.1 and $328.4^{\circ} \mathrm{C}$.

TGA was not performed on the dilutions from these tank composites because of the large amount of free liquid associated with the samples. A stable mass of the sample before starting an analysis is difficult to obtain with samples containing free liquid and at the gas flow rates required for this analysis. Therefore, water concentration was obtained by a gravimetric wt $\%$ solids measurement made on samples dried in a drying oven at $105^{\circ} \mathrm{C}$.

\subsection{Total Solids Concentration by Oven Drying}

Total solids concentrations of the dilutions prepared from the tank composites and the homogenized tank composites were determined in duplicate according to PNNL technical procedure TPR-RPP-WTP-211, "Measurement of Physical and Rheological Properties of Solutions, Slurries, and Sludges." Revision 0. Greater than $2 \mathrm{~g}$ of material was weighed and then dried to obtain the TS. The mass of the sample before and after drying was measured on a calibrated balance. The calibration of the 
balance was checked before each batch was tested. A 100-g standard weight was used to check the calibration. The balance was within $0.0001 \mathrm{~g}$ on each calibration check. A digital controller was used to control the temperature in the drying oven at $105 \pm 2{ }^{\circ} \mathrm{C}$. A calibrated thermometer was used to measure the temperature in the oven. After 24 hours of drying, the samples were removed from the furnace and allowed to cool, and the mass of the sample was measured. The samples were again placed in the oven at $105^{\circ} \mathrm{C}$ for a minimum of 15 hours. The dried samples were weighed again to assure that no significant additional mass was lost $(<2 \%$ difference).

\subsection{Settling Behavior}

Settling behavior of the homogenized tank composites and the dilutions prepared from these composites was determined in duplicate according to PNNL technical procedure TPR-RPP-WTP-211, "Measurement of Physical and Rheological Properties of Solutions, Slurries, and Sludges." Revision 0. Duplicate aliquots of the samples were allowed to gravity settle and then were centrifuged at a force of approximately $1000 \times \mathrm{g}$ for 15,30 , and 90 minutes. The volumes of free liquid, centrifuged and settled solids, and total sample were determined for each aliquot for each duration. The mass of each fraction was measured at the completion of the centrifugation.

Duplicate aliquots of the mixed dilutions and tank composites were transferred into clear 15-mL centrifuge cones, and the sediment volume was monitored as a function of time. The sediment volume is the volume from the bottom of the suspension column to the interface between the clear supernatant liquor and the cloudy suspension. Under the force of gravity, the solids in the suspension sank to the bottom of the cylinder, forming a sludge layer and a clear supernatant layer. The vol\% settled solids was then determined by dividing the final sediment bed volume by the total volume of the slurry.

After gravity settling was complete, the samples were mixed and the centrifuge cones were placed in an International Equipment Company (IEC) general-purpose centrifuge with a swinging bucket rotor that holds six $15-\mathrm{mL}$ centrifuge cones and has a swinging radius of $16.2 \mathrm{~cm}$. The cones were spun at $2300 \pm$ $100 \mathrm{rpm}$, which produces a centrifugal force of $1000 \times \mathrm{g}$ on the sample. The sediment volume was measured on each sample after 15, 30, and 90 minutes of centrifugation. The vol\% centrifuged solids was then determined by dividing the sediment volume by the total volume of the slurry. After centrifuging for 90 minutes, the supernatant liquor was decanted from the centrifuge cones and transferred to a graduated cylinder. The volume and mass of the decanted supernatant liquor were measured to determine the supernatant liquor density. The mass of the sediment remaining in the centrifuge cone was also measured. The densities of the supernatant liquor, centrifuged solids, and bulk sample were calculated from this centrifugation data. The fractions of supernatant and centrifuged solids under these processing conditions were also calculated.

\subsection{Shear Strength}

Shear strength is a semi-quantitative measure of the force required to move the sample from rest and is dependent on sample history. Shear strength can be measured directly by slowly rotating a vane immersed in the sample material and recording the resulting torque as a function of time. The measured torque is converted to a shear stress by Equations 3.1 and 3.2. 


$$
\tau=\mathrm{T} / \mathrm{K}
$$

where

$$
\mathrm{K}=\frac{\pi \mathrm{D}^{3}}{2}\left(\frac{\mathrm{H}}{\mathrm{D}}+\frac{1}{3}\right)
$$

where

$$
\begin{aligned}
\tau & =\text { calculated shear stress in Pascal } \\
\mathrm{T} & =\text { measured torque in Newton-meters } \\
\mathrm{K} & =\text { shear vane constant in cubic meters } \\
\mathrm{D} & =\text { shear vane diameter in meters } \\
\mathrm{H} & =\text { shear vane height in meters. }
\end{aligned}
$$

A typical stress/time profile is shown in Figure 2.2. The profile shows an initial linear region $\left(\tau_{\mathrm{y}}\right)$ followed by a nonlinear region, a stress maximum $\left(\tau_{\mathrm{s}}\right)$, and a stress-decay region. The stress maximum is the transition between the visco-elastic and fully viscous flow. Shear strength is defined as the transition between these two flows and is measured at the stress maximum.

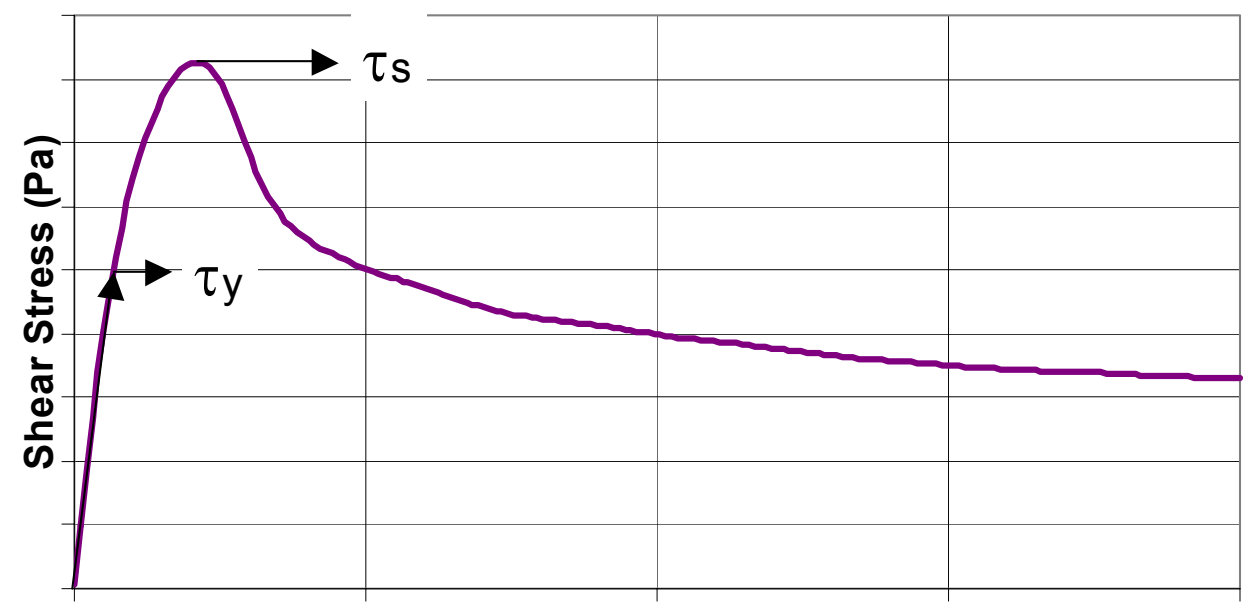

Time

Figure 2.2. Typical Stress-Versus-Time Profile for a Shear Vane at Constant Shear Rate

A Haake RS300 instrument was used to measure the shear strength of the tank composites and those dilutions that had measurable shear strengths. The diameter and height of the shear vane were 1.6 and $3.2 \mathrm{~cm}$, respectively. The rotation speed of the shear vane was constant at $0.3 \mathrm{rpm}$. The temperature of the sample was controlled at $25{ }^{\circ} \mathrm{C}$. The measurements were made in accordance with PNNL technical procedure TPR-RPP-WTP-211, "Measurement of Physical and Rheological Properties of Solutions, Slurries, and Sludges," Revision 0. 
To minimize history effects, the shear-strength samples were placed in the sample cup a minimum of 48 hours before the measurement. The shear-strength measurement was repeated one hour after the initial measurement at nominally the same location in the sample to provide information about the effect of previous shear on the shear strength of these materials.

\subsection{Extrusion Tests}

Gauglitz and Aikin developed a methodology to estimate the shear strength of tank waste materials based on visual observations of horizontal extrusion behavior (Gauglitz and Aikin 1997). Rassat et al. (2003a) developed a related technique based on core-extrusion shear strength. This technique is based strictly on extrusion length and was developed from the simulant extrusion results presented by Gauglitz and Aikin (1997).

An extrusion system was developed to make these observations on small quantities of waste. A KD-100 infusion syringe pump was modified to mimic the extrusions performed on the core samples from the Hanford tanks (Figure 2.3).

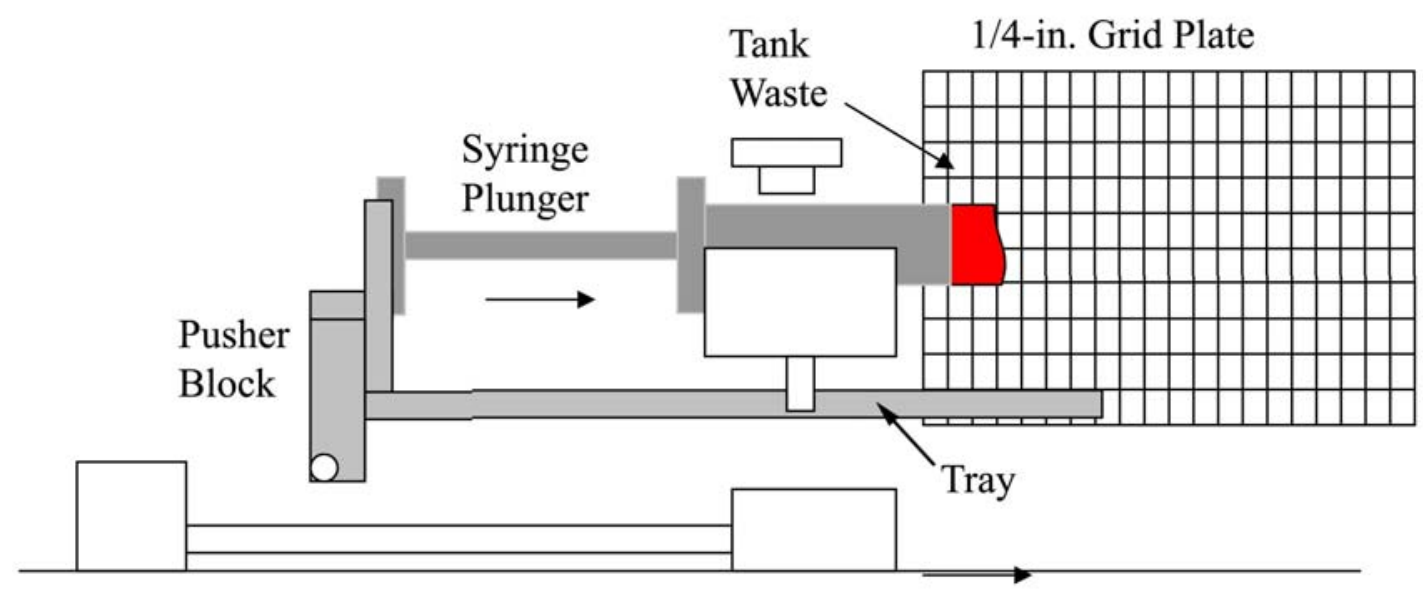

Figure 2.3. Mini-Extrusion Design

The pump was controlled by a micro-stepping motor drive. The motor drive pushed the pusher block against the syringe plunger, displacing the sample. The syringe pump was modified by adding a tray mounted directly to the pusher block. As the core was being extruded, the tray moved at the same speed the core was being pushed out.

For the extrusions, 10-mL Becton Dickinson plastic syringes were used. The ends of the syringes were cut off so that the extrusion core would be the inner diameter of the syringe barrel. The cores were approximately $7 \mathrm{~cm}$ in length with a diameter of $1.45 \mathrm{~cm}$. The height from the bottom of the core to the tray was approximately $1.5 \mathrm{~cm}$. The rate at which the core was extruded was $0.5 \mathrm{in} . / \mathrm{min}$. The syringe was filled with the sample in approximately $0.5-\mathrm{mL}$ increments. A micro-spatula was used to fill the syringe and remove voids in the sample. The syringes were filled a minimum of 72 hours before the extrusion. Parafilm was used to minimize drying of the sample. The samples were also placed in a closed plastic bag. 
During the extrusions, video images were recorded and then analyzed to estimate the shear strength. To estimate the lengths of the extruded cores at shear failure, a $6 \times 3$-in. plate with a $1 / 4$-in. grid pattern was fabricated and attached to the syringe pump. The camera was placed directly in front of the syringe at a location to capture the entire extrusion. The camera was not moved during the extrusions.

\subsection{Viscosity}

The shear stress of the dilutions as a function of shear rate was determined using a Haake RS300 rheometer with a concentric-cylinder sensor system with a 3-mm gap. A Bohlin constant stress (CS) rheometer with a cone and plate geometry $(40-\mathrm{mm}$ diameter with a 4-degree pitch) was used to measure the shear stress as a function of shear rate on the homogenized composites. Calibration was checked with certified 10-cP viscosity standards for the concentric cylinder geometry and a 100,000-cP viscosity standard for the cone and plate geometry to assure that the rheometer was operating properly. These standards are silicon oils exhibiting Newtonian behavior that were measured with a viscometer that had been calibrated against a primary standard traceable to the National Institute of Standards and Technology (NIST). The sample was transferred to the rheometer cup (concentric-cylinder geometry) or plate (cone and plate geometry), and the sample was controlled at the desired temperature $\left(25^{\circ} \mathrm{C}\right)$ with a constanttemperature bath. Shear stress was recorded as function of shear rate. The viscosity was then calculated by dividing the shear stress by the shear rate. The yield stress was also obtained from this measurement.

With the RS300 rheometer, shear stress as a function of shear rate was determined as the shear rate was increased from 0 to $1000 \mathrm{~s}^{-1}$ over 5 minutes and then decreased back to $0 \mathrm{~s}^{-1}$ at the same rate. This sequence of ramps was repeated a second time. For the constant-stress rheometer, shear rate as a function of shear stress was determined as the shear stress was ramped from 0 to $580 \mathrm{~Pa}$ and then back to $0 \mathrm{~Pa}$.

A rheogram (shear stress vs. shear rate) for a material with a yield stress has two portions to it. The first portion appears as a nearly vertical line beginning at the origin and running up the ordinate. This portion of the rheogram shows the behavior of the material as it acts like a solid or gel. When sufficient force is transmitted to the material to break the gel or make it yield, the rheogram angles sharply to the right, and from then on the behavior of the material as a fluid is recorded. The point in the curve at which the sample transfers from a solid or gel to a fluid is the yield point. The stress at this point on the ordinate is the value of the yield stress.

\subsection{Paint Filter Test}

A modified paint filter liquids test, SW-846 Method 9095A (EPA 1994) was used to determine whether free liquid existed in the sample. A sample mass of approximately $100 \mathrm{~g}$ was used for these tests. Insufficient sample was available for three of the initial dilutions (30 wt $\%$ solids dilutions for Tanks B-203, T-203, and T-204); therefore, all the sample available was used (at least $75 \mathrm{~g}$ ). The sample was placed in a paint filter (mesh number $60 \pm 5 \%$ ) supported in a glass funnel and weighed. The glass funnel was placed on top of a graduated cylinder. The sample was allowed to drain for 5 minutes into the graduated cylinder. The mass of filtrate collected in the graduated cylinder was determined. 


\subsection{Stickiness}

A qualitative evaluation of the "stickiness" of the sample was determined by weighing the amount of material that adhered to the surface of a 2-cm-diameter cylindrical stainless steel plate after it was pushed into the sample. The plate was $7 \mathrm{~mm}$ thick and was pushed into the sample until it was immersed to the thickness of the plate. After the plate was removed from the sample, it was allowed to drain until no additional drops were observed and then the mass of sample adhering to the plate was measured.

\subsection{Supernatant Liquor Density}

The supernatant liquor densities of the centrifuged homogenized and diluted tank composites were determined using a digital pipettor and an analytical balance. After centrifugation, the supernatant liquor was decanted and transferred into glass vials. This was done for all samples with at least $1 \mathrm{~mL}$ of centrifuged supernatant liquor.

The calibration of the digital pipettor was verified before each batch of analyses by pipetting $1000 \mu \mathrm{L}$ of deionized water and weighing it on an analytical balance. The mass of water measured during these calibration checks was $1.005 \pm 0.002 \mathrm{~g}$, which is less than $1 \%$ variance from the theoretical density of $0.998 \mathrm{~g} / \mathrm{mL}$ at $20{ }^{\circ} \mathrm{C}$. The volume delivered was adjusted to the mass measured of the nominal $1000 \mu \mathrm{L}$ pipet withdrawal.

The glass vial with the supernatant liquor was weighed on the analytical balance, and a $1000-\mu \mathrm{L}$ sample was pipetted from the vial. The difference in the mass of the vial was measured on the analytical balance, and the density was determined by dividing the sample mass by the sample volume $(1000 \mu \mathrm{L})$. Three or more tests were conducted for each supernatant sample.

\section{$2.10 \mathrm{pH}$}

The $\mathrm{pH}$ of the centrifuged supernatant liquors from the homogenized tank composites and the diluted composites was measured using a calibrated $\mathrm{pH}$ meter. The same supernatant sample was used for both the density and $\mathrm{pH}$ analyses. The $\mathrm{pH}$ meter was calibrated with $\mathrm{pH} 4.0$ and $\mathrm{pH} 10.0$ standards before use. A pH 7.0 standard was also used to check the stability of the $\mathrm{pH}$ meter after the calibration.

The $\mathrm{pH}$ probe was rinsed with deionized water and dried between each measurement. A mini-stir bar and a stir plate were used to agitate the solution to obtain homogeneous mixing during the $\mathrm{pH}$ analysis. The $\mathrm{pH}$ of each supernatant liquor was recorded when the $\mathrm{pH}$ reading stabilized. After the $\mathrm{pH}$ analysis, the calibration of the $\mathrm{pH}$ meter was checked using $\mathrm{pH} 4.0,7.0$, and 10.0 standards. 


\subsection{Sample Preparation}

Composites from four Hanford tanks that may meet the criteria for designation as TRU waste were received from the 222-S Laboratory. The sample identification, tank number, and mass of sample for each composite are listed in Table 3.1. The jars were packed full with sample material, and the samples were not homogenized before being transferred to PNNL; therefore, the samples were transferred into larger jars at PNNL where homogenization could be performed. Because of the sticky nature of several samples (composites from Tanks B-203, T-203, and T-204), some sample was lost to the original sample jar and spatula during transfer as noted in Table 3.1.

Table 3.1. TRU Composite Sample Identification and Quantities

\begin{tabular}{|c|c|c|c|c|c||}
\hline $\begin{array}{c}\text { Lab Core } \\
\text { Identifier }\end{array}$ & Tank No. & Jar No. & $\begin{array}{c}\text { Received } \\
\text { Sample Total } \\
\text { Mass (g) }\end{array}$ & $\begin{array}{c}\text { Sample Loss } \\
\text { Total Sample } \\
\text { Recovered (g) }\end{array}$ & $\begin{array}{c}\text { Recovery } \\
\text { (g) }\end{array}$ \\
\hline S03T000053 & B-203 & 19031 & 559.0 & 522.9 & 36.1 \\
\hline S03T000081 & T-203 & 19032 & 562.9 & 519.7 & 43.2 \\
\hline S03T000200 & T-110 & 19025 & 539.5 & 535.4 & 4.1 \\
\hline S03T000148 & T-204 & 19026 & 555.4 & 533.9 & 21.5 \\
\hline
\end{tabular}

Visual observation of these composites indicated that three of the samples are similar. These three composites (Tanks B-203, T-203, and T-204) were black in color with a consistency like shoe polish. The composite from Tank T-110 was light tan in color and forms dry clay-like particles. Only enough moisture was present to form small balls of material, but the sample did not form a consistent slurry.

The radiation dose for these composites was relatively low, which allowed the material to be characterized in fume hoods and glove boxes. In Table 3.2, the gamma radiation dose (window closed reading) of these samples at contact as provided in the shipping manifests is reported. The composite from Tank B-203 had the highest dose $(70 \mathrm{mR} / \mathrm{h})$. The dose for the other three samples was less than or equal to $8 \mathrm{mR} / \mathrm{h}$.

Table 3.2. TRU Composite Sample Radiation at Contact

\begin{tabular}{|c|c|c||}
\hline Tank No. & Jar No. & $\begin{array}{c}\text { Radiation at Contact } \\
(\mathbf{m R} / \mathbf{h})\end{array}$ \\
\hline B-203 & 19031 & 70 \\
\hline T-203 & 19032 & 4 \\
\hline T-110 & 19025 & 1 \\
\hline T-204 & 19026 & 8 \\
\hline
\end{tabular}

Various amounts of water were added to the tank composites to prepare dilutions at varying water concentrations. The physical properties of these TRU waste samples were then measured as a function of water concentration (solids concentration). Dilutions were prepared as described in Section 3.0. 
The preparation of the initial dilution for Tank T-110 and the $30-\mathrm{wt} \%$ solids dilution for Tank T-204 are described in Section 3.0. Based on the calculated water concentration of this dilution (approximately $30 \mathrm{wt} \%$ solids), water was added to the composites from the other tanks to form slurries with solids concentrations of approximately $30 \mathrm{wt} \%$. One part of water by mass was added to one part of homogenized composite to form the third dilution, and four parts of water were added to one part tank sample to form the fourth dilution. The third and fourth dilutions of the Tank T-110 composite were based on 1:1 and 4:1 mass ratios of water to tank composite that would have a solids concentration equivalent to the average solids concentration of the core composites from the other three tanks as measured by TGA (37.6 wt $\%$ solids). All of the diluted samples were homogenized with a plastic spatula. The ratio of water to tank composite for each dilution is summarized in Table 3.3.

Table 3.3. Dilution Table for all the Tank Samples

\begin{tabular}{|c|c|c|}
\hline \multirow{3}{*}{ Dilution } & Tank No. & $\begin{array}{c}\text { Added Water to Sample } \\
\text { Mass Ratio }\end{array}$ \\
\hline Initial & $\mathrm{T}-110$ & 0.31 \\
\hline \multirow{4}{*}{$30 \mathrm{wt} \%$} & $\mathrm{~T}-110$ & 1.00 \\
\cline { 2 - 3 } & $\mathrm{T}-204$ & 0.05 \\
\cline { 2 - 3 } & $\mathrm{B}-203$ & 0.47 \\
\cline { 2 - 3 } & $\mathrm{T}-203$ & 0.19 \\
\hline \multirow{4}{*}{$1: 1$} & $\mathrm{~T}-110$ & 2.43 \\
\cline { 2 - 3 } & $\mathrm{T}-204$ & 1.00 \\
\cline { 2 - 3 } & $\mathrm{B}-203$ & 1.00 \\
\cline { 2 - 3 } & $\mathrm{T}-203$ & 1.00 \\
\hline \multirow{3}{*}{$4: 1$} & $\mathrm{~T}-110$ & 7.63 \\
\cline { 2 - 3 } & $\mathrm{T}-204$ & 4.00 \\
\cline { 2 - 3 } & $\mathrm{B}-203$ & 4.00 \\
\cline { 2 - 3 } & $\mathrm{T}-203$ & 3.96 \\
\hline
\end{tabular}

After the dilutions and tank composites were homogenized, duplicate 10- to 15-g aliquots of these slurries were transferred into $15-\mathrm{mL}$ graduated centrifuge cones. The slurry density of each sample was calculated on the basis of the total sample weight and the sample volume. The total sample weight was measured on an analytical balance, and the sample volume was measured using the graduations on the centrifuge cones after centrifugation. The slurry density prior to centrifugation was similar to the density after centrifugation. The slurry densities of each of the diluted tank samples and the homogenized tank composites are reported in Table 3.4 through Table 3.7. Except for Tank B-203, the homogenized composites have slightly lower densities than the first dilution (initial or $30-\mathrm{wt} \%$ solids dilution) due to the presence of voids. With the exception of Tank T-110, these voids were removed by gravity settling and centrifugation (see Section 6). The densities of diluted samples, in general, decrease as dilution increases. 
Table 3.4. Densities of Original and Diluted Tank T-110 Samples

\begin{tabular}{|c|c|c|c|}
\hline \multirow[t]{2}{*}{ Dilution } & \multicolumn{2}{|c|}{$\begin{array}{l}\text { Density } \\
(\mathrm{g} / \mathrm{mL})\end{array}$} & \multirow{2}{*}{$\begin{array}{l}\text { Average Density } \\
(\mathrm{g} / \mathrm{mL})\end{array}$} \\
\hline & Settled & Centrifuged & \\
\hline \multirow{2}{*}{ Composite } & \multirow{2}{*}{$\mathrm{NM}^{(\mathrm{a})}$} & 1.32 & \multirow{2}{*}{1.31} \\
\hline & & 1.30 & \\
\hline \multirow{2}{*}{ Initial Dilution } & 1.50 & 1.49 & \multirow{2}{*}{1.50} \\
\hline & 1.47 & 1.50 & \\
\hline \multirow{2}{*}{30 -wt $\%$ dilution } & 1.22 & 1.25 & \multirow{2}{*}{1.26} \\
\hline & 1.31 & 1.26 & \\
\hline \multirow{2}{*}{ 1:1 Dilution } & 1.13 & 1.14 & \multirow{2}{*}{1.13} \\
\hline & 1.14 & 1.12 & \\
\hline \multirow{2}{*}{ 4:1 Dilution } & 1.04 & 1.04 & \multirow{2}{*}{1.04} \\
\hline & 1.05 & 1.04 & \\
\hline
\end{tabular}

Table 3.5. Densities of Original and Diluted Tank T-204 Samples

\begin{tabular}{|c|c|c|c|}
\hline \multirow[t]{2}{*}{ Dilution } & \multicolumn{2}{|c|}{$\begin{array}{l}\text { Density } \\
(\mathrm{g} / \mathrm{mL})\end{array}$} & \multirow{2}{*}{$\begin{array}{c}\text { Average Density } \\
\qquad(\mathrm{g} / \mathrm{mL})\end{array}$} \\
\hline & Settled & Centrifuged & \\
\hline \multirow{2}{*}{ Composite } & \multirow{2}{*}{$\mathrm{NM}^{(\mathrm{a})}$} & 1.16 & \multirow{2}{*}{1.17} \\
\hline & & 1.18 & \\
\hline \multirow{2}{*}{30 -wt $\%$ dilution } & \multirow{2}{*}{$\mathrm{NM}^{(\mathrm{a})}$} & 1.28 & \multirow{2}{*}{1.28} \\
\hline & & 1.28 & \\
\hline \multirow{2}{*}{ 1:1 Dilution } & 1.11 & 1.12 & \multirow{2}{*}{1.13} \\
\hline & 1.13 & 1.13 & \\
\hline \multirow{2}{*}{ 4:1 Dilution } & 1.05 & 1.05 & \multirow{2}{*}{1.05} \\
\hline & 1.05 & 1.05 & \\
\hline
\end{tabular}


Table 3.6. Densities of Original and Diluted Tank B-203 Samples

\begin{tabular}{|c|c|c|c|}
\hline \multirow[t]{2}{*}{ Dilution } & \multicolumn{2}{|c|}{$\begin{array}{l}\text { Density } \\
(\mathrm{g} / \mathrm{mL})\end{array}$} & \multirow{2}{*}{$\begin{array}{c}\text { Average Density } \\
\qquad(\mathrm{g} / \mathrm{mL})\end{array}$} \\
\hline & Settled & Centrifuged & \\
\hline \multirow{2}{*}{ Composite } & \multirow{2}{*}{$\mathrm{NM}^{(\mathrm{a})}$} & 1.27 & \multirow{2}{*}{1.28} \\
\hline & & 1.29 & \\
\hline \multirow{2}{*}{$30-\mathrm{wt} \%$ dilution } & \multirow{2}{*}{$\mathrm{NM}^{(\mathrm{a})}$} & 1.25 & \multirow{2}{*}{1.26} \\
\hline & & 1.26 & \\
\hline \multirow{2}{*}{ 1:1 Dilution } & 1.18 & 1.18 & \multirow{2}{*}{1.18} \\
\hline & 1.17 & 1.17 & \\
\hline \multirow{2}{*}{ 4:1 Dilution } & 1.07 & 1.06 & \multirow{2}{*}{1.06} \\
\hline & 1.06 & 1.05 & \\
\hline
\end{tabular}

Table 3.7. Densities of Original and Diluted Tank T-203 Samples

\begin{tabular}{|c|c|c|c|}
\hline \multirow[t]{2}{*}{ Dilution } & \multicolumn{2}{|c|}{$\begin{array}{c}\text { Density } \\
(\mathrm{g} / \mathrm{mL})\end{array}$} & \multirow{2}{*}{$\begin{array}{c}\text { Average Density } \\
(\mathrm{g} / \mathrm{mL})\end{array}$} \\
\hline & Settled & Centrifuged & \\
\hline \multirow{2}{*}{ Composite } & \multirow{2}{*}{$\mathrm{NM}^{(\mathrm{a})}$} & 1.25 & \multirow{2}{*}{1.22} \\
\hline & & 1.18 & \\
\hline \multirow{2}{*}{$30-w t \%$ dilution } & \multirow{2}{*}{$\mathrm{NM}^{(\mathrm{a})}$} & 1.28 & \multirow{2}{*}{1.29} \\
\hline & & 1.29 & \\
\hline \multirow{2}{*}{ 1:1 Dilution } & 1.12 & 1.14 & \multirow{2}{*}{1.14} \\
\hline & 1.12 & 1.14 & \\
\hline \multirow{2}{*}{ 4:1 Dilution } & 1.05 & 1.05 & \multirow{2}{*}{1.05} \\
\hline & 1.04 & 1.04 & \\
\hline
\end{tabular}




\subsection{Solids Concentration}

The solids concentration of the homogenized composites and dilutions were determined by three different methods. These methods were TGA, Temperature-Controlled Thermogravimetric Analysis (TCTGA), and oven drying at $105{ }^{\circ} \mathrm{C}$. TGA was the initial method used to determine the total solids concentration on the homogenized composites and those dilutions with minimal free liquid. Controlling the temperature ramp rate as water evaporates (TC-TGA) provides a more accurate method of the mass loss at a given temperature; therefore, this method was used to improve the accuracy of the quantity of water lost from the sample at $105^{\circ} \mathrm{C}$. Both of the TGA methods provide additional data on the amount of bound water associated with the sample. The oven drying method provides mass loss at a single temperature only, but utilizes larger samples that may be more representative of the bulk sample. The total solids concentration of samples with large amounts of free liquid can also be accurately determined by the oven drying method. The results obtained by all three methods are compared.

\subsection{Thermogravimetric Analysis}

The TGA method used to measure the total solids concentrations of the homogenized composites and those dilutions with minimal free liquid is described in Section 3.1. The total solids concentration measured by TGA for each homogenized sample is reported in Table 4.1. The total solids concentration of each sample was determined by the mass loss of the sample at $165^{\circ} \mathrm{C}$. This temperature was chosen because the initial mass loss of all the samples stabilized at around $165^{\circ} \mathrm{C}$. Small mass losses continued beyond $165^{\circ} \mathrm{C}$, but the rate of the mass loss between this first transition and the later transitions (onset temperature of about $450{ }^{\circ} \mathrm{C}$ ) stabilized around $165^{\circ} \mathrm{C}$. TGA curves for each of the homogenized composites are presented in Figure 4.1.

Table 4.1. Total Solids Concentrations of Homogenized Tank Composites as Analyzed by TGA and TC-TGA Methods

\begin{tabular}{|c|c|c|c|}
\hline Tank No. & Sample No. & $\begin{array}{c}\text { TGA TS } \\
\text { (wt\%) }\end{array}$ & $\begin{array}{c}\text { TC-TGA TS } \\
\text { (wt\%) }\end{array}$ \\
\hline T-110 & $19025-\mathrm{HM}$ & 70.3 & 62.7 \\
\hline T-204 & $19026-\mathrm{HM}$ & 31.6 & 33.4 \\
\hline B-203 & $19031-\mathrm{HM}$ & 44.1 & 42.0 \\
\hline T-203 & $19032-\mathrm{HM}$ & 37.1 & 35.5 \\
\hline
\end{tabular}




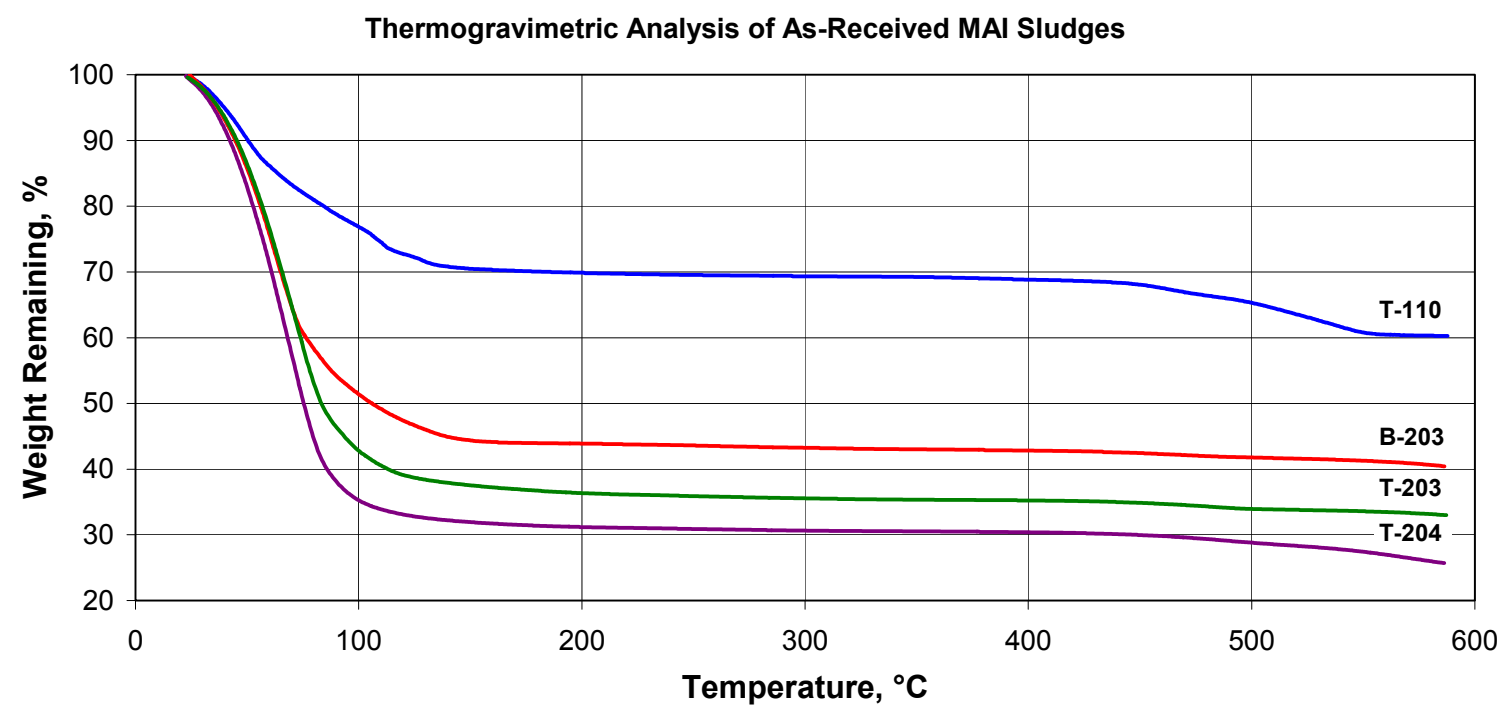

Figure 4.1. Thermogravimetric Analysis of Homogenized Tank Composites

\subsection{Temperature-Controlled TGA}

In addition to the standard thermogravimetric analysis, a TC-TGA was also completed on each sample with minimal free liquid. The method used to analyze these samples is described in Section 3.1. The same subsamples used in the standard TGA measurements described above were used in the TC-TGA. An example of a TC-TGA curve for the Tank B-203 composite is provided in Figure 4.2.

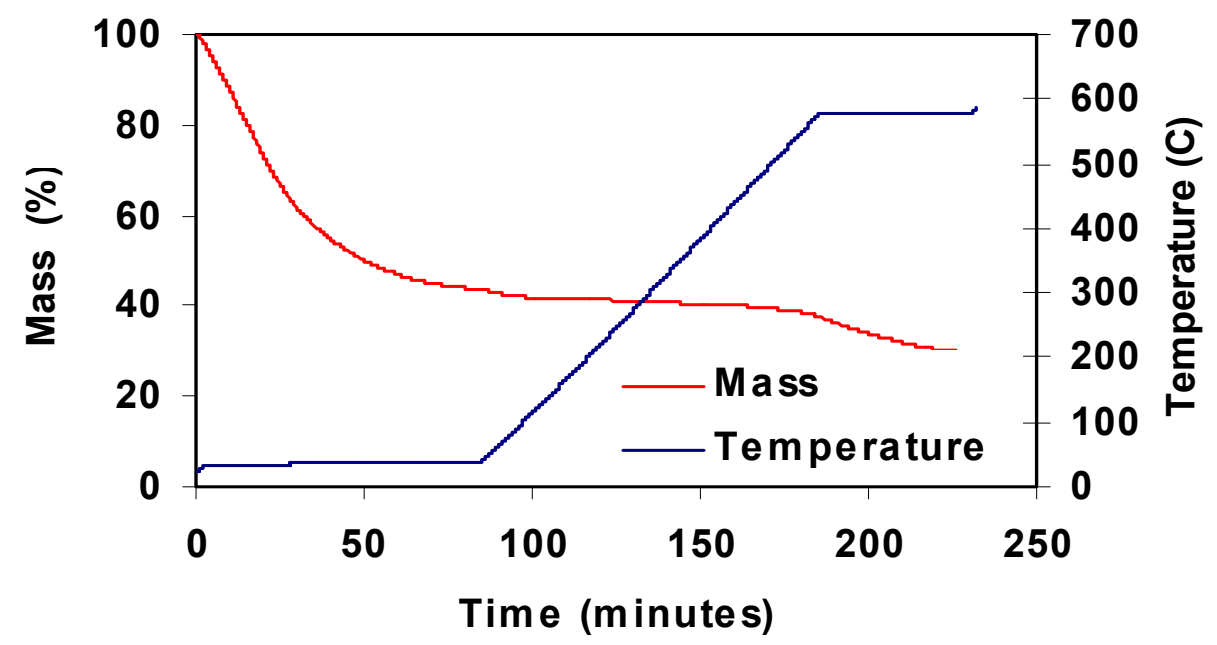

Figure 4.2. TC-TGA Curve for the Homogenized Composite from Tank B-203 
The TC-TGA results are also shown in Table 4.1. These results represent the total solids concentration at $105^{\circ} \mathrm{C}$. Because this method holds the temperature constant until minimal change in the mass of the sample is observed, mass loss due to the loss of water became stable at approximately $105^{\circ} \mathrm{C}$. The total solids concentration determined by TC-TGA is slightly lower than the values obtained by the standard TGA method for all of the tank composites except for the composite from Tank T-204. This difference is probably due to drying of the sample between the two analyses or variations in the two subsamples obtained for these analyses.

\subsection{Oven Drying}

Total solids concentration were also measured by a gravimetric method after drying samples transferred to scintillation vials in a drying oven held at a temperature of $105^{\circ} \mathrm{C}$ until the mass of the dried sample had stabilized. The size of these samples $(\sim 2 \mathrm{~g})$ was approximately two orders of magnitude larger than was used for TGA. The method used for these analyses is described in Section 3.2.

The total solids concentrations of the homogenized tank composites and diluted samples are provided in Table 4.2 through Table 4.5. Mass loss from the 1:1 and 4:1 dilutions was essentially complete after 24 hours of drying in the oven ( 0.01 to $0.13 \%$ difference in mass was measured after 15 hours of additional drying). Similar results were observed for the $30-\mathrm{wt} \%$ solids dilutions ( 0.04 to $0.21 \%$ mass loss between 24 and 39 hours of drying). Slightly larger changes were observed in all the homogenized tank composites and the initial dilution from Tank T-110 (0.2 to $1.0 \%$ and 0.21 to $0.59 \%$ change after 90 hours of drying, respectively). The solids concentrations measured by the drying oven method are judged to be more accurate because larger and more representative samples were taken; therefore, results from the drying oven method are generally used throughout this report.

Table 4.2. Total Solids Concentrations of Tank T-110 Samples after Drying at $105 \pm 2^{\circ} \mathrm{C}$

\begin{tabular}{|c|c|c|c|c|}
\hline Dilution & $\begin{array}{c}\text { TS after } 24 \\
\text { hours } \\
(\%)\end{array}$ & $\begin{array}{c}\text { TS at Final } \\
\text { Reading } \\
(\%)\end{array}$ & $\begin{array}{c}\text { TS Difference Between } \\
24 \text { hours and Final } \\
\text { Reading } \\
(\%)\end{array}$ & $\begin{array}{c}\text { Average TS } \\
(\%)\end{array}$ \\
\hline \multirow{2}{*}{ Composite } & 62.4 & 61.4 & 1.00 & \multirow[t]{2}{*}{62.2} \\
\hline & 63.9 & 63.0 & 0.91 & \\
\hline \multirow{2}{*}{ Initial } & 48.6 & 48.0 & 0.59 & \multirow[t]{2}{*}{48.4} \\
\hline & 48.9 & 48.7 & 0.21 & \\
\hline \multirow{2}{*}{$30-w t \%$} & 29.4 & 29.3 & 0.09 & \multirow[t]{2}{*}{29.3} \\
\hline & 29.2 & 29.2 & 0.04 & \\
\hline \multirow{2}{*}{$1: 1$} & 15.3 & 15.3 & 0.01 & \multirow[t]{2}{*}{15.3} \\
\hline & 15.3 & 15.3 & 0.02 & \\
\hline \multirow{2}{*}{$4: 1$} & 7.3 & 7.2 & 0.06 & \multirow[t]{2}{*}{6.4} \\
\hline & 5.6 & 5.6 & 0.05 & \\
\hline
\end{tabular}


Table 4.3. Total Solids Concentrations of Tank T-204 Samples after Drying at $105 \pm 2{ }^{\circ} \mathrm{C}$

\begin{tabular}{|c|c|c|c|c||}
\hline \multirow{2}{*}{ Dilution } & $\begin{array}{c}\text { TS after 24 } \\
\text { hours (\%) }\end{array}$ & $\begin{array}{c}\text { TS at Final } \\
\text { Reading (\%) }\end{array}$ & $\begin{array}{c}\text { TS Difference Between } \\
\text { 24 hours and Final } \\
\text { Reading (\%) }\end{array}$ & $\begin{array}{c}\text { Average TS } \\
\text { (\%) }\end{array}$ \\
\hline \multirow{2}{*}{ Composite } & 31.2 & 30.8 & 0.49 & \multirow{2}{*}{31.5} \\
\cline { 2 - 5 } & 32.5 & 32.1 & 0.43 & \multirow{2}{*}{29.4} \\
\hline \multirow{2}{*}{$30-\mathrm{wt} \%$} & 29.3 & 29.2 & 0.10 & \multirow{2}{*}{14.6} \\
\cline { 2 - 5 } & 29.9 & 29.6 & 0.21 & \multirow{2}{*}{6.1} \\
\hline \multirow{2}{*}{$1: 1$} & 14.8 & 14.6 & 0.21 & \\
\cline { 2 - 5 } & 14.6 & 14.6 & 0.06 & 0.06 \\
\hline \multirow{2}{*}{$4: 1$} & 5.7 & 5.6 & 0.05 & \\
\cline { 2 - 5 } & 6.7 & 6.6 & \multicolumn{2}{|c}{} \\
\hline
\end{tabular}

Figure 4.3 compares the total solids concentrations analyzed by TGA, TC-TGA, and oven drying methods for the homogenized composites. The total solids concentration results by the TC-TGA and oven drying methods agree very well, while the total solids concentrations measured by the regular TGA are, in general, higher than those analyzed by either the TC-TGA or oven drying method.

Figure 4.4 through Figure 4.6 compare the total solids concentrations measured for the dilutions by the oven drying method and the estimated total solids concentrations of the dilutions calculated from the total solids concentrations of the homogenized composites measured by both the TGA and oven drying methods. These comparisons indicate that the estimated total solids concentrations by the oven drying method are in agreement with the measured total solids concentration results for all the samples, while the TGA based calculation predicts higher total solids concentrations of the diluted samples. It is recommended that total solids concentration be determined by the oven drying or TC-TGA method. In this report, the total solids concentrations determined by oven drying are used to describe the solids content in the subsequent test samples.

Table 4.4. Total Solids Concentrations of Tank B-203 Samples after Drying at $105 \pm 2^{\circ} \mathrm{C}$

\begin{tabular}{|c|c|c|c|c|}
\hline Dilution & $\begin{array}{c}\text { TS after } 24 \mathrm{hr} \\
(\%)\end{array}$ & $\begin{array}{l}\text { TS at Final } \\
\text { Reading } \\
\text { (\%) }\end{array}$ & $\begin{array}{c}\text { TS Difference Between } \\
24 \mathrm{hr} \text { and Final Reading } \\
(\%)\end{array}$ & Average TS (\%) \\
\hline \multirow{2}{*}{ Composite } & 40.7 & 40.5 & 0.20 & \multirow[t]{2}{*}{40.5} \\
\hline & 40.6 & 40.4 & 0.27 & \\
\hline \multirow{2}{*}{$30-w t \%$} & 28.6 & 28.6 & 0.04 & \multirow[t]{2}{*}{28.6} \\
\hline & 28.6 & 28.5 & 0.09 & \\
\hline \multirow{2}{*}{$1: 1$} & 19.9 & 19.7 & 0.17 & \multirow[t]{2}{*}{19.7} \\
\hline & 19.7 & 19.7 & 0.05 & \\
\hline \multirow{2}{*}{$4: 1$} & 7.9 & 7.8 & 0.06 & \multirow[t]{2}{*}{8.5} \\
\hline & 9.1 & 9.1 & 0.03 & \\
\hline
\end{tabular}


Table 4.5. Total Solids Concentrations of Tank T-203 Samples after Drying at $105 \pm 2{ }^{\circ} \mathrm{C}$

\begin{tabular}{|c|c|c|c|c||}
\hline \multirow{2}{*}{ Dilution } & $\begin{array}{c}\text { TS after 24 } \\
\text { hours (\%) }\end{array}$ & $\begin{array}{c}\text { TS at Final } \\
\text { Reading } \\
\mathbf{( \% )}\end{array}$ & $\begin{array}{c}\text { TS Difference Between } \\
\text { 24 hours and Final } \\
\text { Reading (\%) }\end{array}$ & $\begin{array}{c}\text { Average TS } \\
\text { (\%) }\end{array}$ \\
\hline \multirow{2}{*}{ Composite } & 35.0 & 34.7 & 0.30 & 34.3 \\
\cline { 2 - 5 } & 34.2 & 33.8 & 0.33 & \multirow{2}{*}{30.7} \\
\hline \multirow{2}{*}{$30-\mathrm{wt} \%$} & 30.9 & 30.8 & 0.14 & \multirow{2}{*}{6.4} \\
\cline { 2 - 5 } & 30.6 & 30.5 & 0.09 & \multirow{2}{*}{6.4} \\
\cline { 2 - 5 } $1: 1$ & 16.3 & 16.2 & 0.13 & \\
\hline \multirow{2}{*}{$4: 1$} & 16.5 & 16.5 & 0.00 & 0.06 \\
\cline { 2 - 5 } & 6.8 & 6.7 & 0.04 & \\
\hline
\end{tabular}

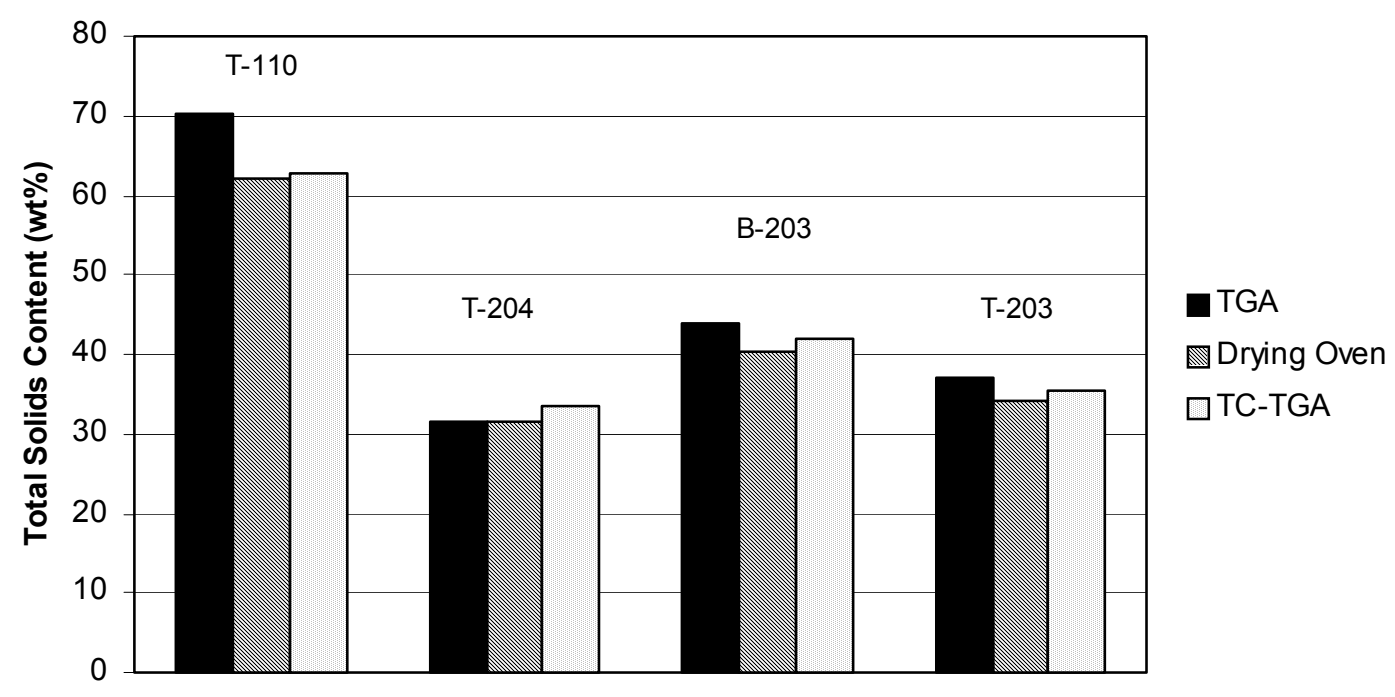

Figure 4.3. Comparison of Total Solids Concentrations of Tank Composite Samples Analyzed by TGA and Drying Oven Methods 


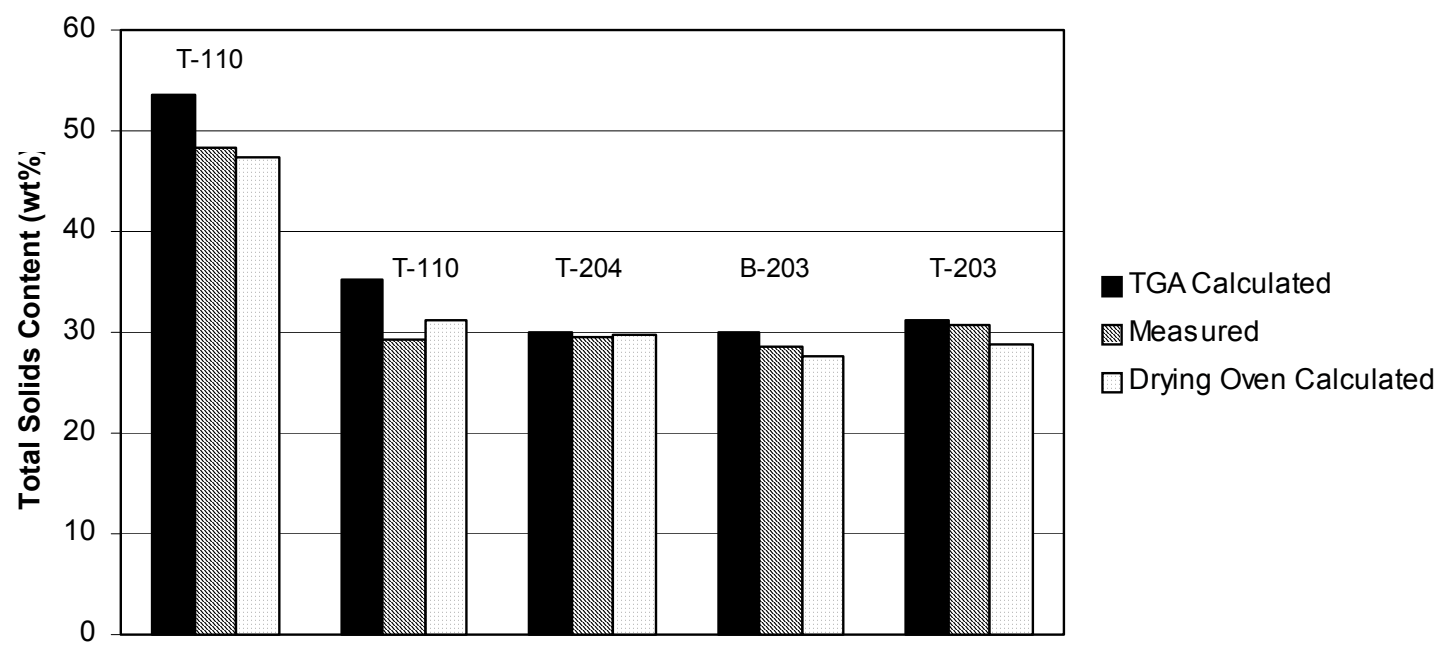

Figure 4.4. Comparison of Calculated and Measured Total Solids Concentrations of Tank Samples with Initial and 30-wt\% Dilutions

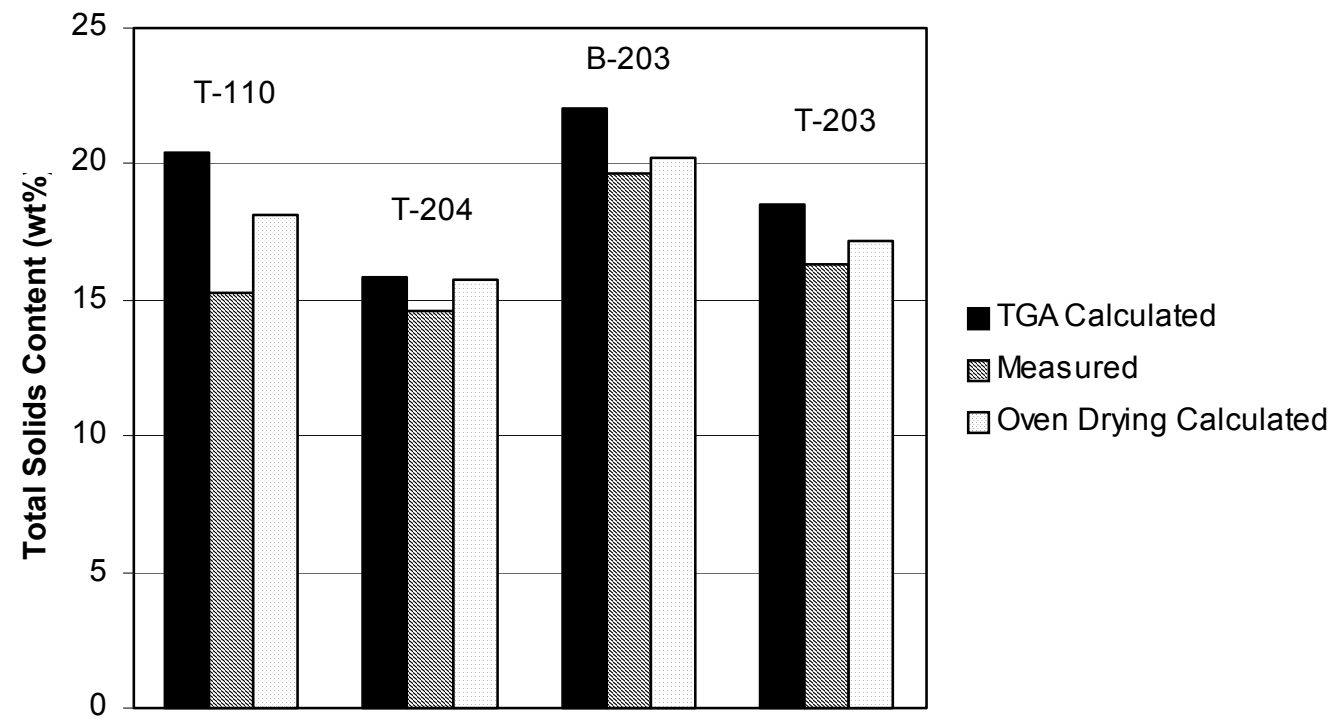

Figure 4.5. Comparison of Calculated and Measured Total Solids Concentrations of Tank Samples with 1:1 Dilution 


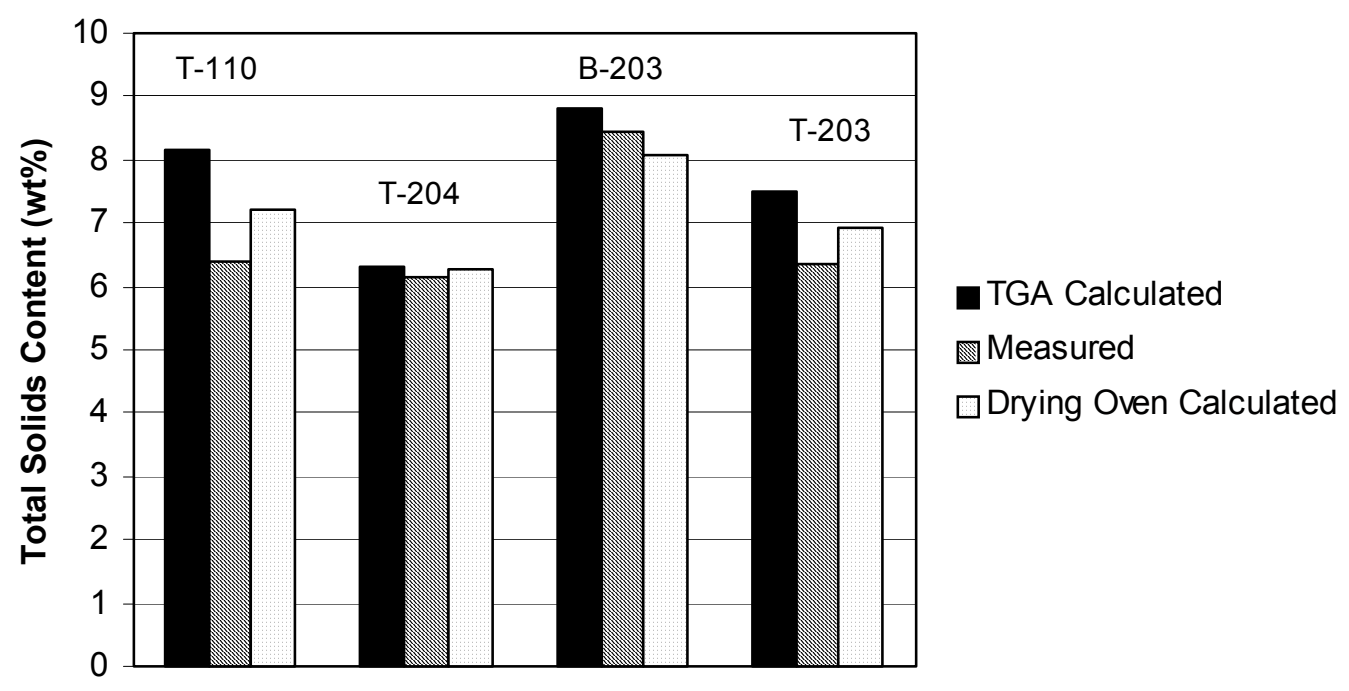

Figure 4.6. Comparison of Calculated and Measured Total Solids Concentrations of Tank Samples with 4:1 Dilution 


\subsection{Settling Behavior}

Settling behavior of the homogenized tank composites and the dilutions was observed during gravityinduced settling and centrifugation. Sediment height was measured as a function of time and dilution. The densities of the settled and centrifuged solids, and the densities and $\mathrm{pH}$ for the centrifuged supernatant liquor were determined.

\subsection{Gravity Settling}

Sediment height as a function of time was measured in duplicate for each of the tank composites and dilutions during gravity-induced settling. The procedure used to make these measurements is described in Section 3. To obtain representative aliquots, the samples were well mixed before being transferred to the centrifuge cones. At the start of these settling tests, each aliquot was also well mixed with a microspatula or by inverting the centrifuge cones. Samples of approximately 6 to $14 \mathrm{~mL}$ were used for this analysis. Mass was measured on an analytical balance, which was checked for calibration before and after the analysis. The sample tube was capped tightly to prevent water evaporation.

All the aliquots were placed vertically on a metal rack after they were mixed. Subsequently, the natural settling test was initiated by recording time zero and the initial volume. By reading the graduated centrifuge tube, the settled volumes of suspended solids and clarified supernatant liquor were recorded in time intervals of $5,10,15,20,25,30$, and 60 minutes, and 1.5, 2, 3, 4, 6, and 8 hours. The settling data were further recorded after 24 hours, two days, and three days for all samples. Additional settling times were recorded for some samples. Settled-solids volumes measured during these settling tests are plotted as a function of time in Figure 5.1 through Figure 5.4.

No gravity settling of solids was observed for any of the tank composite samples or for samples diluted to $30 \mathrm{wt} \%$ solids from Tanks B-203, T-203, and T-204. Gravity-induced settling was observed in the remainder of the dilutions including all diluted Tank T-110 samples.

Settling results of the 1:1 and 4:1 dilutions from Tank T-204 are shown in Figure 5.1. All settling results were obtained on duplicate samples, and the results of each sample are provided. The total solids content of these dilutions is $14.6 \mathrm{wt} \%$ and $6.1 \mathrm{wt} \%$, respectively. The results indicate that the sedimentbed volume of the $4: 1$ dilution settled to approximately $51.0 \%$ of the total sample volume within the first three hours. Additional settling reduced the sediment-bed volume to about $46.2 \%$ of the total slurry volume over the next 117 hours, indicating that the gravity settling was most significant during the first three hours. The 1:1 dilution settled much slower than the 4:1 dilution, and minimal settling was observed in the first three hours. After 80 hours of settling, the sediment-bed volume still occupied about $88 \%$ of the total sample volume.

Similar results were obtained for the settling behavior of the dilutions from Tanks B-203 and T-203. Settling results for these dilutions are presented in Figure 5.2 and Figure 5.3. Total solids concentrations of these dilutions are $19.7 \mathrm{wt} \%$ and $8.5 \mathrm{wt} \%$ for Tank B-203 and $16.4 \mathrm{wt} \%$ and $6.4 \mathrm{wt} \%$ for T-203 for 1:1 and 4:1 dilutions, respectively. The results indicate that the majority of the settling for the $4: 1$ dilution from both tanks occurs in the first few hours of settling. The sediment bed for the 4:1 dilution from B203 occupied about $48 \%$ of the total sample volume within the first two hours. Additional settling time resulted in a sediment-bed volume of about $43.8 \%$ of the total slurry volume over the next 81 hours. The 
sediment bed for the 4:1 dilution from T-203 occupied approximately $51.1 \%$ of the total sample volume within the first three hours. Additional settling time resulted in a sediment-bed volume of about $44.8 \%$ over the next 115 hours.

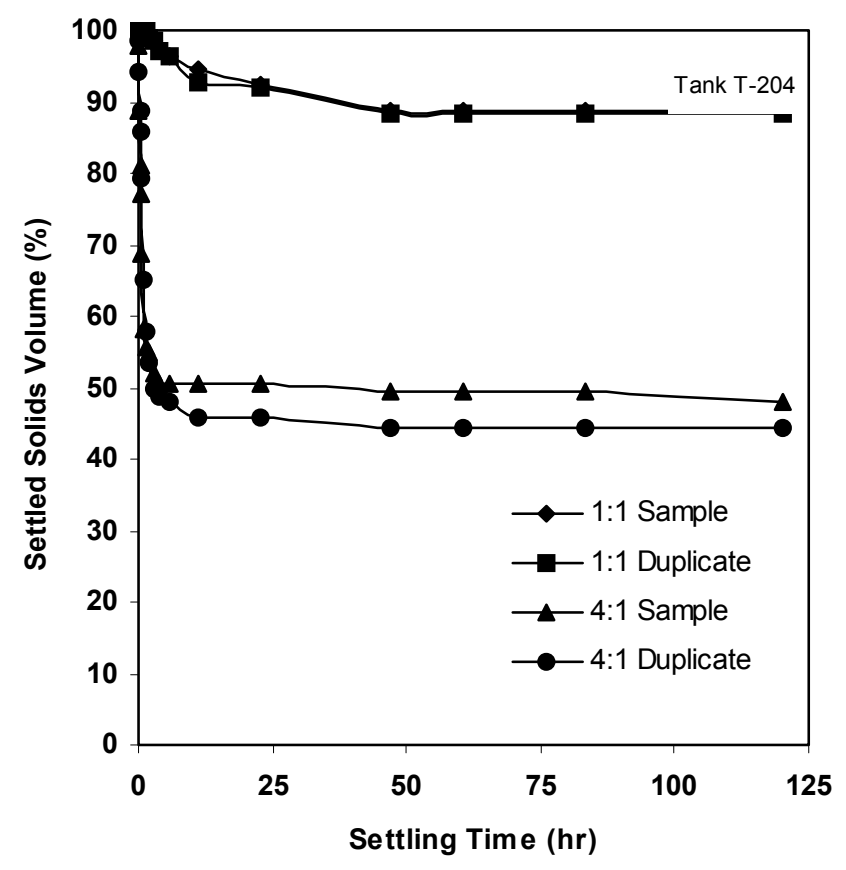

Figure 5.1. Settled Solids Volume Profiles of the 1:1 and 4:1 Dilutions of Tank T-204

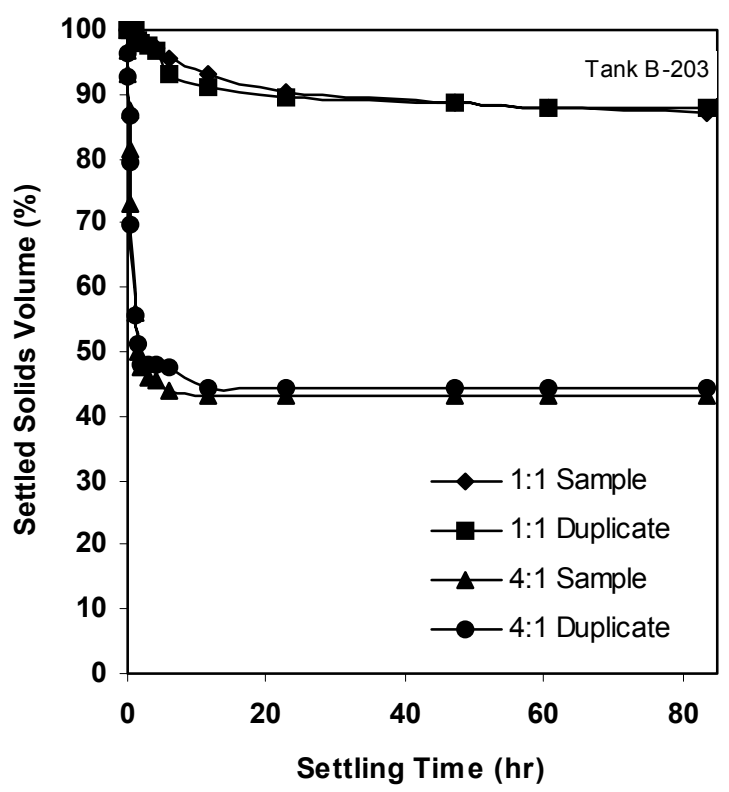

Figure 5.2. Settled Solids Volume Profiles of the 1:1 and 4:1 Dilutions of Tank B-203 


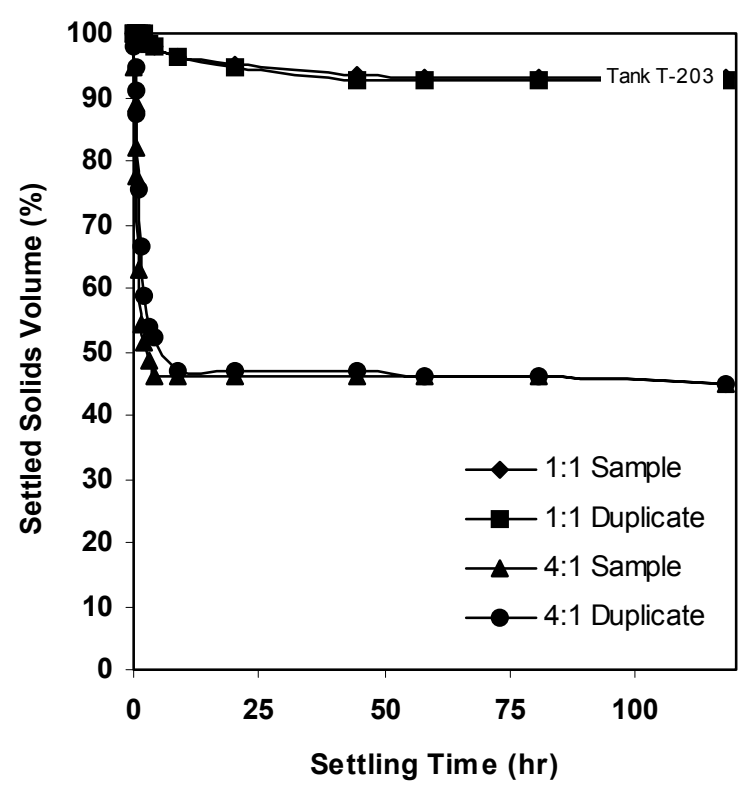

Figure 5.3. Settled Solid Volume Profiles of the 1:1 and 4:1 Dilutions of Tank T-203

The 1:1 dilutions from these tanks settled much slower than the 4:1 dilutions. Minimal settling was observed in the first three hours for these 1:1 dilutions. Only $2 \%$ reduction was observed in sediment-bed volume for the first two hours of settling in the 1:1 dilution of Tank B-203, and the final sediment bed volume after settling was complete was $87.5 \%$ of the total slurry volume. For the $1: 1$ dilution from Tank T-203, only $1.5 \%$ reduction was observed in sediment-bed volume over the first three hours. The final sediment-bed volume for this dilution was $92.8 \%$ of the total slurry volume.

Figure 5.4 shows the gravity settling results for all of the dilutions of the Tank T-110 composite. The total solids content of these dilutions is $48.4 \mathrm{wt} \%, 29.3 \mathrm{wt} \%, 15.3 \mathrm{wt} \%$, and $6.4 \mathrm{wt} \%$, respectively, for the initial dilution, $30-\mathrm{wt} \%$ dilution, and the $1: 1$ and $4: 1$ dilutions. The sediment-bed volume of the $4: 1$ dilution occupied approximately $32.4 \%$ of the total slurry volume within the first three hours and was further reduced to about $22.2 \mathrm{vol} \%$ over the next 70 hours. The sediment-bed volume for the $1: 1$ dilution occupied $53.3 \%$ of the total slurry volume after 14 hours, with an additional 59.5 hours of settling resulting in a bed volume of $46.4 \%$ of the total slurry volume. Very slow settling was observed in the 30 $\mathrm{wt} \%$ dilution, and a sediment-bed volume of only $87.1 \%$ of the total slurry volume was observed at the completion of the settling test (73.6 hours). No settling was observed in the initial dilution. At higher solids concentrations, for example, the initial and $30-\mathrm{wt} \%$ dilutions hindered settling results in slower settling rates and longer settling times to achieve equilibrium. 


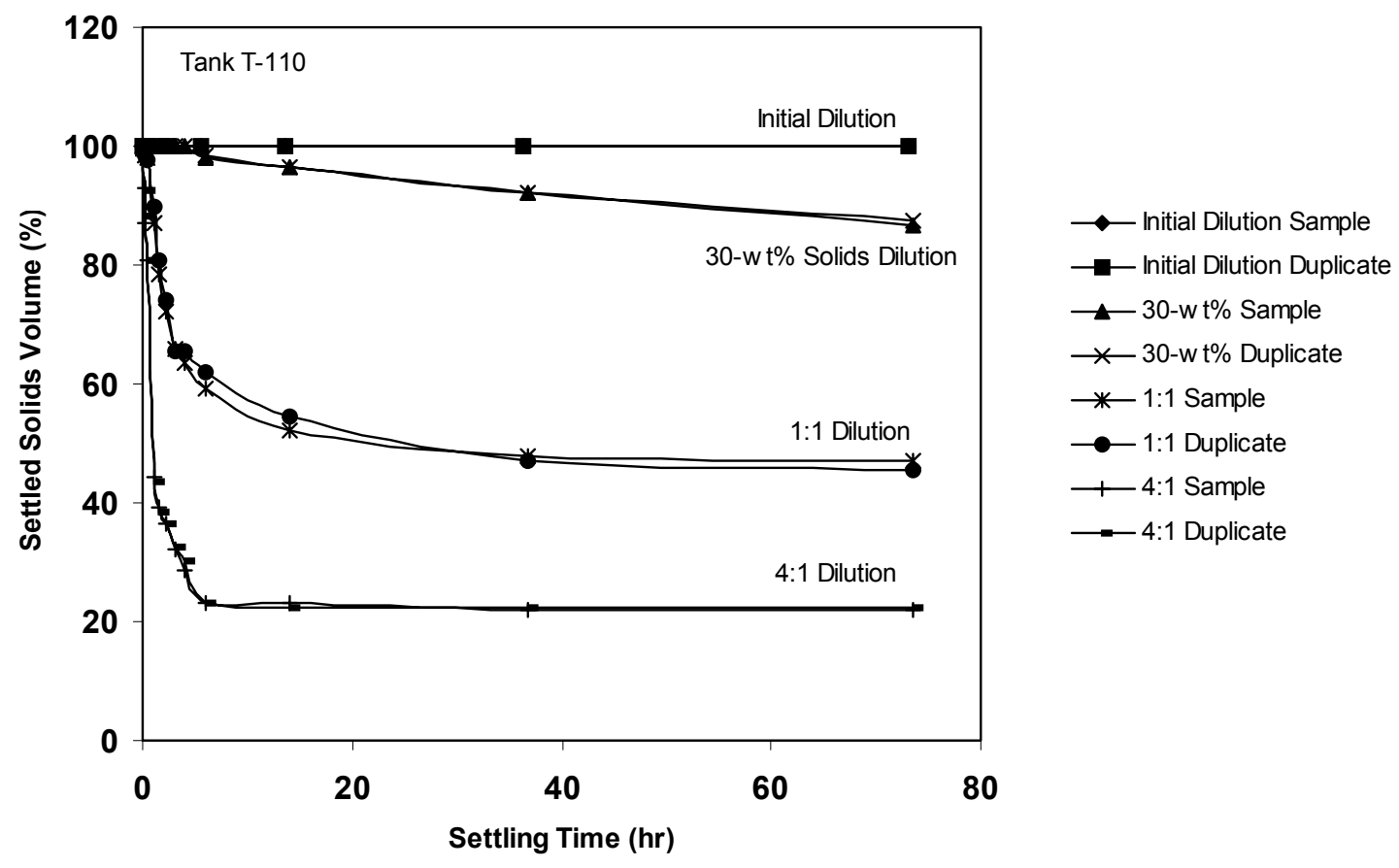

Figure 5.4. Settled Solids Volume Profiles of the Dilutions of Tank T-110

The settling behavior of the dilutions from Tank T-110 is significantly different than the other tank dilutions because the tank composite for this tank was prepared from core samples that had lost significant amounts of water. When water is added back to dried tank waste samples, these rehydrated samples do not form the same structures and agglomerates that were present in the original sample; therefore, settling behavior is modified. The chemical composition of Tank T-110 is also significantly different than that of the other three tanks (Cooke 2003).

In Figure 5.5, the gravity settling data for the dilutions from Tank T-110 are plotted as a function of total solids concentration to characterize the effect of solids concentration on settling. When the solids concentration is less than approximately $35 \mathrm{wt} \%$, the sediment-bed volume shows a steep linear relationship with solids concentration; however, when the solids concentration is greater than approximately $35 \mathrm{wt} \%$, the impact of solids concentration on the final sediment-bed volume decreases.

In Figure 5.6, the sediment-bed volumes for each of the dilutions from all four tanks are compared as a function of settling time. Table 5.1 summarizes the completeness of the settling process during the first few hours of settling compared with the final sediment-bed volume observed in the gravity-settling tests. Completeness is defined as the percentage of the supernatant volume at a given time versus the final supernatant volume. For the 4:1 dilutions, the settling rate decreases drastically after these first few hours and the majority of the settling is completed during this initial settling. The completeness of settling was also determined at the point after these first few hours where the settling rate decreased significantly and additional settling time resulted in minimal additional compaction of the sediment bed. The time at which this point was reached varied for each tank and each dilution. Both the time and completeness of settling at that time are reported in Table 5.1. For this report this time is called the intermediate settling time. 


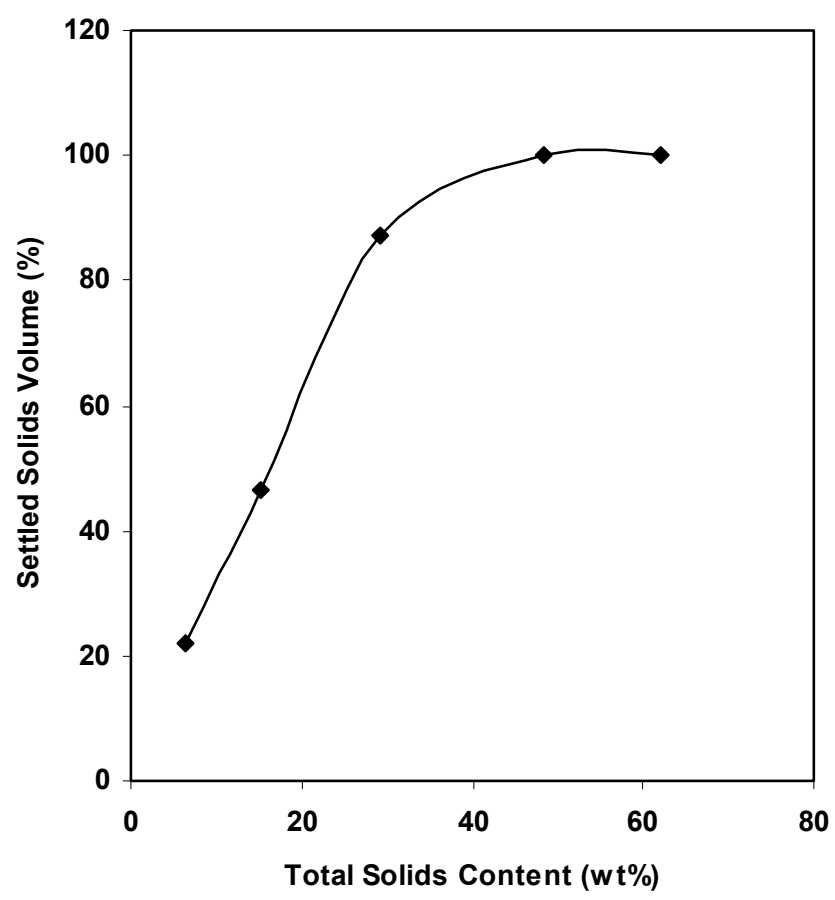

Figure 5.5. Settled Solids Volume as a Function of Total Solids Content of Tank T-110 Dilutions

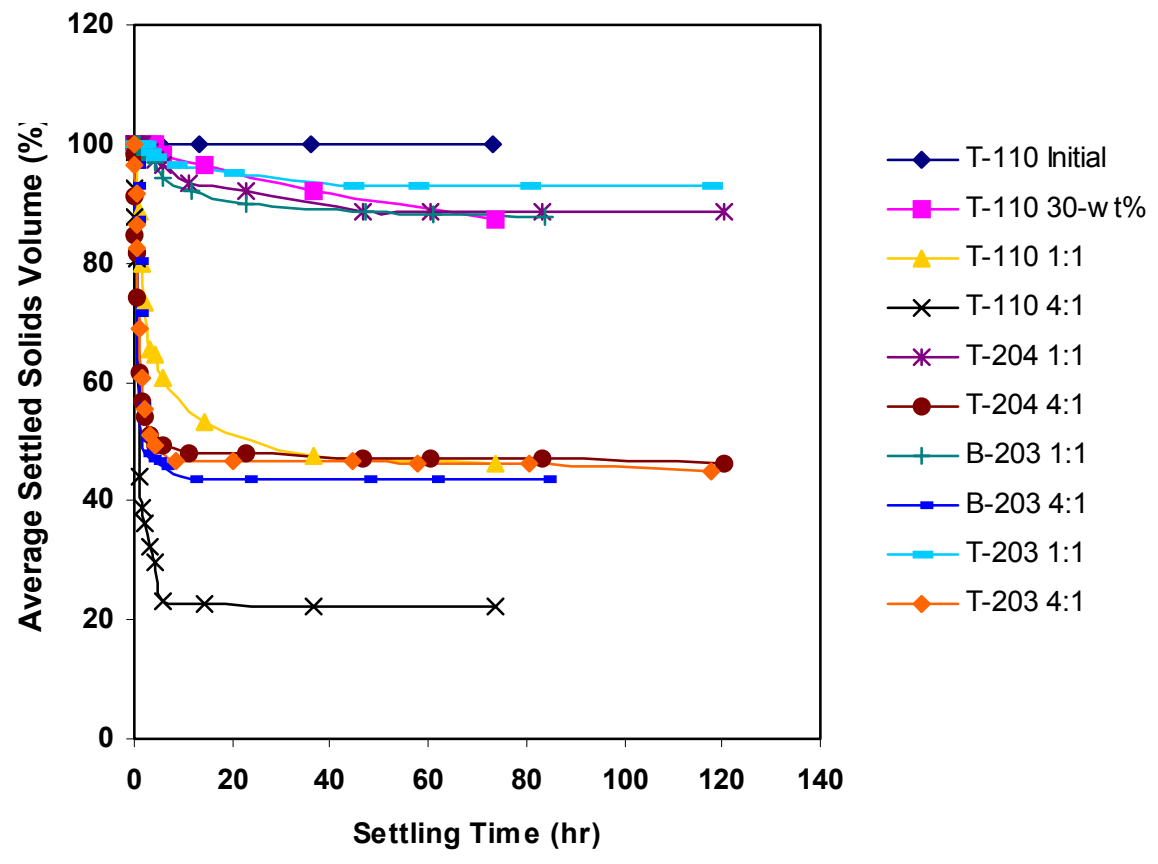

Figure 5.6. Comparison of Sediment-Bed Volume Profiles of All Tested Tank Samples 
Table 5.1. Completeness of the Gravity Settling Process Within the Testing Periods

\begin{tabular}{|c|c|c|c|c|c|}
\hline Dilution & Tank & $\begin{array}{l}\text { Initial Settling } \\
\text { Time } \\
\text { (h) }\end{array}$ & $\begin{array}{c}\text { Completeness } \\
\text { of Settling after } \\
\text { Initial Settling } \\
(\%)\end{array}$ & $\begin{array}{l}\text { Intermediate } \\
\text { Settling Time } \\
\text { (h) }\end{array}$ & $\begin{array}{l}\text { Completeness at } \\
\text { Intermediate } \\
\text { Settling Point } \\
(\%)\end{array}$ \\
\hline Initial & $\mathrm{T}-110$ & $\mathrm{NS}^{(\mathrm{a})}$ & NS & $\mathrm{NS}$ & NS \\
\hline \multirow{4}{*}{$30-\mathrm{wt} \%$} & $\mathrm{~T}-110$ & $6.1^{(\mathrm{b})}$ & 13.9 & 73.6 & 100.0 \\
\hline & T-204 & NS & NS & NS & NS \\
\hline & B-203 & NS & NS & NS & NS \\
\hline & T-203 & NS & NS & NS & NS \\
\hline \multirow{4}{*}{$1: 1$} & $\mathrm{~T}-110$ & 3.1 & 64.2 & 36.8 & 98.0 \\
\hline & T-204 & 2.0 & 9.4 & 46.9 & 100.0 \\
\hline & B-203 & 2.0 & 15.2 & 60.8 & 97.0 \\
\hline & T-203 & 3.0 & 20.0 & 44.5 & 95.1 \\
\hline \multirow{4}{*}{$4: 1$} & T-110 & 2.2 & 81.8 & 6.1 & 98.6 \\
\hline & T-204 & 2.0 & 85.0 & 4.0 & 93.9 \\
\hline & B-203 & 2.0 & 92.6 & 6.0 & 96.7 \\
\hline & T-203 & 2.0 & 81.1 & 8.6 & 96.6 \\
\hline
\end{tabular}

\subsection{Centrifugation}

The aliquots in the centrifuge cones used for gravity settling tests of the homogenized tank samples and the dilutions were centrifuged at $1000 \times \mathrm{g}(2300 \pm 100 \mathrm{rpm}$ with a radius of $16.2 \mathrm{~cm})$ for 15,30 , and 90 minutes to determine the centrifuged solids and centrifuged supernatant volumes. The sample was first centrifuged for 15 minutes, and after the data were recorded, the sample was centrifuged for an additional 15 minutes. The sample was then centrifuged for another 60 minutes. Each sample was mixed well by gentle shaking and inversion of the centrifuge cones before the centrifugation process. The centrifuged samples were weighed on an analytical balance to measure any mass loss during testing. Results showed that less than 0.07 to $0.54 \%$ mass loss occurred in the samples. These losses should not significantly affect the results.

Free liquid was observed for each centrifuged aliquot except for the duplicate aliquots of the T-110 homogenized composite. Centrifuged solids volumes for the homogenized composites from the other tanks were approximately $85 \pm 2 \%$ of the total slurry volume. The initial dilution of the Tank T-110 composite had a centrifuged solids volume of $80 \%$. The vol $\%$ centrifuged solids for the other dilutions (30 wt $\%, 1: 1$, and $4: 1$ ) varied significantly between tanks. The vol $\%$ centrifuged solids for all of the aliquots are listed in Table 5.2.

The centrifuged solids volume profiles of the Tank T-110 samples are shown in Figure 5.7. The results indicate that when the solids concentrations are low (less than $15 \mathrm{wt} \%$ ), sedimentation is complete within 15 minutes at $1000 \times \mathrm{g}$. A longer centrifuge time (30 minutes or longer) was needed to complete the sedimentation when the solids concentration was $30 \mathrm{wt} \%$ or greater. 
Table 5.2. Centrifuged Solids Volumes of All Tested Tank Samples after 90-min Centrifugation

\begin{tabular}{|c|c|c|c|}
\hline Tank No. & Dilution & $\begin{array}{c}\text { Centrifuged Solid } \\
\text { volume } \\
(\%)\end{array}$ & $\begin{array}{c}\text { Average Centrifuged } \\
\text { Solid volume } \\
(\%)\end{array}$ \\
\hline \multirow{10}{*}{$\mathrm{T}-110$} & \multirow{2}{*}{ Composite $^{(a)}$} & 100.0 & \multirow{2}{*}{100.0} \\
\hline & & 100.0 & \\
\hline & \multirow{2}{*}{ Initial } & 79.3 & \multirow{2}{*}{79.9} \\
\hline & & 80.4 & \\
\hline & \multirow{2}{*}{$30-w t \%$} & 39.7 & \multirow{2}{*}{39.9} \\
\hline & & 40.1 & \\
\hline & \multirow{2}{*}{$1: 1$} & 17.4 & \multirow{2}{*}{16.4} \\
\hline & & 15.3 & \\
\hline & \multirow{2}{*}{$4: 1$} & 7.9 & \multirow{2}{*}{8.1} \\
\hline & & 8.2 & \\
\hline \multirow{8}{*}{$\mathrm{T}-204$} & \multirow{2}{*}{ Composite } & 84.4 & \multirow{2}{*}{83.7} \\
\hline & & 82.9 & \\
\hline & \multirow{2}{*}{$30-\mathrm{wt} \%$} & 80.5 & \multirow{2}{*}{79.9} \\
\hline & & 79.2 & \\
\hline & \multirow{2}{*}{$1: 1$} & 40.7 & \multirow{2}{*}{40.0} \\
\hline & & 39.3 & \\
\hline & \multirow{2}{*}{$4: 1$} & 17.6 & \multirow{2}{*}{16.7} \\
\hline & & 15.7 & \\
\hline \multirow{8}{*}{ B-203 } & \multirow{2}{*}{ Composite } & 84.4 & \multirow{2}{*}{83.7} \\
\hline & & 83.0 & \\
\hline & \multirow{2}{*}{$30-w t \%$} & 55.6 & \multirow{2}{*}{54.5} \\
\hline & & 53.3 & \\
\hline & \multirow{2}{*}{$1: 1$} & 37.6 & \multirow{2}{*}{38.5} \\
\hline & & 39.4 & \\
\hline & \multirow{2}{*}{$4: 1$} & 13.0 & \multirow{2}{*}{13.9} \\
\hline & & 14.7 & \\
\hline \multirow{8}{*}{$\mathrm{T}-203$} & Comnosite & 88.3 & 876 \\
\hline & & 86.8 & \\
\hline & $30-w t \%$ & 70.9 & 71.5 \\
\hline & $30-w t \%$ & 72.0 & 71.5 \\
\hline & 1 & 38.7 & 206 \\
\hline & $1: 1$ & 38.5 & 38.6 \\
\hline & $4: 1$ & 15.0 & 15.0 \\
\hline & & 14.9 & \\
\hline
\end{tabular}




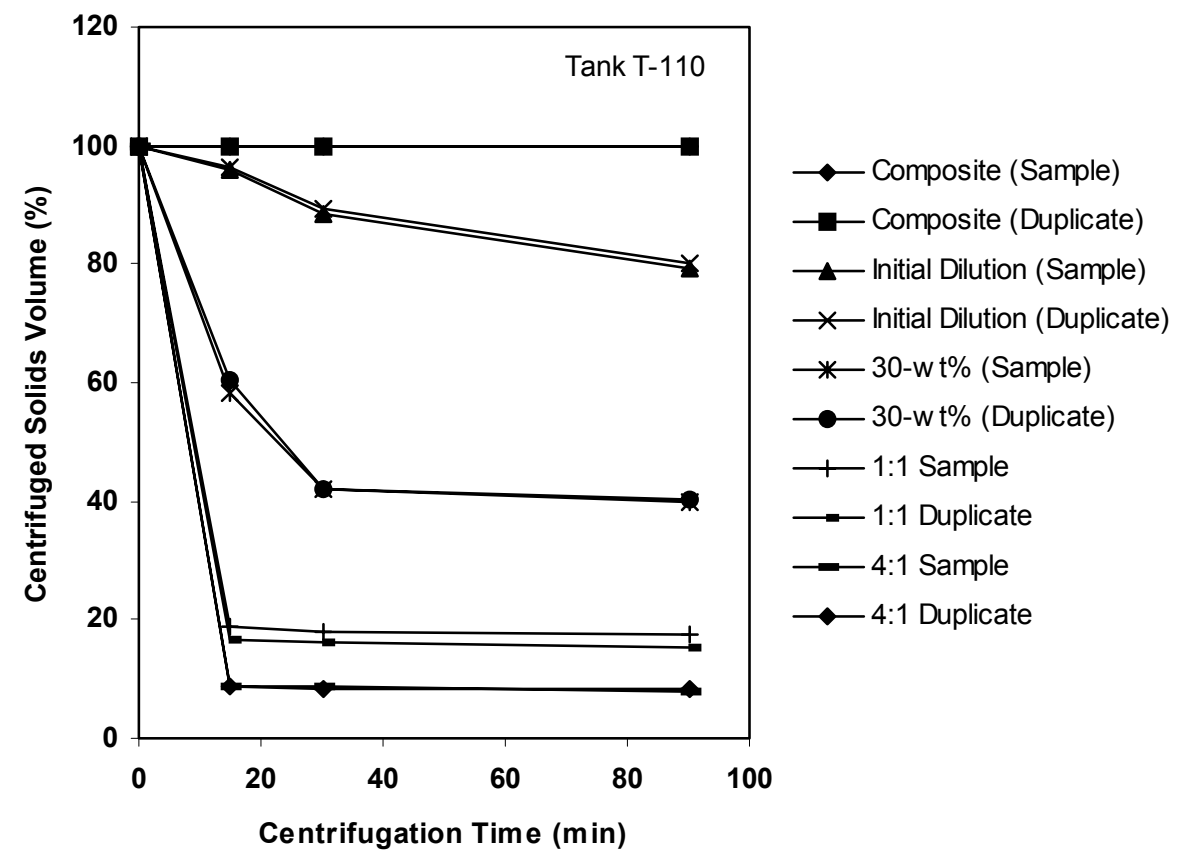

Figure 5.7. Centrifuged Solids-Volume Profiles of T-110 Homogenized Composite and Dilutions

Centrifugation test results of the Tank T-204 homogenized composite and its dilutions are presented in Figure 5.8. Sedimentation of samples with solids concentrations less than $15 \mathrm{wt} \%$ were complete within 15 minutes, but 30 minutes or longer was required for those samples with solids concentrations over $30 \mathrm{wt} \%$.

The centrifuged solids-volume profiles of Tanks B-203 and T-203 samples are shown in Figure 5.9 and Figure 5.10, respectively. The behavior of the samples from these tanks differs slightly from the behavior of the samples from Tank T-204. Sedimentation by centrifugation at $1000 \times \mathrm{g}$ is essentially complete within 15 minutes for all the tested samples with solids concentrations ranging from $6 \mathrm{wt} \%$ to $40 \mathrm{wt} \%$. The sedimentation-bed volume changed less than $6 \%$ after an additional 15 to 75 minutes of centrifugation.

The centrifuged solids volumes of the 1:1 and 4:1 dilutions from all of the tank composites reached their final volume at $1000 \times \mathrm{g}$ in less than or equal to 15 minutes. The $30-\mathrm{wt} \%$ dilutions, the initial dilution for Tank T-110, and the homogenized tank composites approached their final sediment densities in less than or equal to 30 minutes. The 30 -wt\% dilutions from Tanks B-203 and T-203 took only about 15 minutes to reach a stable sediment density. All of the data presented in this report are at a single centrifuge speed, and the sample compacting time may differ at varying centrifugation speeds. 


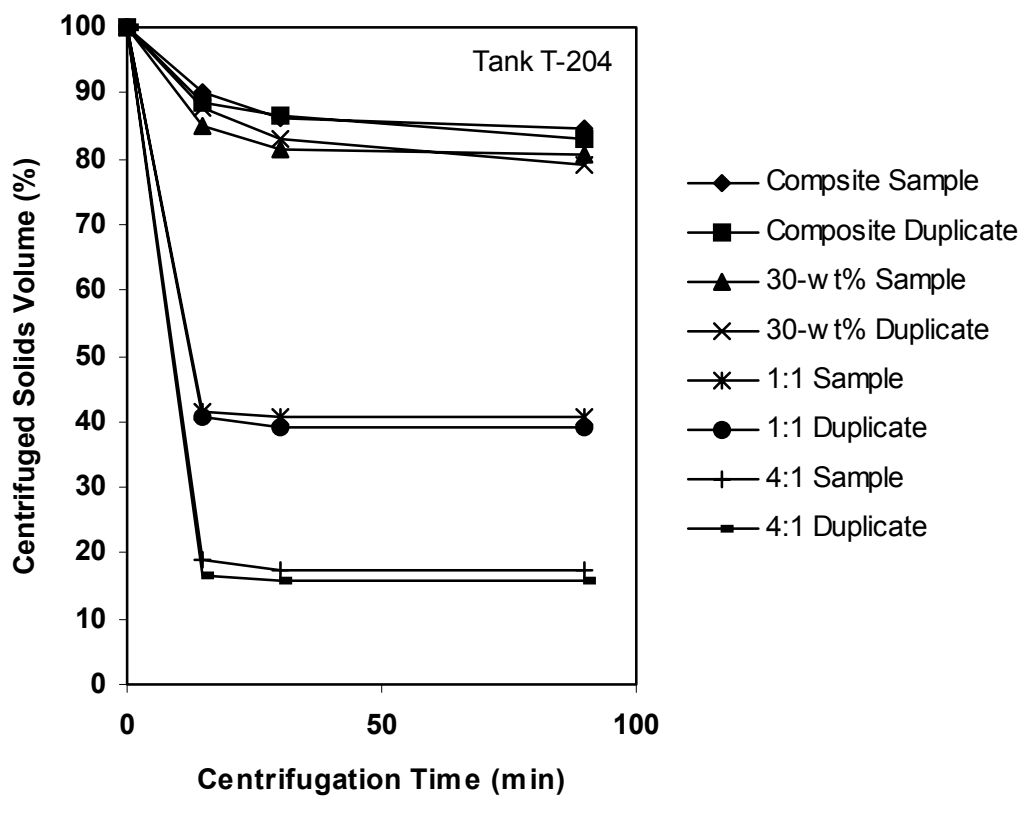

Figure 5.8. Centrifuged Solids Volume Profiles of T-204 Homogenized Composite and Dilutions

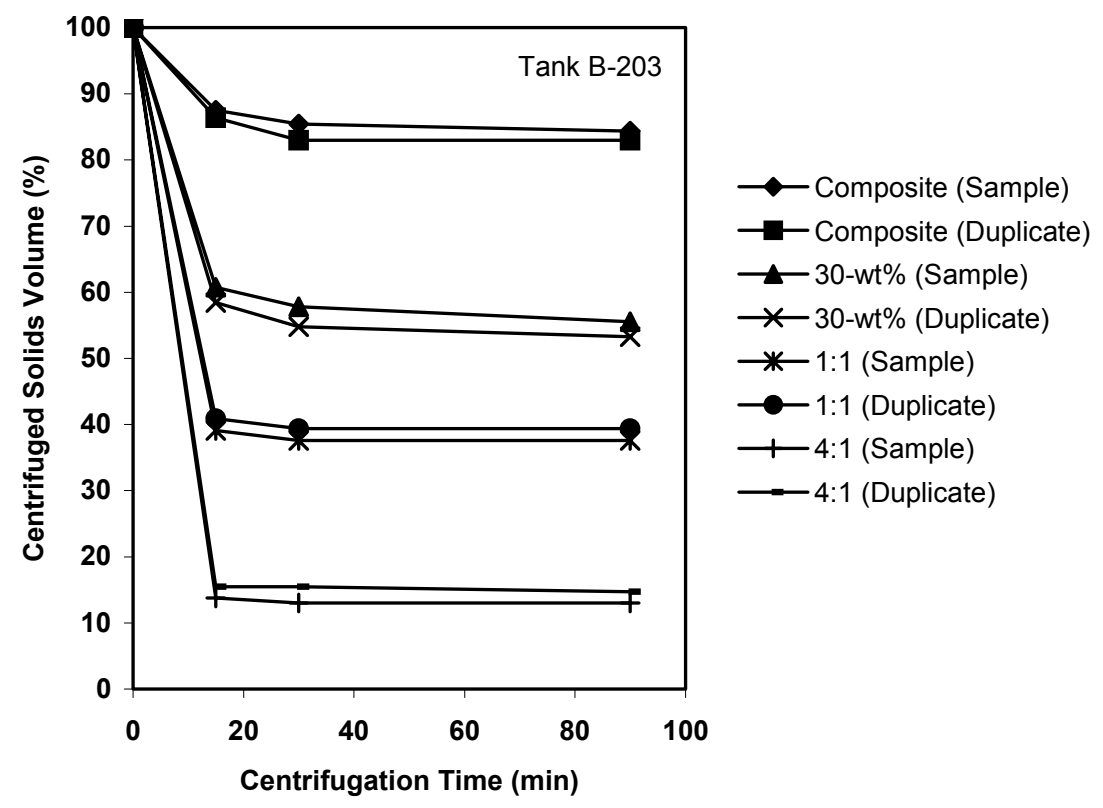

Figure 5.9. Centrifuged Solids Volume Profiles of B-203 Homogenized Composite and Dilutions 


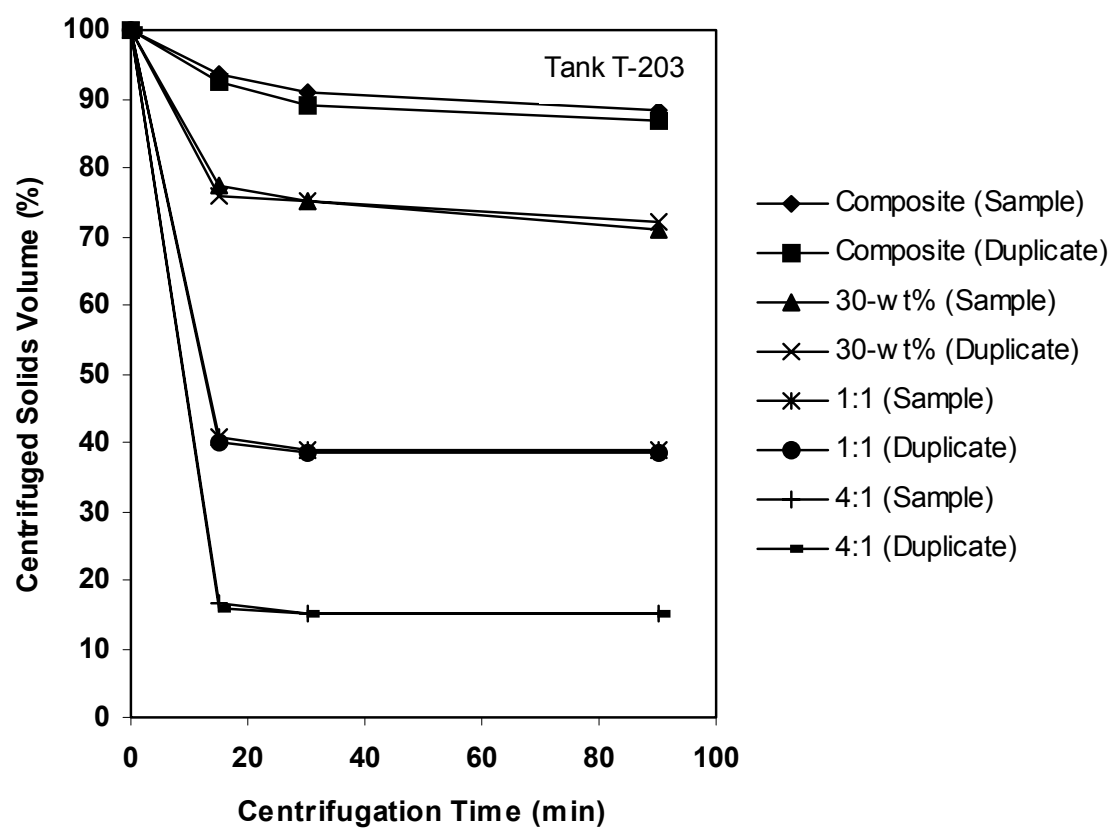

Figure 5.10. Centrifuged Solids-Volume Profiles of T-203 Homogenized Composite and Dilutions

Table 5.2 summarizes the results of the centrifugation behavior of all the tested tank samples after 90 -minute centrifugation at $1000 \times \mathrm{g}$. To better characterize these data, the data points were plotted against the measured total solids concentrations provided in Table 4.3 through 4.5. The results are shown in Figure 5.11. There is a linear relationship between the solids concentration in the slurry and the centrifuged solids volume for all the tested samples. A linear regression model is used:

$$
\mathrm{y}=\mathrm{a}_{1} \mathrm{x}
$$

where $\mathrm{x}$ is the total solids concentration of the tested sample; $\mathrm{y}$ is the centrifuged solids volume, and $\mathrm{a}_{1}$ is the linear regression slope.

This linear model was used to describe the relationship between total solids concentration and the centrifuged solids volume for each tank sample. The linear-regression results are shown in Table 5.3. The slope of the curve fit varied for each tank, indicating that there are differences in the physical properties, such as density, particle size, particle structure, and sample composition for each tank composite. All of these variables can contribute to differences in centrifuged solids volume under the same centrifugation condition.

There are significant differences in the curve shapes in Figure 5.5 and Figure 5.10. The curve in Figure 5.5 represents the gravity-induced sedimentation-bed volume, which is nonlinear with respect to the total solids concentration in the sample, while the centrifuged sedimentation-bed volumes plotted in Figure 5.10 are linear with respect to the solids concentrations. The nonlinear settling phenomena in the gravity-induced settling test were presumably caused by hindered settling, compressibility, and particle aggregation (Rector and Bunker 1995). In the centrifugation tests, all these factors may be overcome by the strong centrifugation force (e. g., $1000 \times$ g), and the centrifuged solids volume has a linear 
relationship to the total solids concentration in the sample. Based on this observation, the phenomena of gravity-induced settling and the centrifuge compacting should be treated differently.

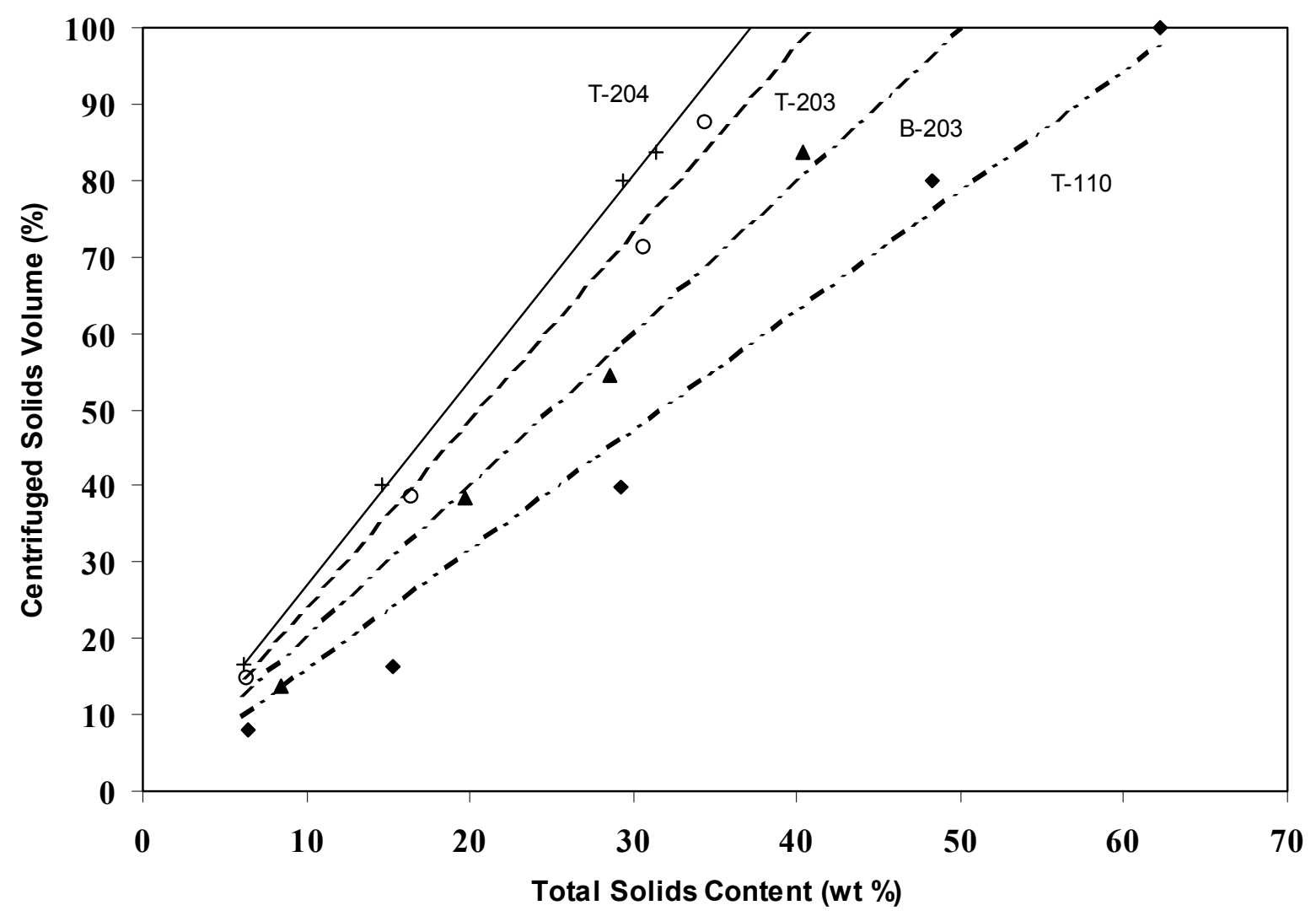

\footnotetext{
- Tank T-110 + Tank T-204 $\quad$ A Tank B-203 O Tank T-203

_... - Linear (Tank T-110) _ L Linear (Tank T-204) _ . - . Linear (Tank B-203) _ - - - Linear (Tank T-203)
}

Figure 5.11. Centrifuged Sample Solids Volume Versus Total Solids Concentration. Linear stands for the linear regression curves for each individual sample.

Table 5.3. Linear Regression Results of Total Solids Concentration and Centrifuged Solids Volume

\begin{tabular}{|c|c|c|}
\hline Tank Sample No. & $\begin{array}{c}\text { Linear Regression Model } \\
\text { Slope, } \mathbf{a}_{1}\end{array}$ & $\begin{array}{c}\text { Curve Fitting } \\
\text { R-Squared Value }\end{array}$ \\
\hline T-110 & 1.540 & 0.982 \\
\hline T-204 & 2.693 & 0.999 \\
\hline B-203 & 1.999 & 0.990 \\
\hline T-203 & 2.444 & 0.991 \\
\hline
\end{tabular}

In practice, gravity-induced settling can be used to separate solid particles and supernatant liquor in a slurry mixture without the need of a mechanical separator when the solids concentration falls within the separable solids concentration range. For example, solid/liquid separations of tank slurries with solids 
concentrations less than $10 \mathrm{wt} \%$ can be quickly settled for solids and supernatant separation within 2 to 3 hours, while slurries with more than $10 \mathrm{wt} \%$ solids concentrations require much longer times (30 to 60 hours for complete settling). However, even at low solids concentrations, dewatering of these solid slurries will be more efficient when a compress-filtering process or a centrifugation process is used. With a compress-filtering or centrifugation process, the total solids volume of the 1:1 and 4:1 dilutions can be reduced by 54 to $70 \%$, depending on the tank samples and sample dilution.

\subsection{Centrifuged Solids and Supernatant Liquor Density}

Upon completion of the centrifugation tests, the centrifuged solids weight as well as the supernatant liquor weight of each sample was measured on an analytical balance, and the centrifuged solids volume was measured using the volumetric readings on the centrifuge tubes. The supernatant liquor densities of the centrifuged samples were determined using a digital pipettor and an analytical balance. The supernatant liquor from each aliquot was transferred into glass vials. A known volume $(1000 \mu \mathrm{L})$ of supernatant liquor was withdrawn by pipet from the vial, and the mass of the pipetted volume was determined by difference. The centrifuged solids volumes ranged from 1.1 to $11.3 \mathrm{~mL}$. The weight and volume data were used to calculate the centrifuged solids densities.

The T-110 solids and supernatant liquor densities are shown in Table 5.4 and Table 5.5. The centrifuged solids densities were $1.37,1.58,1.51,1.61$, and $1.47 \mathrm{~g} / \mathrm{mL}$, respectively, for the homogenized tank composite, initial dilution, and the $30 \mathrm{wt} \%, 1: 1$, and $4: 1$ dilutions. The corresponding supernatant liquor densities for the dilutions are $1.24,1.14,1.08$, and $1.03 \mathrm{~g} / \mathrm{mL}$, respectively. There was no supernatant liquor present in the homogenized tank composite; therefore, no supernatant liquor density could be measured. Salt dissolution causes the aqueous supernatant liquor density to exceed $1.00 \mathrm{~g} / \mathrm{mL}$. The supernatant liquor color for all of these samples was yellow, due primarily to the dissolved hexavalent chromium.

Table 5.4. Densities of Centrifuged Solids of the Composite and Diluted Tank T-110 Samples

\begin{tabular}{|c|c|c|}
\hline Dilution & $\begin{array}{c}\text { Centrifuged } \\
\text { Solids Density } \\
(\mathrm{g} / \mathrm{mL}) \\
\end{array}$ & $\begin{array}{c}\text { Average Centrifuged } \\
\text { Solids Density } \\
(\mathrm{g} / \mathrm{mL})\end{array}$ \\
\hline \multirow{2}{*}{ Composite } & 1.32 & \multirow[t]{2}{*}{ 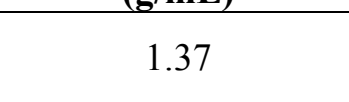 } \\
\hline & 1.41 & \\
\hline \multirow{2}{*}{ Initial } & 1.58 & \multirow{2}{*}{1.58} \\
\hline & 1.58 & \\
\hline \multirow{2}{*}{$30-w t \%$} & 1.52 & \multirow{2}{*}{1.51} \\
\hline & 1.50 & \\
\hline \multirow{2}{*}{$1: 1$} & 1.62 & \multirow{2}{*}{1.61} \\
\hline & 1.61 & \\
\hline \multirow{2}{*}{$4: 1$} & 1.51 & \multirow{2}{*}{1.47} \\
\hline & 1.44 & \\
\hline
\end{tabular}


Table 5.5. Densities of Centrifuged Supernatant Liquor of the Composite and Diluted T-110 Samples

\begin{tabular}{|c|c|c|}
\hline Dilution & $\begin{array}{c}\text { Centrifuged } \\
\text { Supernatant Liquor Density } \\
(\mathbf{g} / \mathbf{m L})\end{array}$ & $\begin{array}{c}\text { Standard Deviation } \\
(\mathbf{g} / \mathbf{m L})\end{array}$ \\
\hline Composite & No supernatant & NA \\
\hline Initial Dilution & 1.24 & 0.001 \\
\hline $30-\mathrm{wt} \%$ solids & 1.14 & 0.004 \\
\hline $1: 1$ & 1.08 & 0.004 \\
\hline $4: 1$ & 1.03 & 0.003 \\
\hline
\end{tabular}

Table 5.6 and Table 5.7 show the centrifuged solids and supernatant liquor densities of the Tank T204 samples. The centrifuged solids densities were 1.40,1.36, 1.30, and $1.35 \mathrm{~g} / \mathrm{mL}$, respectively, for the homogenized tank composite and the $30 \mathrm{wt} \%, 1: 1$, and 4:1 dilutions. The corresponding supernatant liquor densities were $1.14,1.12,1.06$, and $1.03 \mathrm{~g} / \mathrm{mL}$, respectively. All supernatant liquors are light yellow in color.

The centrifuged solids and supernatant liquor densities of the Tank B-203 samples are shown in Table 5.8 and Table 5.9. The centrifuged solids densities were $1.53,1.41,1.38$, and $1.52 \mathrm{~g} / \mathrm{mL}$, respectively, for the homogenized tank composite and the $30 \mathrm{wt} \%, 1: 1$, and $4: 1$ dilutions. The corresponding supernatant liquor densities were 1.21, 1.15, 1.10, and $1.04 \mathrm{~g} / \mathrm{mL}$, respectively. A light yellowish color was observed in all of the supernatant liquors.

Table 5.6. Densities of Centrifuged Solids of Homogenized and Diluted Tank T-204 Samples

\begin{tabular}{|c|c|c|}
\hline \multirow{2}{*}{ Dilution } & $\begin{array}{c}\text { Centrifuged } \\
\text { Solids Density } \\
\text { (g/mL) }\end{array}$ & $\begin{array}{c}\text { Average Centrifuged } \\
\text { Solid Density } \\
(\mathbf{g} / \mathbf{m L})\end{array}$ \\
\hline \multirow{2}{*}{ Composite } & 1.37 & 1.40 \\
\cline { 2 - 3 } 30 30-wt\% solids & 1.43 & 1.36 \\
\cline { 2 - 3 } & 1.36 & \multirow{2}{*}{1.30} \\
\hline \multirow{2}{*}{$1: 1$} & 1.37 & \multirow{2}{*}{1.35} \\
\hline \multirow{2}{*}{$4: 1$} & 1.27 & \multicolumn{2}{|c|}{} \\
\hline
\end{tabular}

Table 5.7. Densities of Centrifuged Supernatant Liquor of Homogenized and Diluted T-204 Samples

\begin{tabular}{|c|c|c|}
\hline Dilution & $\begin{array}{c}\text { Centrifuged } \\
\text { Supernatant Liquor Density } \\
(\mathbf{g} / \mathbf{m L})\end{array}$ & $\begin{array}{c}\text { Standard Deviation } \\
\mathbf{( g / m L )}\end{array}$ \\
\hline Composite & 1.14 & 0.001 \\
\hline $30-\mathrm{wt} \%$ solids & 1.12 & 0.002 \\
\hline $1: 1$ & 1.06 & 0.004 \\
\hline $4: 1$ & 1.03 & 0.004 \\
\hline
\end{tabular}


Table 5.8. Densities of Centrifuged Solids of Homogenized and Diluted Tank B-203 Samples

\begin{tabular}{|c|c|c|}
\hline Dilution & $\begin{array}{c}\text { Centrifuged } \\
\text { Solids Density } \\
(\mathrm{g} / \mathrm{mL}) \\
\end{array}$ & $\begin{array}{c}\text { Average Centrifuged } \\
\text { Solids Density } \\
(\mathrm{g} / \mathrm{mL}) \\
\end{array}$ \\
\hline \multirow{2}{*}{ Composite } & 1.51 & \multirow[t]{2}{*}{ 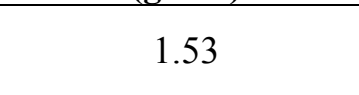 } \\
\hline & 1.55 & \\
\hline \multirow{2}{*}{$30-w t \%$ solids } & 1.39 & \multirow{2}{*}{1.41} \\
\hline & 1.43 & \\
\hline \multirow{2}{*}{$1: 1$} & 1.40 & \multirow{2}{*}{1.38} \\
\hline & 1.35 & \\
\hline \multirow{2}{*}{$4: 1$} & 1.56 & \multirow{2}{*}{1.52} \\
\hline & 1.48 & \\
\hline
\end{tabular}

Table 5.9. Densities of Centrifuged Supernatant Liquor of Homogenized and Diluted B-203 Samples

\begin{tabular}{|c|c|c||}
\hline \hline Dilution & $\begin{array}{c}\text { Centrifuged } \\
\text { Supernatant Liquor Density } \\
(\mathbf{g} / \mathbf{m L})\end{array}$ & $\begin{array}{c}\text { Standard Deviation } \\
(\mathbf{g} / \mathbf{m L})\end{array}$ \\
\hline Composite & 1.21 & 0.005 \\
\hline $30-\mathrm{wt} \%$ solids & 1.15 & 0.003 \\
\hline $1: 1$ & 1.10 & 0.003 \\
\hline $4: 1$ & 1.04 & 0.003 \\
\hline
\end{tabular}

For the Tank T-203 samples, the centrifuged solids and supernatant liquor densities are shown in Table 5.10 and Table 5.11. The centrifuged solids densities were $1.39,1.30,1.31$, and $1.29 \mathrm{~g} / \mathrm{mL}$, respectively, for the homogenized tank composite and the $30 \mathrm{wt} \%, 1: 1$, and $4: 1$ dilutions. The corresponding supernatant liquor densities were $1.17,1.14,1.08$, and $1.03 \mathrm{~g} / \mathrm{mL}$, respectively. Similarly, a light yellowish color was observed in these supernatant liquors.

Table 5.10. Densities of Centrifuged Solids of Homogenized and Diluted Tank T-203 Samples

\begin{tabular}{|c|c|c|}
\hline Dilution & $\begin{array}{c}\text { Centrifuged } \\
\text { Solids Density } \\
(\mathrm{g} / \mathrm{mL}) \\
\end{array}$ & $\begin{array}{c}\text { Average Centrifuged } \\
\text { Solids Density } \\
(\mathrm{g} / \mathrm{mL}) \\
\end{array}$ \\
\hline \multirow{2}{*}{ Composite } & 1.41 & \multirow{2}{*}{1.39} \\
\hline & 1.36 & \\
\hline \multirow{2}{*}{$30-w t \%$ solids } & 1.24 & \multirow{2}{*}{1.30} \\
\hline & 1.36 & \\
\hline \multirow{2}{*}{$1: 1$} & 1.30 & \multirow{2}{*}{1.31} \\
\hline & 1.31 & \\
\hline \multirow{2}{*}{$4: 1$} & 1.31 & \multirow{2}{*}{1.29} \\
\hline & 1.27 & \\
\hline
\end{tabular}


Table 5.11. Densities of Centrifuged Supernatant Liquor of Homogenized and Diluted T-203 Samples

\begin{tabular}{|c|c|c|}
\hline Dilution & $\begin{array}{c}\text { Centrifuged } \\
\text { Supernatant Liquor Density } \\
(\mathrm{g} / \mathrm{mL})\end{array}$ & $\begin{array}{c}\text { Standard Deviation } \\
(\mathrm{g} / \mathrm{mL})\end{array}$ \\
\hline Composite & 1.17 & 0.002 \\
\hline $30-w t \%$ solids & 1.14 & 0.005 \\
\hline $1: 1$ & 1.08 & 0.005 \\
\hline 4:1 & 1.03 & 0.003 \\
\hline
\end{tabular}

The centrifuged solids densities of all the tested samples ranged from 1.29 to $1.61 \mathrm{~g} / \mathrm{mL}$, depending on the sample source. The centrifuged supernatant liquor densities vary from 1.03 to $1.24 \mathrm{~g} / \mathrm{mL}$ and decrease with increasing dilution. The supernatant liquor densities are higher than the density of water due to the dissolution of salts into the supernatant. The color of the supernatant liquors was light yellow.

\section{$5.4 \mathrm{pH}$}

The $\mathrm{pH}$ of the diluted tank composites is important to the retrieval, transport, separation (centrifugation or compress-filtering), and packaging processes. Tank composites with higher $\mathrm{pH}$ values may be less corrosive to steel materials, and composites with lower $\mathrm{pH}$ values may need to have special processing equipment during handling and packaging of the various TRU tank wastes.

Supernatant liquors of the original and the diluted tank composites were obtained after centrifugation, and the $\mathrm{pH}$ of these supernatant liquors was measured with a calibrated $\mathrm{pH}$ meter. Diluted tank composites were transferred into $15-\mathrm{mL}$ centrifugation cones and subjected to centrifugation at $1000 \times \mathrm{g}$ for about 30 to 90 minutes. Yellowish supernatant liquors were obtained from each diluted tank composite. If greater than $1 \mathrm{~mL}$ of supernatant was obtained after centrifugation, the supernatant was decanted, transferred into a small glass vial, and a $\mathrm{pH}$ measurement was performed.

In Table 5.12, the $\mathrm{pH}$ of the various supernatant liquors in both the original and the diluted composites of Tank T-110, T-204, B-203, and T-203 are reported. The Tank T-110 composite contains no free liquid, presumably due to the loss of substantial amounts of water before the composite was prepared; therefore, no $\mathrm{pH}$ was obtained for that sample. High concentrations of phosphate $(5$ to $11 \mathrm{~g} / \mathrm{L}$ of total phosphorus [Rassat et al. 2003b]) are present in the liquid associated with the Tank T-110 composite. The high concentration of phosphate in the composite buffers the supernatant liquor produced during the dilution process. The $\mathrm{pH}$ value of the centrifuged supernatant liquor from the initial dilution was 8.30, which is similar to the $\mathrm{pH}$ value (8.4) reported by Rassat et. al. (2003b) for the original composite. No significant change in the $\mathrm{pH}$ of the supernatant liquor was observed upon further dilution to $30-\mathrm{wt} \%$ solids, to a $1: 1$ dilution, and to a $4: 1$ dilution of the Tank T-110 composite. The $\mathrm{pH}$ values of these supernatant liquors were $8.25,8.29$, and 8.26 , respectively. 
Table 5.12. pH Values of Diluted TRU Composite Supernatant liquors

\begin{tabular}{||c|c|c|}
\hline Tank & Sample Dilution & pH \\
\hline \multirow{4}{*}{ T-110 } & Initial Dilution & 8.30 \\
\cline { 2 - 3 } & 30-wt\% Dilution & 8.25 \\
\cline { 2 - 3 } & $1: 1$ Dilution & 8.29 \\
\cline { 2 - 3 } & $4: 1$ Dilution & 8.26 \\
\hline \multirow{4}{*}{ T-204 } & Composite & 11.00 \\
\cline { 2 - 3 } & $30-w t \%$ Dilution & 11.03 \\
\cline { 2 - 3 } & $1: 1$ Dilution & 11.11 \\
\cline { 2 - 3 } & $4: 1$ Dilution & 10.98 \\
\hline \multirow{4}{*}{ B-203 } & Composite & 11.40 \\
\cline { 2 - 3 } & $30-w t \%$ Dilution & 11.53 \\
\cline { 2 - 3 } & $1: 1$ Dilution & 11.47 \\
\cline { 2 - 3 } & $4: 1$ Dilution & 11.30 \\
\hline \multirow{5}{*}{ T-203 } & Composite & 10.95 \\
\cline { 2 - 3 } & $30-w t \%$ Dilution & 11.02 \\
\cline { 2 - 3 } & $1: 1$ Dilution & 11.07 \\
\cline { 2 - 3 } & $4: 1$ Dilution & 10.97 \\
\hline
\end{tabular}

The supernatant liquor $\mathrm{pH}$ values of the homogenized composites in Tanks T-204 and T-203 were equal or close to $\mathrm{pH}$ 11.0. Upon 30 -wt\% dilution, $1: 1$ dilution, and $4: 1$ dilution, the supernatant liquor $\mathrm{pH}$ values did not change and remained between 11.0 and 11.1. The supernatant liquors of the homogenized composite and its dilutions (30-wt\% dilution, 1:1 dilution, and 4:1 dilution) in Tank B-203 have a pH range from 11.3 to 11.5 .

The change in the supernatant liquor $\mathrm{pH}$ as a function of total solids concentration is shown in Figure 5.12. The results show that the supernatant liquor $\mathrm{pH}$ does not change significantly when the solids concentration decreases from 50 to $6 \mathrm{wt} \%$. 


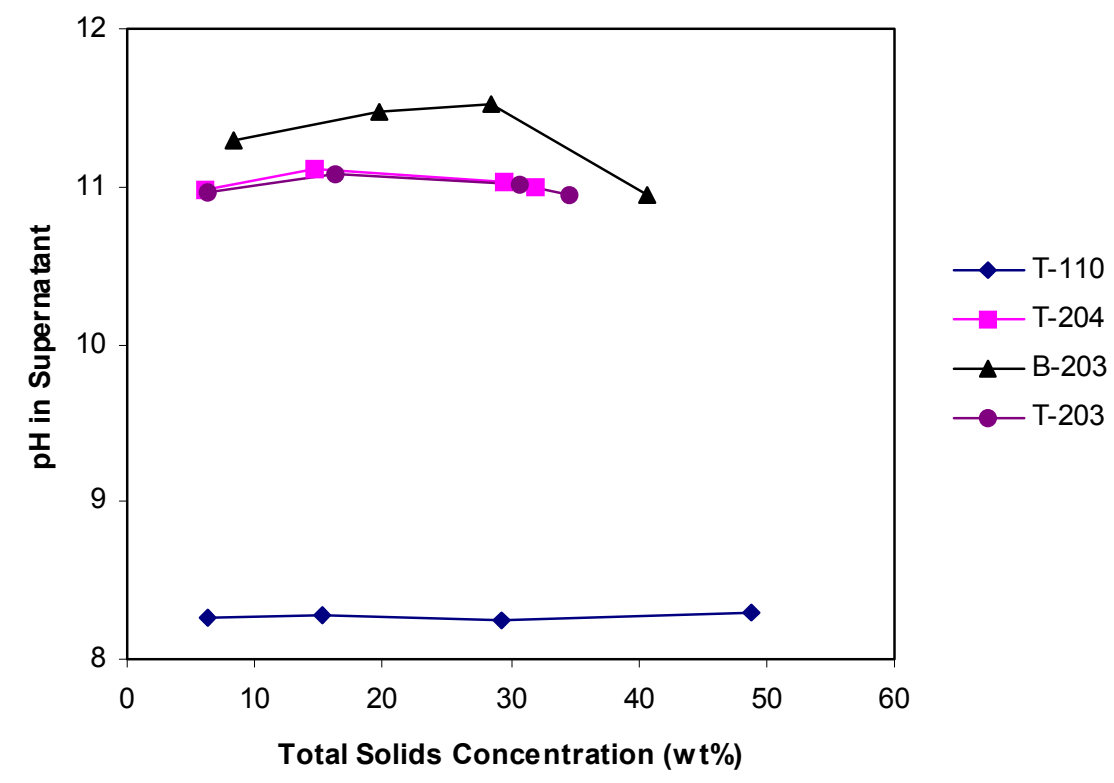

Figure 5.12. Supernatant Liquor pH vs. Total Solids Concentration (wt\%) of Homogenized and Diluted Tank Composites in Tanks T-110, T-203, B-203, and T-203 


\subsection{Rheological Characterization}

In the tests described in this section, rheological properties, including viscosity and yield strength, were measured on the dilutions prepared from the tank composites. Shear strength was measured on the homogenized core composite as well as the initial dilution from Tank T-110 and the $30-\mathrm{wt} \%$ dilutions from the other three tank composites. Shear-strength estimates were calculated based on small-scale extrusions (mini extrusions) of the homogenized tank composites and $30-\mathrm{wt} \%$ dilutions from Tanks B-203, T-203, and T-204.

\subsection{Viscosity}

Viscosities of the diluted tank samples were measured as a function of shear rate. A concentric cylinder sensor system was used for the viscosity analysis of those samples that could be poured or pipetted into the measuring cup. A $10.0 \mathrm{cP}(0.0100 \mathrm{~Pa} \cdot \mathrm{s})$ viscosity standard was measured as a check of the rheometer calibration. At least two rheograms were recorded for each sample. A single rheogram includes measuring shear stress as the shear rate is increased (up) from 0 to $1000 \mathrm{~s}^{-1}$ followed by decreasing the shear rate (down) from 1000 to $0 \mathrm{~s}^{-1}$.

Rheograms for those samples that could not be measured in the concentric cylinder sensor systems were made on the cone-and-plate rheometer system. Due to the high yield stress of these materials, no viscous flow was observed in these rheograms. These measurements were made on the Bohlin CS rheometer with a 40-mm diameter cone and a 4-degree pitch. The maximum stress for this sensor system is $580 \mathrm{~Pa}$. The yield stress for all of these samples exceeded $580 \mathrm{~Pa}$. The T-110 samples also had large agglomerates whose diameters approached the gap size of the cone and plate sensor system. Valid rheology measurements cannot be made when the particle diameter approaches the gap dimensions of the sensor system.

Various rheological models were used to fit the data. These models include Bingham plastic, yield power law, and Newtonian models (Bird et al. 1960). These models can be used to estimate viscosity and shear stress as a function of shear rate, as well as the yield stress of the sample. The Newtonian model is the simplest of the rheological models and is described by Equation 7.1.

$$
\tau=\mu \gamma
$$

where $\tau$ is the shear stress $(\mathrm{Pa}), \mu$ is the viscosity $(\mathrm{Pa} \cdot \mathrm{s})$, and $\gamma$ is the shear rate $\left(\mathrm{s}^{-1}\right)$.

Viscosity is independent of shear rate for Newtonian fluids, but for non-Newtonian fluids (i.e., Bingham plastic and yield pseudoplastic fluids), viscosity is a function of shear rate. In both Bingham plastic and yield pseudoplastic fluids, viscosity decreases with increasing shear rate. The Bingham plastic and yield power law (yield pseudoplastic) fits are described by Equations 7.2 and 7.3, respectively. The Bingham plastic is a yield power law fit with the power law index equal to 1 .

Bingham Plastic Fit $\quad \tau=\tau_{0}+\mu_{0} \gamma$ 
where

$\tau \quad$ shear stress $(\mathrm{Pa})$

$\tau_{0} \quad$ yield stress $(\mathrm{Pa})$

$\mu_{0} \quad$ consistency factor (Pa.s)

$\gamma \quad$ shear rate $\left(\mathrm{s}^{-1}\right)$.

Yield Power Law Fit

$$
\tau=\tau_{0}+\kappa \gamma^{\mathrm{n}}
$$

where

$\tau=$ shear stress $(\mathrm{Pa})$

$\tau_{0}=$ the yield stress $(\mathrm{Pa})$

$\kappa=$ consistency factor $(\mathrm{Pa} \cdot \mathrm{s})$

$\mathrm{N}=$ power law index

$\gamma=$ shear rate $\left(\mathrm{s}^{-1}\right)$.

Viscosity is plotted as a function of shear rate for each of the dilutions in Figure 6.1 through Figure 6.11. The model results are summarized in Table 6.1 through Table 6.7. Figure 6.1 through Figure 6.3 show viscosity as a function of shear rate for the $30-\mathrm{wt} \%, 1: 1$, and $4: 1$ dilutions from Tank T-110, respectively. The measured viscosities of the $30-\mathrm{wt} \%$ dilution, as shown in Figure A.1 in Appendix A are very reproducible within the analyzed shear-rate range of 0 to $1000 \mathrm{~s}^{-1}$. Hysteresis was observed between the up and down curves in the rheogram of the 1:1 dilution, but the reproducibility between the two up curves and the two down curves was good as shown in Figure A.2. The hysteresis is indicative of the effect of shear on the viscosity of the sample. The data for this sample were valid over a limited shearrate range $\left(0\right.$ to $\left.450 \mathrm{~s}^{-1}\right)$ because of Taylor fluid instability at the higher shear-rate ranges. Similar behavior was observed for the $4: 1$ dilution, and the valid shear-rate range ( 0 to $\left.250 \mathrm{~s}^{-1}\right)$ was even more limited than for the 1:1 dilution as indicated in Figure A.3. The down curves for the 4:1 dilution exhibit Newtonian behavior with a viscosity of approximately $1 \mathrm{cP}$. The accuracy of the rheometer sensor system is diminished at low viscosities and shear rates, as seen by the noise in the down curves for the 4:1 dilution at lower shear rates $\left(<30 \mathrm{~s}^{-1}\right)$ in Figure 6.3. This inaccuracy in the viscosity of low-viscosity fluids at low shear rates is also observed in the $10 \mathrm{cP}$ standard at shear rates less than $10 \mathrm{~s}^{-1}$ as shown in Figure 6.12 through Figure 6.14.

A Bingham plastic model was used to fit the shear-stress data as a function of shear rate for these T-110 dilutions. Table 6.1 summarizes the results of these regressions except for the down curves of the 4:1 dilution, where a Newtonian model was sufficient to fit the data. The Bingham plastic model fit the data well with R-squared values from 0.980 to 0.998 . The overall yield stresses are $1.5,0.18$, and $0.03 \mathrm{~Pa}$ for the $30 \mathrm{wt} \%$ solid, 1:1, and 4:1 dilutions, respectively. The yield stresses for the $1: 1$ and 4:1 dilutions are based on the up curves only because of the hysteresis observed in these samples.

A yield power law model was also used to fit the data for $30-\mathrm{wt} \%$ solids and $1: 1$ dilution, and a Newtonian model was used to fit the down curves of the 4:1 dilution. A comparison of the Bingham plastic model regressions to the yield power law and Newtonian model fits is provided in Table 6.2. The yield power law model fits the data set better as shown by a higher R-squared value, but the slight improvement in the curve fit is not sufficient to substantiate the need to describe the rheological behavior of these samples as yield pseudoplastic. The yield stresses obtained by the Power Law fit are also similar to those obtained by the Bingham plastic fit. 


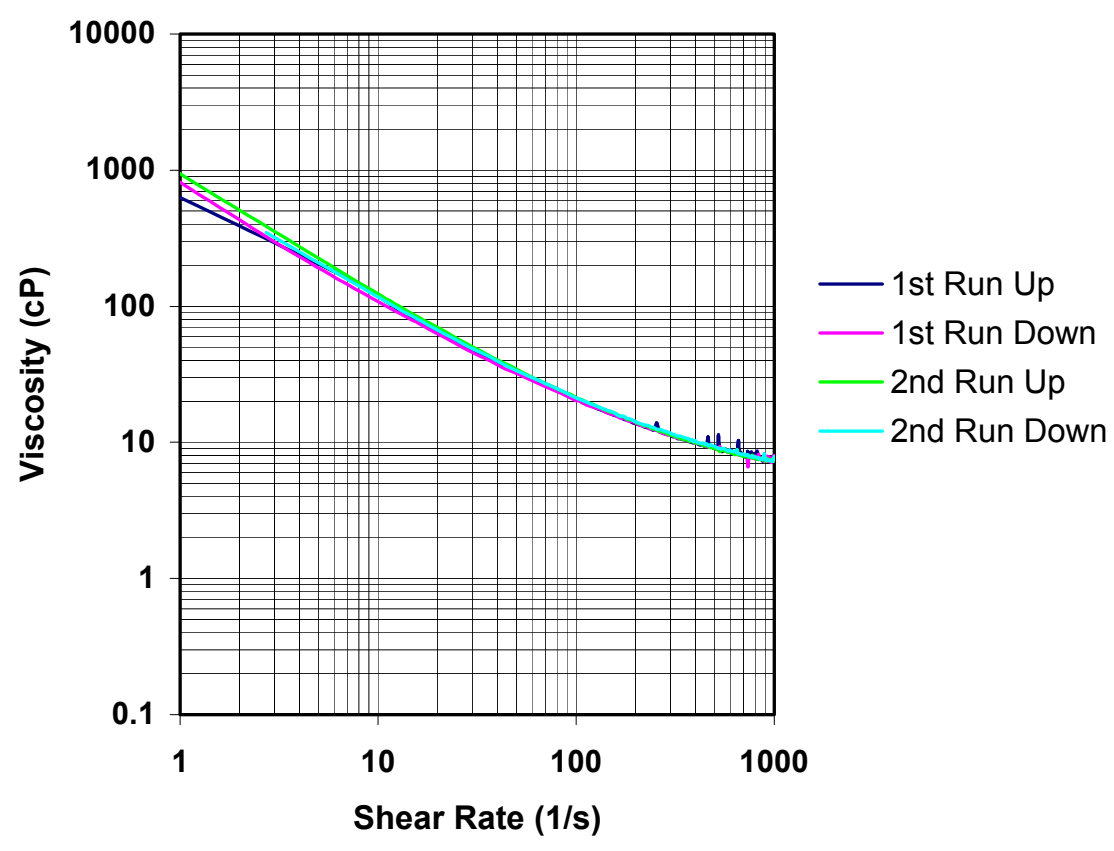

Figure 6.1. Viscosity Versus Shear Rate of Tank T-110 30-wt\% Solids Dilution

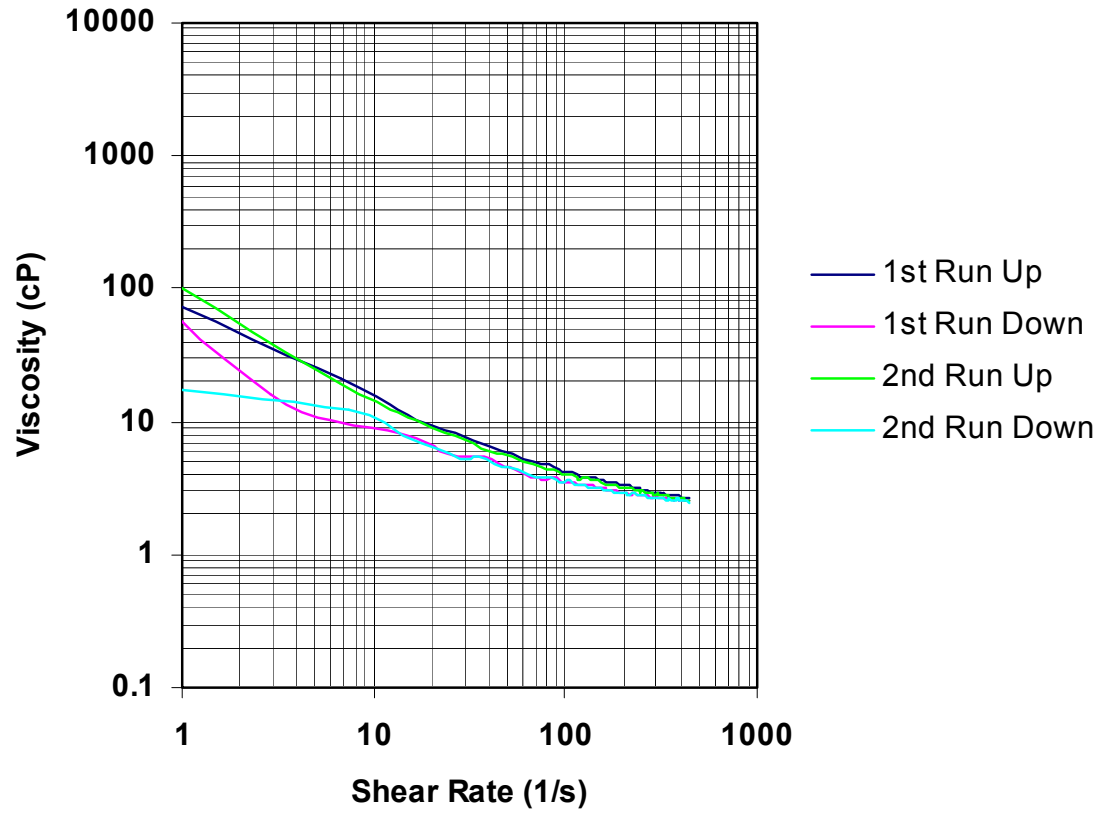

Figure 6.2. Viscosity Versus Shear Rate of the Tank T-110 1:1 Dilution 


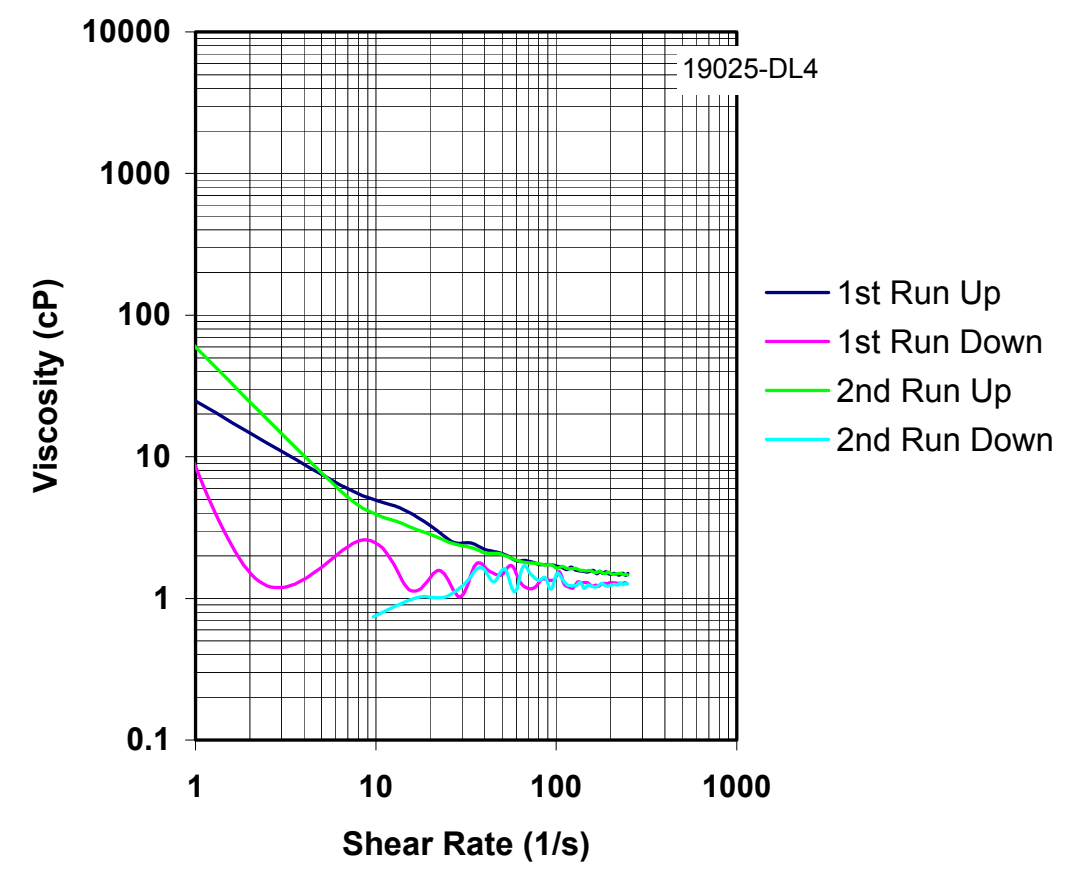

Figure 6.3. Viscosity Versus Shear Rate of the Tank T-110 4:1 Dilution

Table 6.1. Summary of Bingham Plastic Curve Fit Parameters of Tank T-110 Dilutions

\begin{tabular}{|c|c|c|c|c|c|}
\hline Dilution & Test Run Status & $\begin{array}{c}\text { Shear Rate } \\
\text { Range } \\
\gamma(\mathbf{1} / \mathbf{s})\end{array}$ & $\begin{array}{c}\text { Yield Stress } \\
\tau_{0}(\mathbf{P a})\end{array}$ & $\begin{array}{r}\mu_{0} \times 10^{3} \\
(\mathbf{P a} \cdot \mathbf{s})\end{array}$ & $\begin{array}{l}\text { R-Squared } \\
\text { Value }\end{array}$ \\
\hline \multirow{4}{*}{$30 \mathrm{wt} \%$} & $1^{\text {st }}$ run-up & \multirow{4}{*}{$0-1000$} & 1.48 & 6.09 & 0.980 \\
\hline & $1^{\text {st }}$ run-down & & 1.50 & 5.90 & 0.990 \\
\hline & $2^{\text {nd }}$ run-up & & 1.58 & 5.77 & 0.993 \\
\hline & $2^{\text {nd }}$ run-down & & 1.62 & 5.84 & 0.992 \\
\hline \multirow{4}{*}{$1: 1$} & $1^{\text {st }}$ run-up & \multirow{4}{*}{$0-450$} & 0.181 & 2.31 & 0.992 \\
\hline & $1^{\text {st }}$ run-down & & 0.112 & 2.32 & 0.997 \\
\hline & $2^{\text {nd }}$ run-up & & 0.172 & 2.24 & 0.995 \\
\hline & $2^{\text {nd }}$ run-down & & 0.108 & 2.31 & 0.996 \\
\hline \multirow{4}{*}{$4: 1$} & $1^{\text {st }}$ run-up & \multirow{4}{*}{$0-250$} & 0.0334 & 1.34 & 0.998 \\
\hline & $\begin{array}{l}1^{\text {st }} \text { run-down } \\
\text { (Newtonian) }\end{array}$ & & N/A & 1.28 & 0.991 \\
\hline & $2^{\text {nd }}$ run-up & & 0.0359 & 1.33 & 0.994 \\
\hline & $\begin{array}{l}2^{\text {nd }} \text { run-down } \\
\text { (Newtonian) }\end{array}$ & & N/A & 1.26 & 0.989 \\
\hline
\end{tabular}


Table 6.2. Comparison of Different Curve Fits of Tank T-110 Samples

\begin{tabular}{|c|c|c|c|c|c|c|}
\hline Dilution & Model & $\begin{array}{c}\text { Model } \\
\text { Formula }\end{array}$ & $\begin{array}{c}\text { Yield } \\
\text { Stress } \\
\tau_{0}(\mathrm{~Pa}) \\
\end{array}$ & $\begin{array}{c}\text { Power Law } \\
\text { Index } \\
\text { n }\end{array}$ & $\begin{array}{c}\mu_{0} \text { or } \kappa \times 10^{3} \\
(\mathrm{~Pa} \cdot \mathrm{s})\end{array}$ & $\begin{array}{c}\text { R-Squared } \\
\text { Value }\end{array}$ \\
\hline \multirow{2}{*}{$30 \mathrm{wt} \%$} & Bingham & $\tau=\tau_{0}+\mu_{0} \gamma$ & 1.54 & NA & 5.90 & 0.988 \\
\hline & Yield Power Law & $\tau=\tau_{0}+\kappa \gamma^{\mathrm{n}}$ & 1.11 & 0.82 & 21.25 & 0.992 \\
\hline \multirow{2}{*}{$1: 1$} & Bingham & $\tau=\tau_{0}+\mu_{0} \gamma$ & 0.14 & NA & 2.29 & 0.985 \\
\hline & Yield Power Law & $\tau=\tau_{0}+\kappa \gamma^{\mathrm{n}}$ & 0.0749 & 0.83 & 6.82 & 0.988 \\
\hline \multirow{2}{*}{$4: 1$} & Bingham & $\tau=\tau_{0}+\mu_{0} \gamma$ & 0.0204 & NA & 1.29 & 0.949 \\
\hline & Newtonian & $\tau=\mu \gamma$ & NA & NA & 1.41 & 0.937 \\
\hline
\end{tabular}

Viscosity is plotted as a function of shear rate for the 1:1 and 4:1 dilutions of the Tank T-204 composite in Figure 6.4 and Figure 6.5. The viscosity of the 30 -wt $\%$ solids dilution was not measured because the yield strength of the sample exceeded the torque limits of the sensor system.

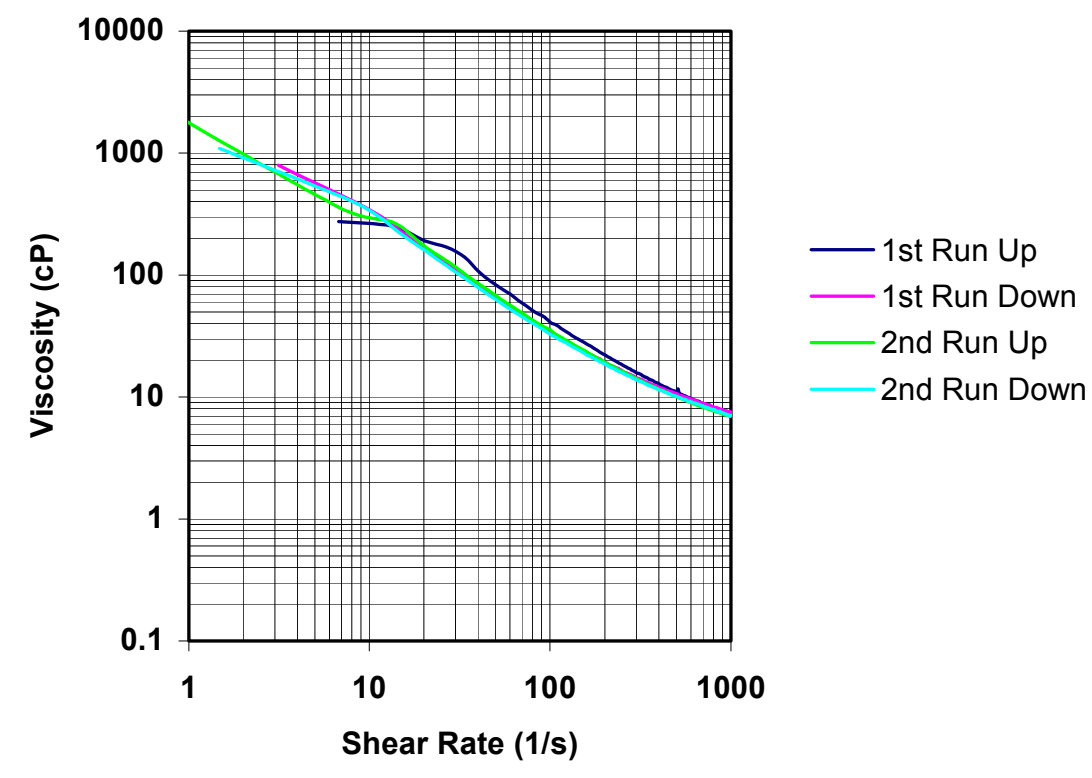

Figure 6.4. Viscosities Versus Shear Rate of the Tank T-204 1:1 Dilution 


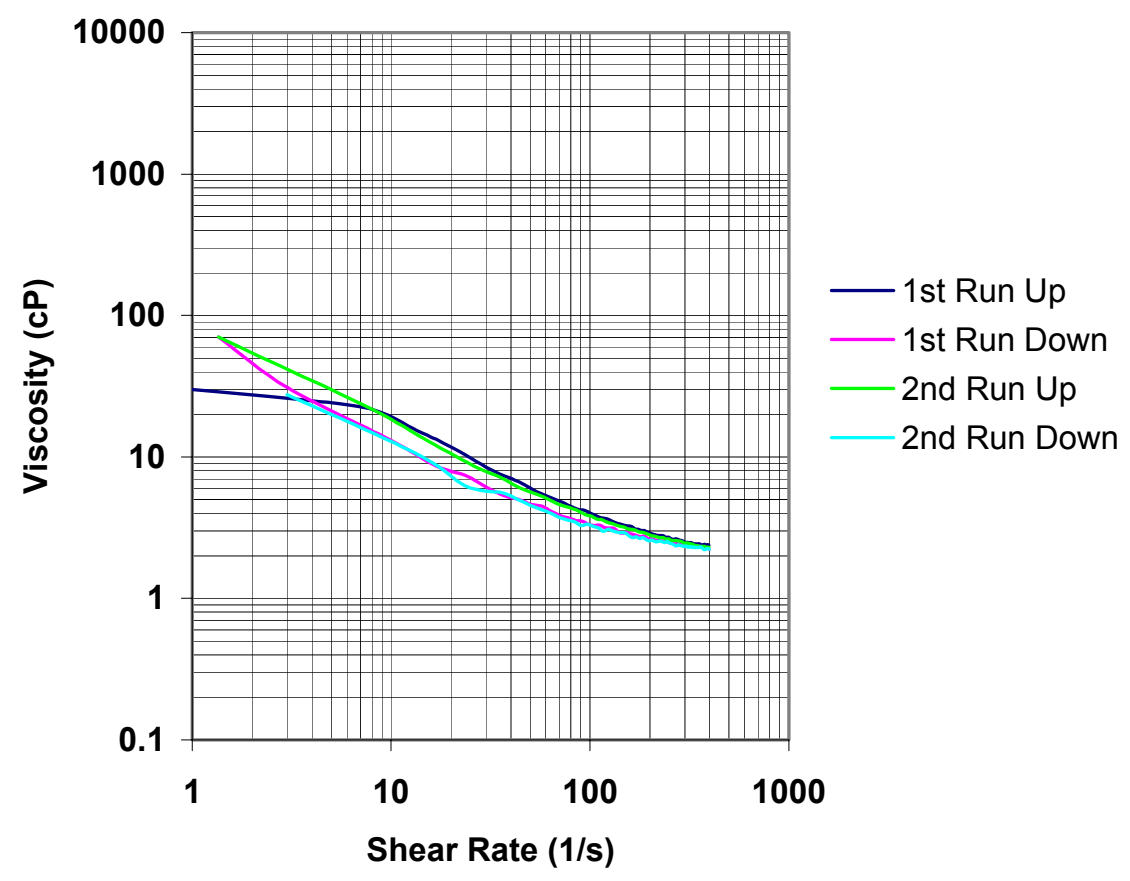

Figure 6.5. Viscosities Versus Shear Rate of the Tank T-204 4:1 Dilution

Table 6.3. Summary of Bingham Plastic Curve Fit Parameters of Tank T-204 Dilutions

\begin{tabular}{|c|c|c|c|c|c|}
\hline Dilution & Test Run Status & $\begin{array}{c}\text { Shear Rate } \\
\text { Range } \\
\gamma(1 / \mathbf{s})\end{array}$ & $\begin{array}{c}\text { Yield Stress } \\
\tau_{0}(\mathbf{P a})\end{array}$ & $\begin{array}{r}\mu_{0} \times 10^{3} \\
(\mathbf{P a} \cdot \mathbf{s})\end{array}$ & $\begin{array}{l}\text { R-Squared } \\
\text { Value }\end{array}$ \\
\hline $30 \mathrm{wt} \%$ & \multicolumn{5}{|c|}{ Yield stress exceeds limits of the sensor system } \\
\hline \multirow{4}{*}{$1: 1$} & $1^{\text {st }}$ run-up & \multirow{4}{*}{$75-1000$} & 3.73 & 3.55 & 0.997 \\
\hline & $1^{\text {st }}$ run-down & & 3.00 & 4.53 & 0.999 \\
\hline & $2^{\text {nd }}$ run-up & & 3.11 & 3.82 & 1.000 \\
\hline & $2^{\text {nd }}$ run-down & & 2.90 & 4.22 & 0.998 \\
\hline \multirow{4}{*}{$4: 1$} & $1^{\text {st }}$ run-up & \multirow{4}{*}{$0-400$} & 0.19 & 1.90 & 0.985 \\
\hline & $1^{\text {st }}$ run-down & & 0.14 & 1.95 & 0.997 \\
\hline & $2^{\text {nd }}$ run-up & & 0.19 & 1.85 & 0.995 \\
\hline & $2^{\text {nd }}$ run-down & & 0.13 & 1.93 & 0.997 \\
\hline
\end{tabular}

Hysteresis was observed between the up and down curves of the first run of the 1:1 dilution as indicated in Figure A.4. At low shear rates, the shear stress increases linearly, followed by a decrease in the shear stress with an increase in the shear rate. Finally, the curve begins to exhibit Bingham-like behavior. The down curve generally exhibits Bingham plastic behavior throughout the appropriate shearrate range. This behavior is normal in thixotropic fluids. The initial behavior on the up curve is due to the structure that develops in the fluid when it is at rest. This structure is destroyed under shear. The second set of up and down curves did not exhibit this same behavior. No significant hysteresis was observed between the up and down curves of this second run. Curve fits for these rheograms were performed over a shear-rate range from 75 to $1000 \mathrm{~s}^{-1}$. 
Only a limited range of shear rates $\left(0\right.$ to $\left.400 \mathrm{~s}^{-1}\right)$ was valid for the 4:1 dilution of the Tank T-204 composite because of Taylor fluid instability. This dilution exhibited Bingham plastic behavior throughout the appropriate shear-rate range. No significant hysteresis was observed as shown in Figure A.5. Table 6.3 summarizes the Bingham model fits to the experimental data for both the $1: 1$ and $4: 1$ dilutions. All the individual regression R-squared values are larger than 0.985 , indicating that the rheological characteristics of the tested samples follow the Bingham plastics model. The averaged yield stresses are 3.19 and $0.16 \mathrm{~Pa}$, respectively, for the 1:1 and 4:1 dilutions. The peak stress observed at low shear rates on the initial up curve of the $1: 1$ dilution is $4.72 \mathrm{~Pa}$.

The yield power law model was also used to simulate the relationship between shear rate and viscosity for these dilutions. The yield power law model gives lower yield stress and higher consistency factors for all cases while the regression R-squared values are similar for both Bingham and yield power law models. Both curve fits were plotted along with the data, and the yield power law model did not provide a significantly better fit to the data. Since the yield power law model does not fit the data significantly better than the Bingham plastic model, the Bingham plastic model is used to describe the behavior of these dilutions. A comparison of the Bingham and yield power law curve fits for the 4:1 dilution is provided in Table 6.4 as an example of the difference between these curve fits.

Table 6.4. Comparison of Different Curve Fits of Tank T-204 Samples

\begin{tabular}{|c|c|c|c|c|c|c|}
\hline Rheogram & Model & $\begin{array}{c}\text { Model } \\
\text { Formula }\end{array}$ & $\begin{array}{c}\text { Yield Stress } \\
\tau_{0}(\mathrm{~Pa})\end{array}$ & $\begin{array}{c}\text { Power } \\
\text { Law Index } \\
n\end{array}$ & $\begin{array}{c}\mu_{0} \text { or } \kappa \times 10^{3} \\
(\mathrm{~Pa} \cdot \mathbf{s})\end{array}$ & $\begin{array}{c}\text { R-Squared } \\
\text { Value }\end{array}$ \\
\hline \multirow{2}{*}{$\begin{array}{c}4: 1 \\
\left(1^{\text {st }} \mathrm{Up}\right)\end{array}$} & Bingham & $\tau=\tau_{0}+\mu_{0} \gamma$ & 0.19 & NA & 1.90 & 0.985 \\
\hline & Yield Power Law & $\tau=\tau_{0}+\kappa \gamma^{\mathrm{n}}$ & 0.12 & 0.75 & 8.81 & 0.992 \\
\hline \multirow{2}{*}{$\begin{array}{c}4: 1 \\
\left(2^{\text {nd }} U p\right)\end{array}$} & Bingham & $\tau=\tau_{0}+\mu_{0} \gamma$ & 0.19 & NA & 1.85 & 0.995 \\
\hline & Yield Power Law & $\tau=\tau_{0}+\kappa \gamma^{\mathrm{n}}$ & 0.14 & 0.83 & 5.22 & 0.998 \\
\hline
\end{tabular}

Viscosity is plotted as a function of shear rate for the $30-\mathrm{wt} \%, 1: 1$, and $4: 1$ dilutions of the Tank B203 composite in Figure 6.6, Figure 6.7, and Figure 6.8, respectively. Some noise in the data was observed, probably because large particles were present in the sample. Thixotropic behavior similar to that observed in the 1:1 dilution of the Tank T-204 composite was observed in the $30-\mathrm{wt} \%$ and $1: 1$ dilutions from this tank as shown in Figures A.6 and A.7 in Appendix A. A small amount of hysteresis was observed between the initial up and down curves for the 4:1 dilution as indicated in Figure A.8. The data for the 4:1 dilution were valid over a limited shear-rate range $\left(0\right.$ to $\left.400 \mathrm{~s}^{-1}\right)$ due to Taylor fluid instability. 


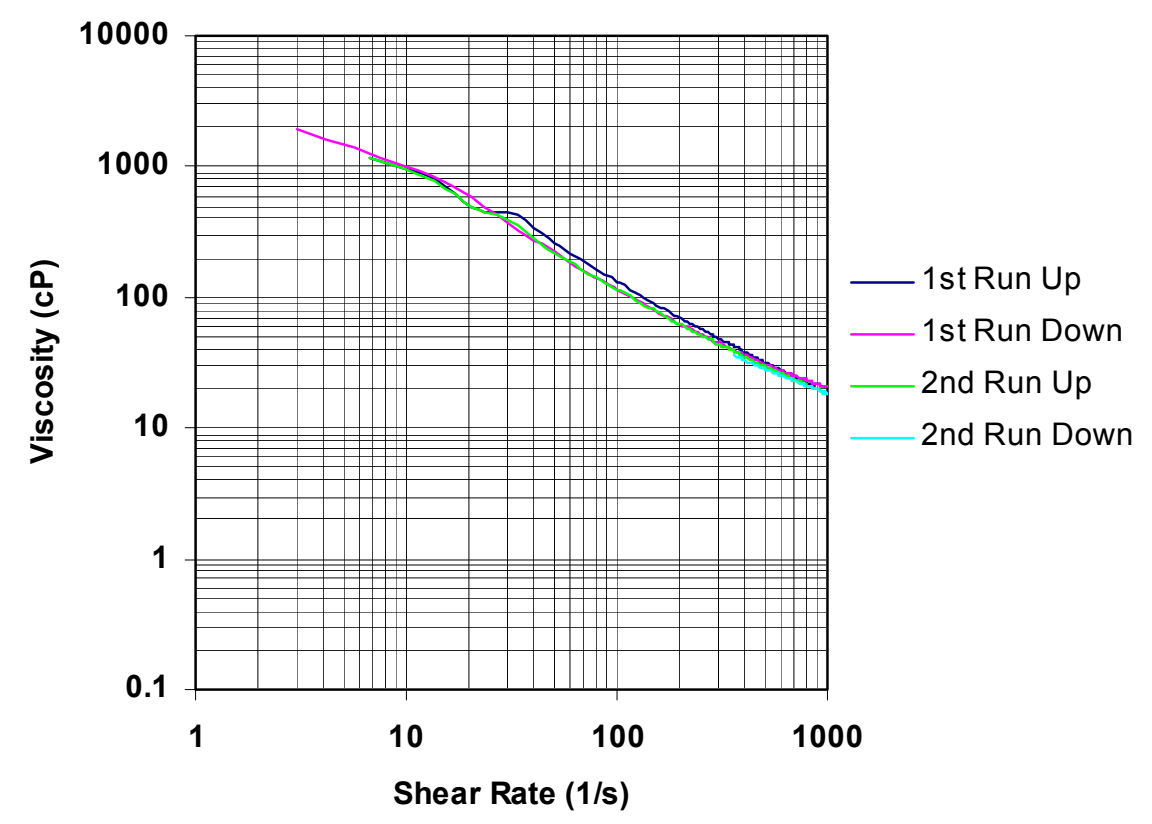

Figure 6.6. Viscosities Versus Shear Rate of the Tank B-203 30-wt\% Solids Dilution

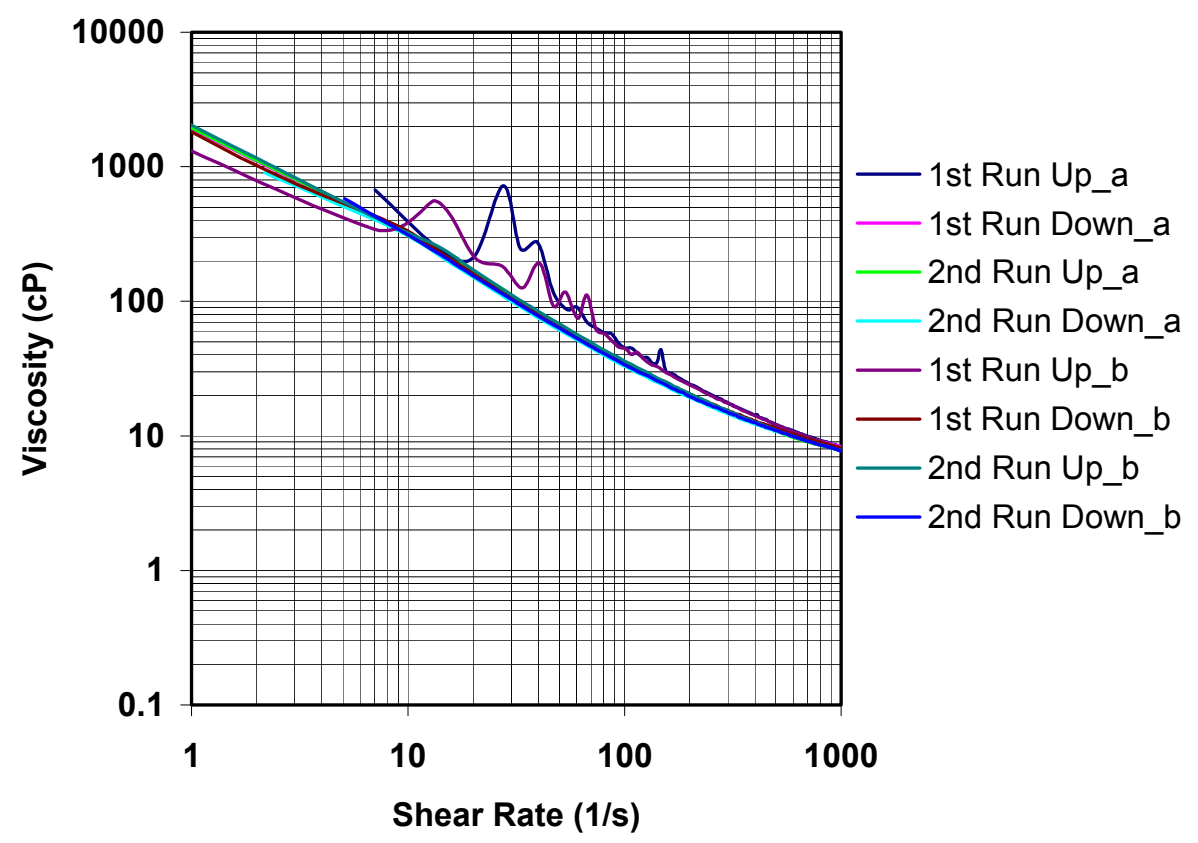

Figure 6.7. Viscosities Versus Shear Rate of the Tank B-203 1:1 Dilution 


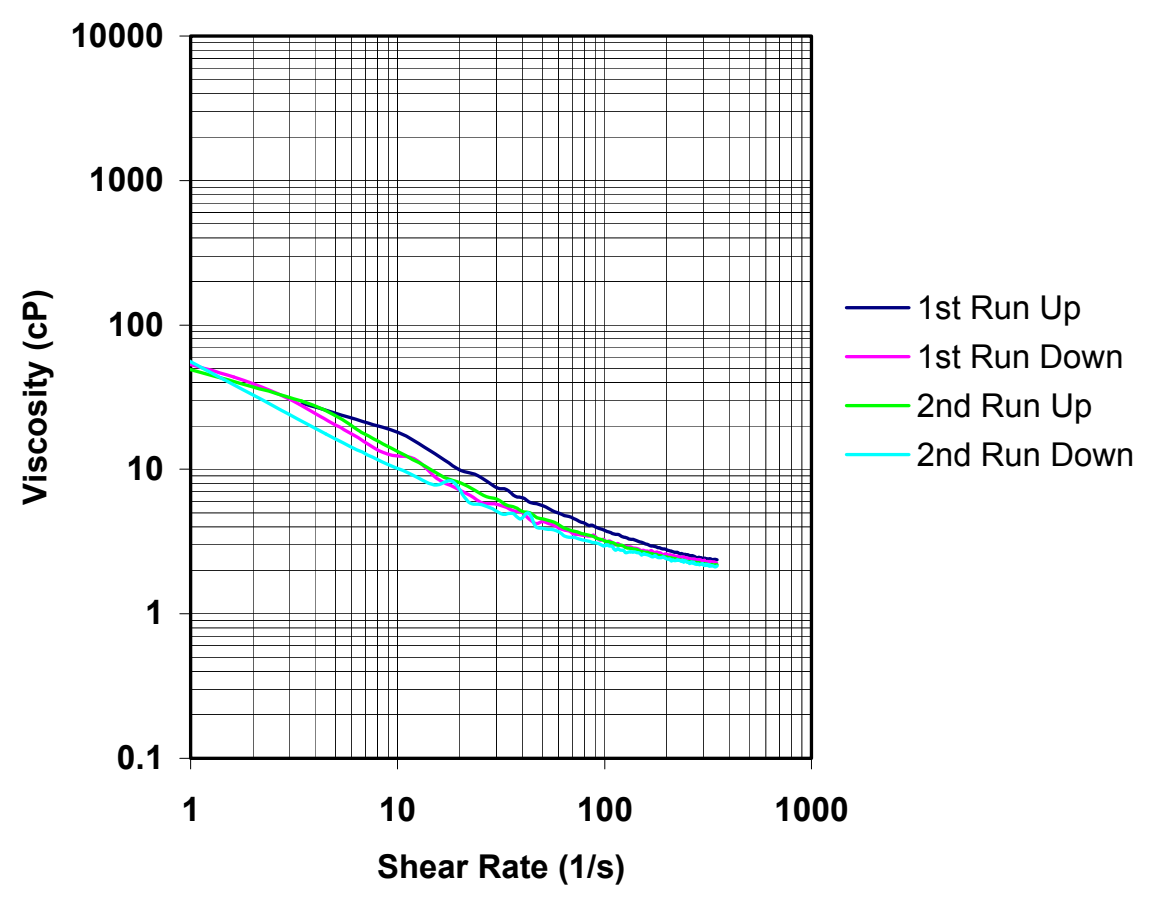

Figure 6.8. Viscosities Versus Shear Rate of the Tank B-203 4:1 Dilution

A Bingham plastic model was used to fit the shear-stress data as a function of shear rate for these dilutions. Table 6.5 summarizes the Bingham model fit to the experimental data. All the individual regression R-squared values are within 0.979 to 0.999 , indicating that the rheological properties of the tested samples reasonably follow the Bingham plastic model. The average yield stresses are 12.3, 4.13, 4.01, and $0.18 \mathrm{~Pa}$ for the 30-wt\%, 1:1 (Runs 1 and 2), and 4:1 dilutions, respectively. The peak stresses observed at low shear rates on the initial up curves of the 30 -wt $\%$ solids and $1: 1$ dilutions are 14.7 and 7.8 $\mathrm{Pa}$, respectively.

The yield power law model was also used to fit shear stress as a function of shear rate for these samples. Both curve fits were plotted along with the data, and the yield power law model did not provide a significantly better fit to the data. Since the yield power law model does not fit the data significantly better than the Bingham plastic model, the Bingham plastic model is used to describe the behavior of these dilutions. A comparison of the Bingham and yield power law curve fits for the 4:1 dilution is provided in Table 6.6 as an example of the difference between these curve fits.

In Figure 6.9 through Figure 6.11, viscosity is plotted as a function of shear rate for each of the dilutions of the Tank T-203 composite. The results are similar to those obtained for the Tank B-203 dilutions. Thixotropic behavior similar to that observed in the dilutions of the Tank T-204 and B-203 composites was observed in the $30-\mathrm{wt} \%$ and $1: 1$ dilutions from this tank as shown in Figures A.9 and A.10 in Appendix A. The initial behavior on the up curve due to the structure in the slurry is more pronounced in the 30 -wt\% dilution from this tank than was observed in the other tank dilutions. The yield and peak stresses for this dilution (approximately $40 \mathrm{~Pa}$ for the yield stress and $52 \mathrm{~Pa}$ for the peak stress) were also significantly higher than was observed in the 30 -wt $\%$ dilution from Tank B-203 (approximately 10 and $15 \mathrm{~Pa}$ for the yield and peak stresses respectively). 
Table 6.5. Summary of Bingham Plastic Curve Fit Parameters of Tank B-203 Dilutions

\begin{tabular}{|c|c|c|c|c|c|}
\hline Dilution & $\begin{array}{c}\text { Test Run } \\
\text { Status }\end{array}$ & $\begin{array}{c}\text { Shear Rate } \\
\text { Range } \\
\gamma(1 / \mathbf{s})\end{array}$ & $\begin{array}{c}\text { Yield } \\
\text { Stress } \\
\tau_{0}(\mathrm{~Pa})\end{array}$ & $\mu_{0} \times 10^{3}(\mathrm{~Pa} \cdot \mathrm{s})$ & $\begin{array}{c}\text { R-Squared } \\
\text { Value }\end{array}$ \\
\hline \multirow{4}{*}{$30 \mathrm{wt} \%$} & $1^{\text {st }}$ run-up & \multirow{4}{*}{$75-1000$} & 12.3 & 7.50 & 0.990 \\
\hline & $1^{\text {st }}$ run-down & & 10.4 & 10.2 & 0.999 \\
\hline & $2^{\text {nd }}$ run-up & & 10.9 & 7.88 & 0.998 \\
\hline & $2^{\text {nd }}$ run-down & & 9.88 & 8.63 & 0.997 \\
\hline \multirow{4}{*}{$1: 1$} & $1^{\text {st }}$ run-up & \multirow{4}{*}{$75-1000$} & 4.13 & 4.07 & 0.977 \\
\hline & $1^{\text {st }}$ run-down & & 2.98 & 5.39 & 0.998 \\
\hline & $2^{\text {nd }}$ run-up & & 3.07 & 4.71 & 0.985 \\
\hline & $2^{\text {nd }}$ run-down & & 2.83 & 5.09 & 0.997 \\
\hline \multirow{4}{*}{$\begin{array}{c}1: 1 \\
\text { (Repeat) }\end{array}$} & $1^{\text {st }}$ run-up & \multirow{4}{*}{$100-1000$} & 4.01 & 4.09 & 0.999 \\
\hline & $1^{\text {st }}$ run-down & & 3.06 & 5.13 & 0.996 \\
\hline & $2^{\text {nd }}$ run-up & & 3.15 & 4.65 & 0.987 \\
\hline & $2^{\text {nd }}$ run-down & & 2.99 & 4.85 & 0.999 \\
\hline \multirow{4}{*}{$4: 1$} & $1^{\text {st }}$ run-up & \multirow{4}{*}{$0-350$} & 0.18 & 1.87 & 0.987 \\
\hline & $1^{\text {st }}$ run-down & & 0.12 & 1.95 & 0.997 \\
\hline & $2^{\text {nd }}$ run-up & & 0.13 & 1.80 & 0.994 \\
\hline & $2^{\text {nd }}$ run-down & & 0.11 & 1.86 & 0.997 \\
\hline
\end{tabular}

Table 6.6. Comparison of Different Curve Fits of Tank B-203 Samples

\begin{tabular}{|c|c|c|c|c|c|c|}
\hline Dilution & Model & $\begin{array}{c}\text { Model } \\
\text { Formula }\end{array}$ & $\begin{array}{c}\text { Yield } \\
\text { Stress } \\
\tau_{0}(\mathrm{~Pa})\end{array}$ & $\begin{array}{c}\text { Power Law } \\
\text { Index } \\
\text { n }\end{array}$ & $\begin{array}{c}\mu_{0} \text { or } \kappa \times 10^{3} \\
(\mathbf{P a} \cdot \mathbf{s})\end{array}$ & $\begin{array}{c}\text { R-Squared } \\
\text { Value }\end{array}$ \\
\hline \multirow[t]{2}{*}{$4: 1$} & Bingham & $\tau=\tau_{0}+\mu_{0} \gamma$ & 0.13 & NA & 1.87 & 0.973 \\
\hline & Yield Power Law & $\tau=\tau_{0}+\kappa \gamma^{\mathrm{n}}$ & 0.0123 & 0.84 & 4.89 & 0.976 \\
\hline
\end{tabular}

The initial up curve for the 30-wt\% dilution in Tank T-203 did not reach the point at which Binghamlike behavior was observed. The down curve for the initial run did exhibit Bingham behavior at higher shear rates $\left(250\right.$ to $\left.1000 \mathrm{~s}^{-1}\right)$, but at low shear rates, the effect of structure in the fluid was still observed. The effect of structure in the fluid was also observed in the second set of up and down curves run immediately after the initial runs, but in both the up and down curves, Bingham-like behavior was observed in the shear-rate range of 250 to $1000 \mathrm{~s}^{-1}$. The yield stress of these curves was similar to that observed in the down curve of the initial run. A second aliquot from this dilution was analyzed, and similar behavior was observed. Only one set of up and down curves was run on this second aliquot. Both of these curves exhibited Bingham-like behavior over the shear-rate range from 500 to $1000 \mathrm{~s}^{-1}$. Due to the effect of structure in the fluid, curve fits of these data were performed on a limited shear-rate range where Bingham-like behavior was observed. 


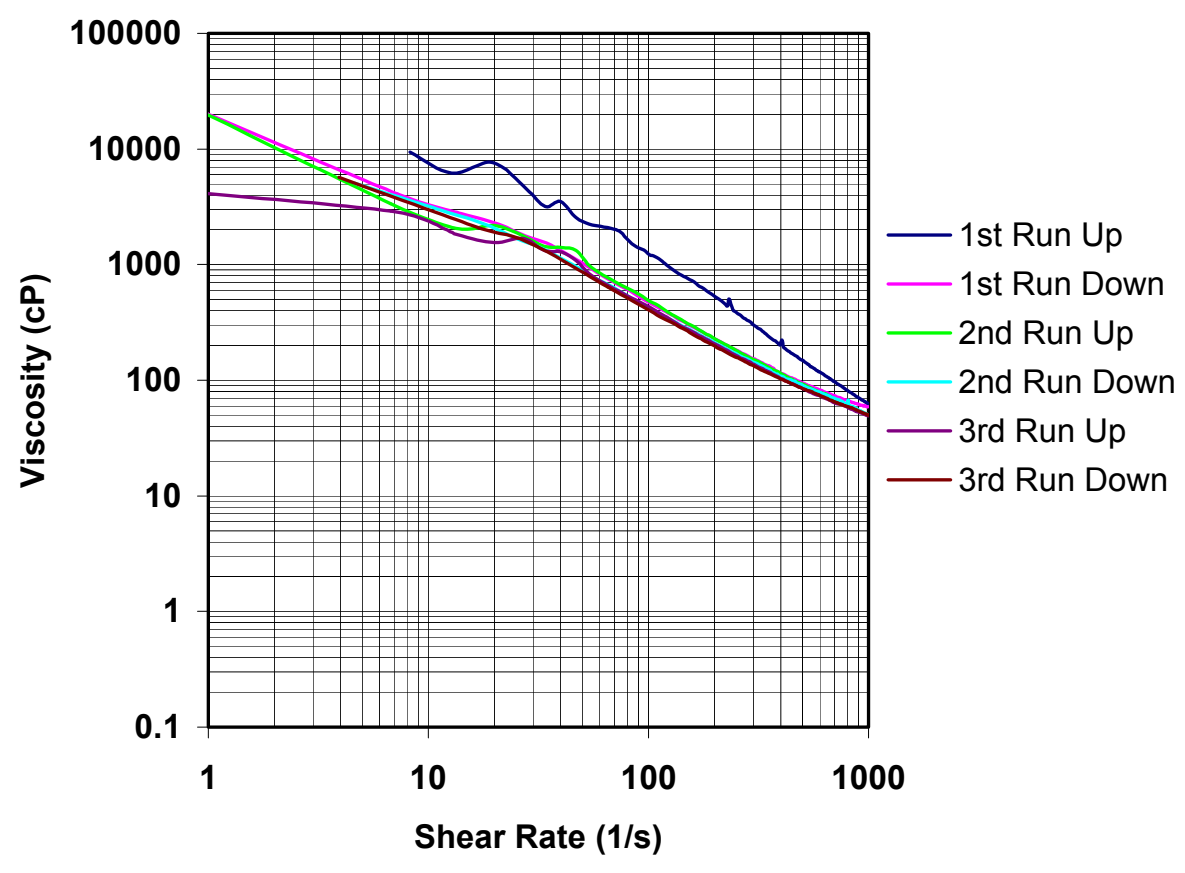

Figure 6.9. Viscosities Versus Shear Rate of the Tank T-203 30-wt\% Solids Dilution

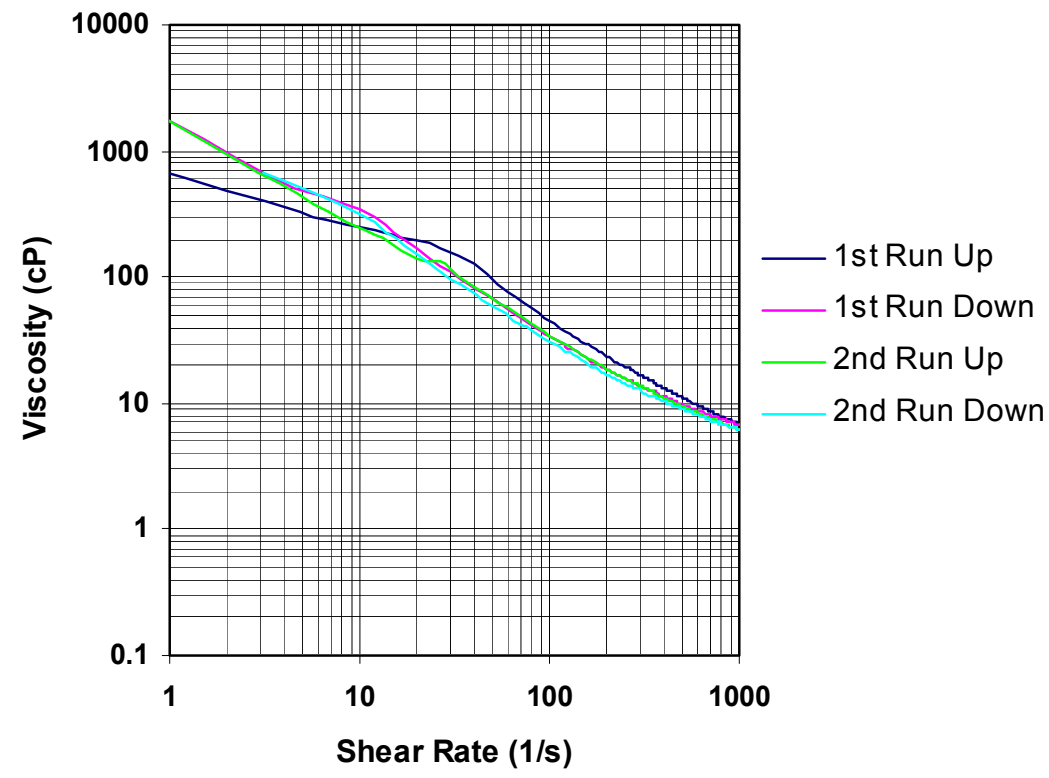

Figure 6.10. Viscosities Versus Shear Rate of the Tank T-203 1:1 Dilution 


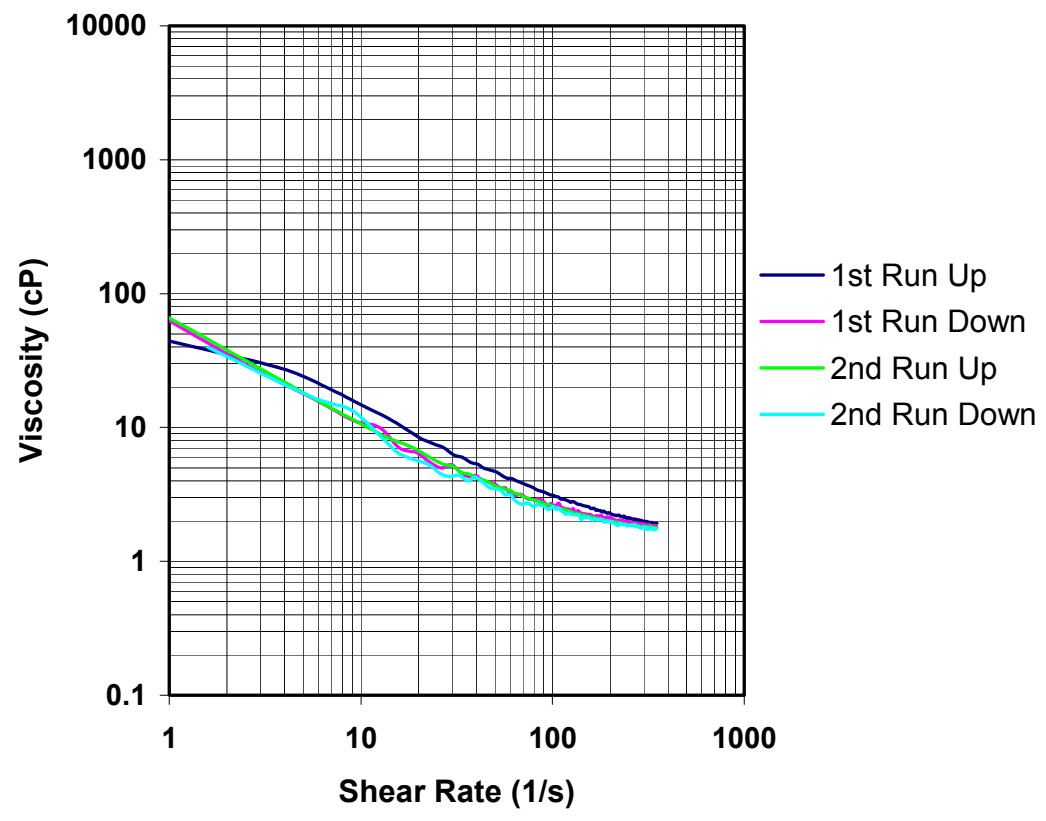

Figure 6.11. Viscosities Versus Shear Rate of the Tank T-203 4:1 Dilution

These data indicate that the effect of structure is more pronounced at higher yield stresses. At about $30-w t \%$ solids, differences in the waste properties from each tank result in large differences in the rheological properties of these fluids. This effect is not as pronounced in the dilutions with higher water concentration (lower solids content).

Hysteresis and the effect of structure on the fluid at low shear rates were also observed in the 1:1 dilution of the Tank T-203 composite, but the effects were similar to those observed in the 1:1 dilutions from Tanks B-203 and T-204. The peak stresses observed at low shear rates on the initial up curves of the $30-\mathrm{wt} \%$ solids dilution (runs 1 and 2) and the 1:1 dilution are 150, 52, and 5.3 Pa, respectively. The peak stress for the second up curve of the first run of the $30-\mathrm{wt} \%$ solids dilution (63 Pa) was similar to the peak stress measured on the initial up curve of the second run of this dilution.

Fits to the rheological models were performed over the shear-rate range from 100 to $1000 \mathrm{~s}^{-1}$ for all the curves from the 1:1 dilution of the Tank T-203 composite. A small amount of hysteresis was observed between the initial up and down curves for the 4:1 dilution as indicated in Figure A.11. The data for the 4:1 dilution were valid over a limited shear-rate range $\left(0\right.$ to $\left.350 \mathrm{~s}^{-1}\right)$ due to Taylor fluid instability.

A Bingham plastic model was used to fit the shear-stress data as a function of shear rate for these dilutions. Table 6.7 summarizes the Bingham model fit to the experimental data. All the individual regression R-squared values are within 0.903 to 1.000 , indicating that the rheological properties of the tested samples follow the Bingham plastic model. The yield stresses are 40.6, 35.7, 3.3, and 0.11 Pa for the 30-wt\% (Runs 1 and 2), 1:1, and 4:1 dilutions, respectively. 
Table 6.7. Summary of Bingham Plastic Curve Fit Parameters of Tank T-203 Dilutions

\begin{tabular}{|c|c|c|c|c|c|}
\hline Dilution & $\begin{array}{c}\text { Test Run } \\
\text { Status }\end{array}$ & $\begin{array}{c}\text { Shear Rate } \\
\text { Range } \\
\gamma(1 / s)\end{array}$ & $\begin{array}{c}\text { Yield } \\
\text { Stress } \\
\tau_{0}(\mathrm{~Pa}) \\
\end{array}$ & $\mu_{0} \times 10^{3}(\mathrm{~Pa} \cdot \mathbf{s})$ & $\begin{array}{c}\text { R-Squared } \\
\text { Value }\end{array}$ \\
\hline \multirow{4}{*}{$30 \mathrm{wt} \%$} & $1^{\text {st }}$ run-up & \multirow{4}{*}{$250-1000$} & \multicolumn{3}{|c|}{$\begin{array}{l}\text { Data not used due to } \\
\text { hysteresis from the structure of the fluid }\end{array}$} \\
\hline & $1^{\text {st }}$ run-down & & 39.4 & 17.9 & 0.959 \\
\hline & $2^{\text {nd }}$ run-up & & 43.0 & 7.15 & 0.947 \\
\hline & $2^{\text {nd }}$ run-down & & 39.4 & 12.3 & 0.903 \\
\hline \multirow{2}{*}{$\begin{array}{l}30 \mathrm{wt} \% \\
\text { (repeat) }\end{array}$} & $1^{\text {st }}$ run-up & \multirow{2}{*}{$500-1000$} & 35.9 & 13.3 & 0.978 \\
\hline & $1^{\text {st }}$ run-down & & 35.5 & 14.8 & 0.990 \\
\hline \multirow{4}{*}{$1: 1$} & $1^{\text {st }}$ run-up & \multirow{4}{*}{$100-1000$} & 4.23 & 2.62 & 0.999 \\
\hline & $1^{\text {st }}$ run-down & & 3.00 & 3.77 & 1.000 \\
\hline & $2^{\text {nd }}$ run-up & & 3.18 & 3.06 & 1.000 \\
\hline & $2^{\text {nd }}$ run-down & & 2.74 & 3.47 & 0.999 \\
\hline \multirow{4}{*}{$4: 1$} & $1^{\text {st }}$ run-up & \multirow{4}{*}{$0-350$} & 0.15 & 1.51 & 0.990 \\
\hline & $1^{\text {st }}$ run-down & & 0.10 & 1.55 & 0.998 \\
\hline & $2^{\text {nd }}$ run-up & & 0.10 & 1.48 & 0.997 \\
\hline & $2^{\text {nd }}$ run-down & & 0.0910 & 1.49 & 0.995 \\
\hline
\end{tabular}

The yield power law model was also used to fit shear stress as a function of shear rate for these samples. Analysis of these curve fits indicated that the yield power law curve fits were not significantly better than the Bingham plastic fits; therefore, the Bingham plastic model is used to describe the behavior of these dilutions.

To demonstrate the rheological properties of various tank samples at the same dilution, viscosity was plotted as a function of shear rate in Figure 6.12 through Figure 6.14. Figure 6.12 compares the viscosities of the 30-wt\% dilutions from Tanks T-110, B-203, and T-203. The total solids content of these dilutions are $29.3,28.6$, and $30.7 \mathrm{wt} \%$, respectively. The $30-\mathrm{wt} \%$ solids dilution from Tank T-203 had the highest viscosity, followed by B-203 and then T-110. The 10-cP viscosity standard was also plotted on the same chart, showing that the behavior of a Newtonian fluid is very different from these Bingham plastic fluids.

Figure 6.13 compares the results of the 1:1 dilutions from Tanks T-110, T-204, B-203, and T-203, which have total solids contents of $15.3,14.6,19.7$, and $16.4 \mathrm{wt} \%$, respectively. The results show that the dilution from Tank T-110 behaves very differently from the rest of the samples, even at a similar solids content, and has much lower viscosity than the dilutions from the other tanks. The 1:1 dilution from Tank B-203 has a slightly larger solids content than the dilutions from Tanks T-204 and T-203 (3.3\% and 5.1\% higher, respectively), but the viscosity is similar to that of the other two samples. All of these dilutions display Bingham plastic fluid behavior. 


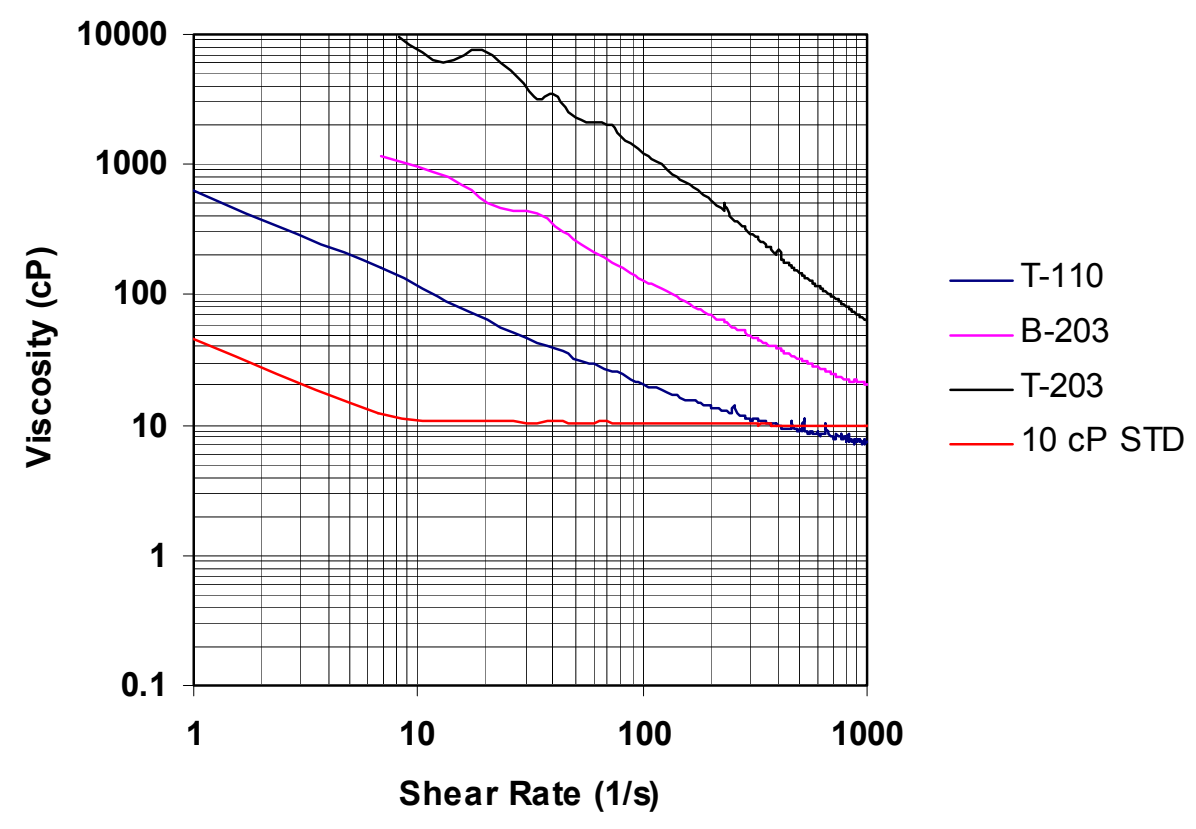

Figure 6.12. Viscosity Versus Shear Rate of the 30-wt\% Solids Dilutions

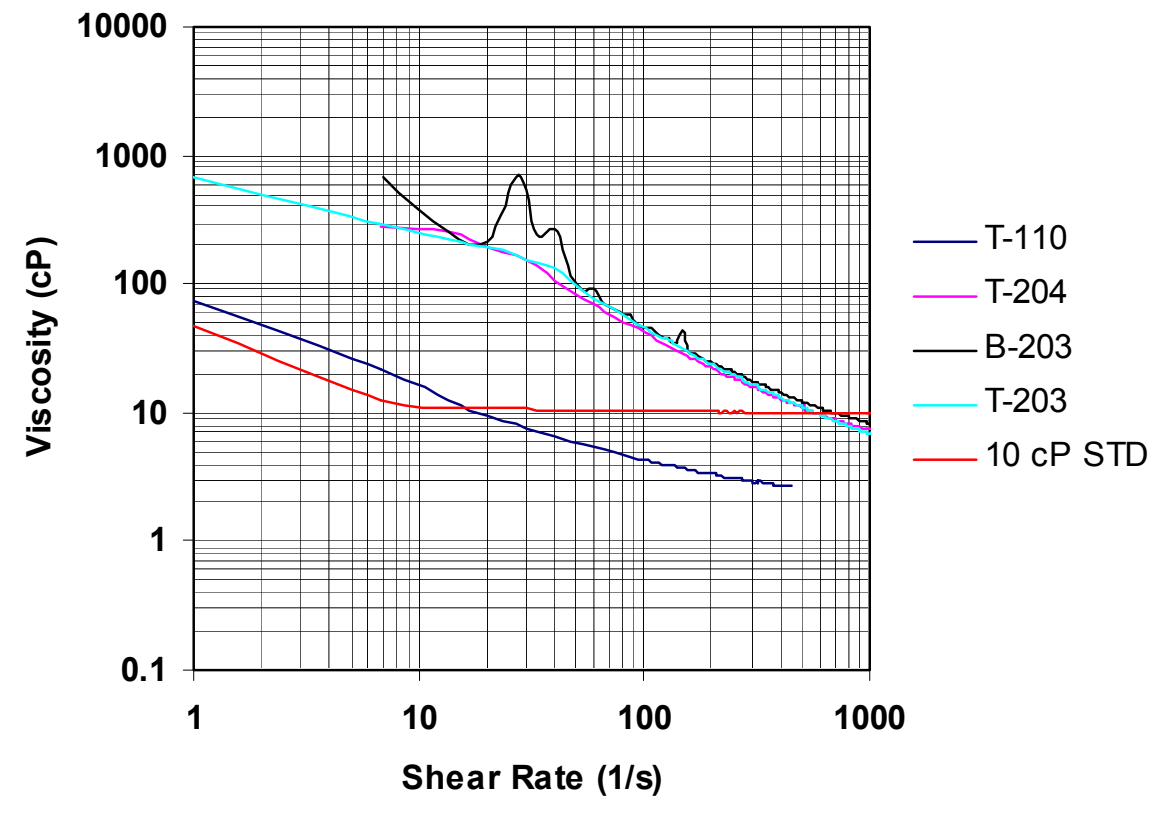

Figure 6.13. Viscosity Versus Shear Rate of the 1:1 Dilutions 


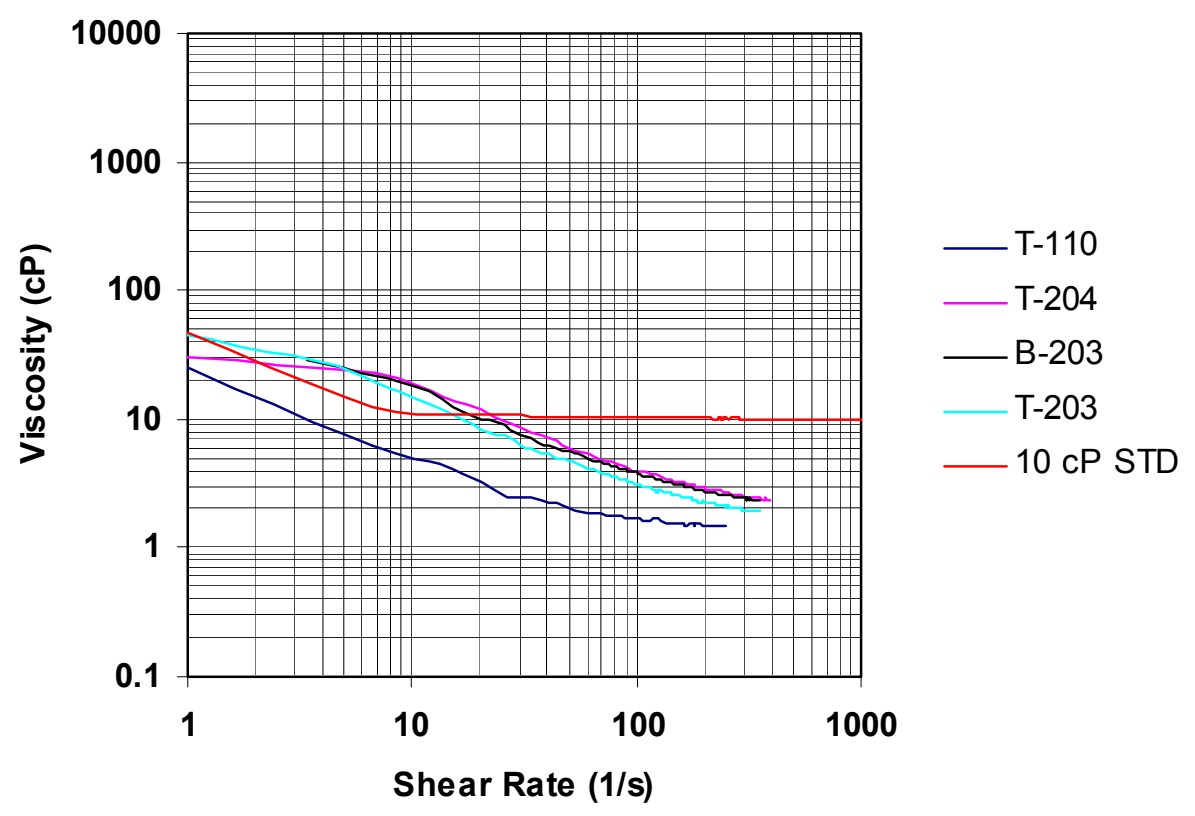

Figure 6.14. Viscosity Versus Shear Rate of 4:1 Dilutions

In Figure 6.14, viscosity is plotted as a function of shear rate for the 4:1 dilutions of each tank composite. These dilutions were prepared at solids contents of $6.4,6.1,8.5$, and $6.4 \mathrm{wt} \%$, respectively, for Tanks T-110, T-204, B-203, and T-203. Three tank samples (T-204, B-203, and T-203) behave very much alike, while the dilution from Tank T-110 shows a lower viscosity. All the sample viscosity profiles of the up curves follow the Bingham plastic fluid model, as described previously. The down curves for Tanks T-204, B-203, and T-203 exhibit this same behavior, but the down curves for the 4:1 dilution from Tank T-110 follow the Newtonian fluid model.

The viscosity of the dilutions from each tank decreased with increasing water concentration (lower solids concentration). Furthermore, the yield stress reduced significantly, between 300 and 45 times lower, when the samples were diluted with water from $30 \mathrm{wt} \%$ solids to approximately $7 \mathrm{wt} \%$ solids (4:1 dilution), while the viscosity at $250 \mathrm{~s}^{-1}$ only reduced 85 to 8 times over this same dilution. The rheological behavior of the Tank T-110 composite and its dilutions was significantly different than was observed for the other three tanks. The rheological behavior of the other three tanks (B-203, T-203, and T-204) was similar, but in general, T-203 samples changed more drastically in both yield stress and viscosity when the sample is diluted than the other tanks. Most of the samples still behaved like Bingham plastics fluids and had substantial yield stresses over the range of dilutions tested. When the tank composites were diluted 4:1 with water, the viscosity decreased to about $2 \mathrm{cP}(1.5$ to $2.7 \mathrm{cP})$ at $250 \mathrm{~s}^{-1}$, which is close to the viscosity of water $(1 \mathrm{cP})$. Due to the high yield stress of the homogenized tank composites and the $30-\mathrm{wt} \%$ solids dilution from Tank T-204, no viscous flow was observed in these rheograms. The yield stress for these samples exceeded the maximum stress allowed for the available sensor systems $(580 \mathrm{~Pa})$. The T-110 initial dilution (approximately $50 \mathrm{wt} \%$ solid) also had large agglomerates whose diameters approached the gap size of the cone and plate sensor system; therefore, valid rheology measurements could not be made. 


\subsection{Shear Strength Measurements}

Shear strength was measured directly according to the method described in Section 3.4 on each of the homogenized tank composites and the 30 -wt $\%$ solids dilutions from each tank except for Tank T-110.

Shear strength from Tank T-110 was measured only on the initial dilution (approximately $50 \mathrm{wt} \%$ solids). The total solids contents were slightly different for each of these samples. The shear strength for the 30wt $\%$ solids dilution from Tank T-110 and the 1:1 and 4:1 dilutions from all of the tanks were too small to be accurately measured by this method; however, the shear strength of the gravity settled solids of the 1:1 dilution of the Tank T-204 composite was measured. The solids concentration for the settled solids (18 wt $\%$ ) was estimated from the wt $\%$ total solids, volume fraction of settled solids, and supernatant liquor and centrifuged solids densities for this dilution.

Figure 6.15 shows the results of shear-strength testing of each tank sample. The shear strength is plotted as a function of the total solids content. The shear strength was plotted on a logarithmic scale. Three shear strengths were measured for Tank T-204 at varying dilutions, and these three shear strengths can be fit to a straight line as a function of the total solids content on this semi-log plot. Shear strength was measured at only two solids contents for Tanks B-203 and T-203 and at a single solids content for Tank T-110.

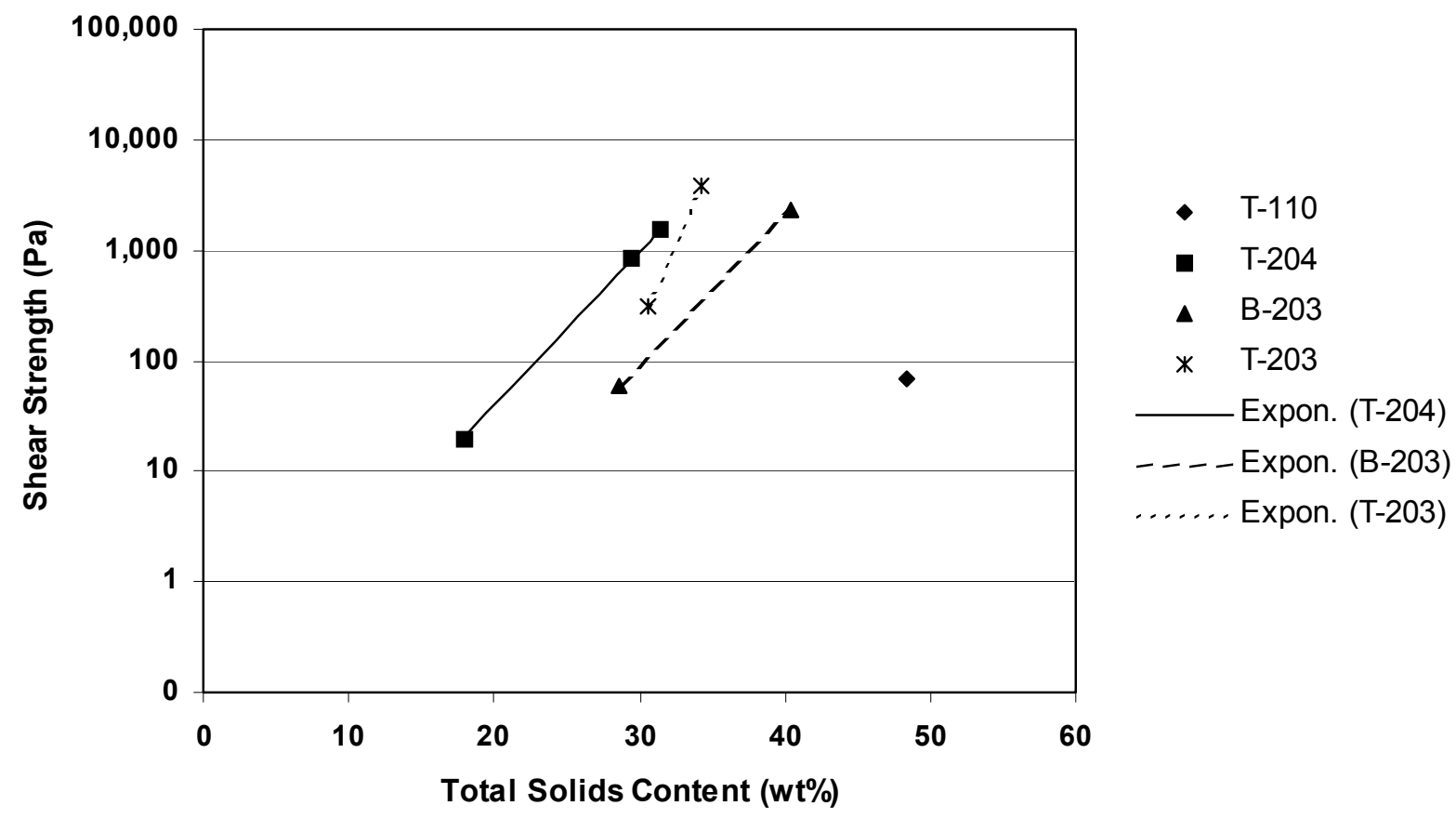

Figure 6.15. Shear-Strength Results for Tank T-110, T-204, B-203, and T-203 Samples

The shear-strength data are described using a power regression model. This model fits the data well as shown in Figure 6.15. The R-squared value for the regression on the data for the Tank T-204 samples was 1.000. The power regression model was also used to fit the B-203 and T-203 data, even though each set contained only two data points, to determine whether the shear strength approaches zero at a total solids content equal to zero. The power-regression results are summarized in Table 6.8. The results show 
that the regression constant $\mathrm{a}_{0}$ is very small (close to zero), and the shear strength will approach zero when the total solids content becomes very small.

With the regression model, the shear strength can be predicted as a function of total solids content for these tank composite materials. Table 6.9 compares the measured shear strength and the calculated shear strength using the power regression model. It can be seen that the power regression model describes the relationship between shear strength and total solids content with minimum errors.

Table 6.8. Summary of Power Regression Model of the Shear Strengths for Tested Samples of Tanks T-204, B-203, and T-203

\begin{tabular}{|c|c|c|c|c|}
\hline \multirow[b]{2}{*}{ Tank No. } & \multirow{2}{*}{$\begin{array}{c}\text { Power Regression } \\
\text { Model }\end{array}$} & \multicolumn{2}{|c|}{ Constants } & \multirow{2}{*}{$\begin{array}{l}\text { R-Squared } \\
\text { Value }\end{array}$} \\
\hline & & $\mathbf{a}_{0}$ & $\mathbf{b}_{0}$ & \\
\hline T-204 & \multirow{3}{*}{$\tau=\mathrm{a}_{0} \mathrm{e}^{\mathrm{b} 0 \mathrm{x}}$} & $5.9 \times 10^{-2}$ & 0.324 & 1.000 \\
\hline B-203 & & $9.9 \times 10^{-3}$ & 0.306 & $\mathrm{NA}^{(\mathrm{a})}$ \\
\hline T-203 & & $2.4 \times 10^{-7}$ & 0.685 & $\mathrm{NA}^{(\mathrm{a})}$ \\
\hline
\end{tabular}

(a) Only two samples from Tanks B-203 and T-203 were tested, and thus R-squared values cannot be assessed.

Table 6.9. Comparison of Measured and Calculated Shear Strengths of Various Tank Samples

\begin{tabular}{|c|c|c|c|c|}
\hline $\begin{array}{c}\text { Tank } \\
\text { No. }\end{array}$ & Dilution & $\begin{array}{c}\text { TS } \\
(\%)\end{array}$ & $\begin{array}{c}\text { Measured } \\
\text { Shear Strength } \\
\tau(\mathrm{Pa}) \\
\end{array}$ & $\begin{array}{c}\text { Calculated Shear } \\
\text { Strength } \\
\tau(\mathbf{P a}) \\
\end{array}$ \\
\hline \multirow[t]{3}{*}{$\mathrm{T}-204$} & Settled $1: 1^{\text {(a) }}$ & 18.0 & 20 & 20 \\
\hline & $30-w t \%$ & 29.4 & 842 & 819 \\
\hline & Composite & 31.5 & 1520 & 1552 \\
\hline \multirow[t]{2}{*}{ B-203 } & $30-\mathrm{wt} \%$ & 28.6 & 60 & 60 \\
\hline & Composite & 40.5 & 2280 & 2285 \\
\hline \multirow[t]{2}{*}{ T-203 } & $30-\mathrm{wt} \%$ & 30.7 & 310 & 310 \\
\hline & Composite & 34.3 & 3770 & 3764 \\
\hline
\end{tabular}

(a) The settled solids from the 1:1 dilution had a total solids content of $18.0 \%$, which is different from the 1:1 dilution (14.6\%) because the settled supernatant liquor was removed before the shear-strength test.

The yield strength of all the tested samples is very sensitive to sample dilution (i.e., total solids content). When the homogenized tank composites were diluted to $30 \mathrm{wt} \%$ total solids, resulting in a change in total solids content from 2 to $12 \%$, the shear strengths decreased by 1 to 37 times the shear strengths of the original composites.

\subsection{Shear Strength Estimates from Extrusion Length}

The methodology developed by Gauglitz and Aikin (1997) to estimate the rheological properties of waste sediment (solid, liquid, and gas matrix) uses a visual comparison of horizontal extrusion behavior for simulants with known yield stress in shear (or "shear strength," as it is commonly called in Hanford 
literature) to that of Hanford waste. Rassat et al. (2003a) developed a related technique to estimate coreextrusion shear strength. This technique is based strictly on extrusion length and was developed from the simulant extrusion results presented in Gauglitz and Aikin. A brief summary of the extrusion length methodology is presented in Section 7.3.1. In Section 7.3.2, the shear-strength results from the application of this methodology to the mini-extrusion experiments on TRU tank waste are presented.

\subsubsection{Extrusion Length Methodology}

Gauglitz and Aikin (1997) horizontally extruded simulants of known shear strength and reported the length at which the extrusion exhibited "failure." As elucidated in the Appendix of Rassat et al. (2003a), we have, with the data of Gauglitz and Aikin, the ability to correlate the shear strength of the material directly with the functional form of maximum tensile stress in a round cantilever beam:

$$
\tau_{\mathrm{y}}=\mathrm{K} \frac{\rho g \mathrm{~L}^{2}}{\mathrm{~d}}
$$

where

$\mathrm{L}=$ beam failure length

$\mathrm{d}=$ beam failure diameter

$\rho=$ material density

$\mathrm{g}=$ acceleration of gravity

$\mathrm{K}=$ proportionality coefficient.

The proportionality coefficient $\mathrm{K}$ of Equation 7.4 provides a means to compute the shear strength of a material given its density and the plastic-failure length of a horizontal extrusion and is likely a function of the material microstructure.

The simulants used by Gauglitz and Aikin (1997) were chosen to reflect the wide variety of mechanical behaviors typical of wastes from the Hanford tanks. A proportionality coefficient was determined from the data of each simulant. If we assume that the simulants bound the mechanical behavior of Hanford waste, we can expect that the shear strength of the waste will be between 0.89 and 1.45 times $\rho \mathrm{gL}^{2} / \mathrm{d}$. These proportionality coefficients are referred to as the "lower" (LB) and "upper" (UB) extrusion length bounds, respectively. The best fit with Equation 7.4 applied to the entire group of simulants is obtained with a $\mathrm{K}$ of 1.15 and is termed the "extrusion length best fit" (BF).

\subsubsection{Mini-Extrusion Shear-Strength Results}

The extrusion-length methodology was applied to mini extrusions performed with TRU waste samples from Tanks B-203, T-203, and T-204. As discussed in Section 3, the samples used in the miniextrusion experiments were the composites of core samples for the respective tanks and 30 -wt $\%$ solids dilutions of the Tank T-203 and T-204 composites. Five extrusions were performed: one for B-203 and two each for T-203 and T-204. A video of the mini-extrusion experiments was evaluated for failure length determined by the point at which failure was judged to occur. Multiple measurements were available for individual samples in most instances. Bulk-waste density values were determined by laboratory analyses, as presented in Section 4. 
The shear-strength estimates are presented in Table 6.10. Shear strengths ranged from a lower bound of $386 \mathrm{~Pa}$ to an upper bound of $628 \mathrm{~Pa}$ for the B-203 sample, 256 to $717 \mathrm{~Pa}$ for the T-203 samples, and 311 to 1,226 Pa for the T-204 samples. Excepting the 30-wt\% solids dilution of the Tank T-204 composite, the multiple measurements in like samples of T-203 and T-204 showed relatively good repeatability.

Given that the mini-extrusion samples were stirred composites of several segments from a tank core, no direct comparison may be made between the mini-extrusion results and those of the minimally disturbed actual core-sample extrusions presented in Rassat et al. (2003a). Therefore, to provide a means of comparison between the two sets of results, the maximum and minimum extrusion-length best-fit results from the actual core-sample extrusions are included in Table 6.10. These values encompass all extrusion-length shear-stress results and thus are affected by sample location (for example, as presented in Rassat et al., estimated shear-strength values increase with depth, possibly due to lithostatic loading). The median extrusion-length best-fit results are therefore also included.

In each case, the actual core extrusions had median and maximum results two to four times greater than those determined from the mini extrusions of the composite samples. Possible explanations may include the effects of sample handling (see Onishi et al. 2003) or the smaller scale of the mini extrusions. Note that the mini extrusion results are generally bounded by the core-extrusion results.

The composite mini extrusion shear strength results are typically less than the rheometer measurements (Section 7.2). This result is not unexpected (Gauglitz and Aikin 1997, Heath 1987). For the B-203 composite, the mini extrusion BF estimate is almost five times less. The mini extrusion BF shear strength for composite samples from T-203 and T-204 ranges from 7.4 to 10 and 1.6 to 3.8 times less than the rheometer results respectively. Additionally, the median extrusion length best-fit results of the actual core sample extrusions presented in Rassat et al. (2003a) are two and four times less than the rheometer measurements for the composite samples in B-203 and T-203. In T-204, the rheometer measurement on the composite sample is approximately equivalent to the median best-fit result of the actual core sample extrusions. For the $30-\mathrm{wt} \%$ diluted samples of T-203 and T-204 waste, the mini extrusion results are 0.6 to 0.9 times and 1.3 to 1.7 times the rheometer results respectively.

It was expected that the 30 -wt $\%$ solids dilutions would have significantly reduced shear strength as compared to the undiluted samples (Onishi et al. 2003). This was achieved only to a limited extent (T-203; the diluted best-fit median is $445 \mathrm{~Pa}$, the undiluted best-fit median is $512 \mathrm{~Pa}$ : T-204; $514 \mathrm{~Pa}$ and $589 \mathrm{~Pa}$, respectively), but does not duplicate the effect identified by the rheometer results presented in Section 7.2. This result is a reflection of the sample density data, as, while longer extrusion lengths were recorded for the undiluted samples (10\% longer on the average), lower bulk density values were recorded for the undiluted composites ( $6 \%$ for T-203, and $9 \%$ for T-204). It is possible that the packing of the samples into the extrusion tubes (see Section 3.5) may have altered the density from that of the asmeasured state.

As noted in Rassat et al. (2003a), because of the numerous variables involved, it is not yet possible to use the core-extrusion methodology to estimate strength values with a high degree of certainty. For example, the mechanical behavior of the simulants may not match or bound that of the actual waste. Applying the extrusion technique to other simulants that more closely match the behavior of actual waste 
over the entire shear-strength range could potentially improve strength evaluations using the technique summarized here.

Table 6.10. Shear-Strength Results Based on Extrusion Length

\begin{tabular}{|c|c|c|c|c|c|c|c|}
\hline \multirow[b]{2}{*}{ Tank } & \multirow[b]{2}{*}{ Dilution } & \multicolumn{3}{|c|}{$\begin{array}{c}\text { Shear Strength (Pa) } \\
\text { Mini-Extrusion }\end{array}$} & \multicolumn{3}{|c|}{$\begin{array}{c}\text { Shear Strength }(\mathbf{P a}) \\
\text { Core Extrusion }^{(\mathrm{a})}\end{array}$} \\
\hline & & LB & UB & BF & BF min & BF max & BF med \\
\hline B-203 & Composite & 386 & 628 & 498 & 765 & 1,970 & 1,140 \\
\hline \multirow{7}{*}{$\mathrm{T}-203$} & \multirow{3}{*}{ Composite } & 440 & 717 & 569 & \multirow{7}{*}{387} & \multirow{7}{*}{1,610} & \multirow{7}{*}{1,030} \\
\hline & & 397 & 646 & 512 & & & \\
\hline & & 292 & 475 & 377 & & & \\
\hline & \multirow{4}{*}{ 30-wt\% Solids } & 319 & 519 & 412 & & & \\
\hline & & 370 & 602 & 478 & & & \\
\hline & & 381 & 620 & 492 & & & \\
\hline & & 256 & 417 & 330 & & & \\
\hline \multirow{6}{*}{$\mathrm{T}-204$} & \multirow{3}{*}{ Composite } & 311 & 507 & 402 & \multirow{6}{*}{581} & \multirow{6}{*}{1,990} & \multirow{6}{*}{1,090} \\
\hline & & 456 & 743 & 589 & & & \\
\hline & & 753 & 1,230 & 973 & & & \\
\hline & \multirow{3}{*}{30 -wt $\%$ Solids } & 391 & 636 & 505 & & & \\
\hline & & 514 & 837 & 664 & & & \\
\hline & & 398 & 648 & 514 & & & \\
\hline
\end{tabular}




\subsection{Paint Filter Test}

A modified paint filter liquids test, SW-846 Method 9095A (EPA 1994), was used to determine whether free liquid existed in the samples. One of the criteria associated with the WIPP Waste Acceptance Criteria is the absence of free liquid in the waste container. A minimum of $100 \mathrm{~g}$ of sample was used for all the paint filter tests except for the 30-wt\% solids dilutions of the Tank B-203, T-203, and T-204 composites. Insufficient sample was available from these dilutions to test 100 -g samples; therefore, the entire sample available (a minimum of $75 \mathrm{~g}$ ) was used for these tests.

The sample was placed in a paint filter (mesh number $60 \pm 5 \%$ ) supported in a glass funnel. The glass funnel was suspended in a ring stand over a graduated cylinder. The sample was allowed to drain for five minutes into the graduated cylinder. The amount of the sample filtrate was collected and measured in the graduated cylinder. If any sample passes through the filter and collects in the graduated cylinder, the sample is considered to contain free liquids and fails the paint filter test. The tests were conducted at room temperature. The fraction of the mass of total aliquot tested that passed through the paint filter and collected in the graduated cylinder for each tank composite and the associated dilutions is reported in Table 7.1 .

The paint filter test results in Table 7.1 indicate that none of the homogenized tank composites contained free liquids; therefore, they all passed the test. The $30-\mathrm{wt} \%$ solids dilutions from Tanks T-204 and T-203 also contained no free liquids and passed the paint filter test. These two dilutions had total solids contents of 29.4 and $30.7 \%$, respectively. The other dilutions, including the initial dilutions from Tank T-110 with a total solids content of $48.3 \%$ and the $30-\mathrm{wt} \%$ solid dilution from Tank B-203 with a total solids content of $28.5 \%$, failed the paint filter test. Only a small fraction of the aliquots, 0.01 and 0.03 from the initial dilution of Tank T-110 and the 30-wt \% solid dilution for Tank B-203, respectively, was present as filtrate at the conclusion of the test. Small adjustments in the amount of water added to prepare these dilutions may eliminate the filtrate obtained from these two samples and allow these dilutions to pass the paint filter test. A large fraction of the aliquots from the 1:1 and 4:1 dilutions of each tank composite was present as filtrate; therefore, these samples failed the paint filter test.

All samples from Tank T-204 with total solids contents larger than $29.4 \%$ and samples from Tank T203 with total solids contents larger than $30.7 \%$ passed the filter test, but samples from Tanks T-110 and B-203 need to contain total solids at concentrations greater than $48.4 \%$ and $28.6 \%$, respectively, to pass the paint filter test. Additional dilutions from Tanks T-110 and B-203 should be prepared and paint filter tests performed to determine the total solids content required to meet the paint filter test for these tank waste materials. 
Table 7.1. Paint Filter Test Results of Composites of Tanks T-110, T-204, B-203, T-203 and Various Dilutions

\begin{tabular}{|c|c|c|c|c|c|}
\hline $\begin{array}{c}\text { Tank } \\
\text { No. }\end{array}$ & Dilution & $\begin{array}{c}\text { Sample } \\
\text { Mass } \\
\text { (g) }\end{array}$ & $\begin{array}{c}\text { Solids by Oven } \\
\text { Drying at } 105^{\circ} \mathrm{C} \\
\text { (wt\%) }\end{array}$ & $\begin{array}{c}\text { Filtrate Fraction } \\
(w t / w t)\end{array}$ & Test Result \\
\hline \multirow{5}{*}{$\mathrm{T}-110$} & Composite & 105 & 62.2 & 0.00 & Pass \\
\hline & Initial & 103 & 48.4 & 0.01 & Fail \\
\hline & $30-w t \%$ & 102 & 29.3 & 0.22 & Fail \\
\hline & $1: 1$ & 121 & 15.3 & 0.71 & Fail \\
\hline & $4: 1$ & 105 & 6.4 & 0.95 & Fail \\
\hline \multirow{4}{*}{$\mathrm{T}-204$} & Composite & 110 & 31.5 & 0.00 & Pass \\
\hline & $30-\mathrm{wt} \%$ & 75 & 29.4 & 0.00 & Pass \\
\hline & $1: 1$ & 103 & 14.6 & 0.20 & Fail \\
\hline & $4: 1$ & 111 & 6.1 & 0.96 & Fail \\
\hline \multirow{4}{*}{ B-203 } & Composite & 103 & 40.5 & 0.00 & Pass \\
\hline & $30-w t \%$ & 82 & 28.6 & 0.03 & Fail \\
\hline & $1: 1$ & 101 & 19.7 & 0.29 & Fail \\
\hline & $4: 1$ & 109 & 8.5 & 0.90 & Fail \\
\hline \multirow{4}{*}{$\mathrm{T}-203$} & Composite & 103 & 34.3 & 0.00 & Pass \\
\hline & $30-\mathrm{wt} \%$ & 76 & 30.7 & 0.00 & Pass \\
\hline & $1: 1$ & 104 & 16.4 & 0.36 & Fail \\
\hline & $4: 1$ & 101 & 6.4 & 0.88 & Fail \\
\hline
\end{tabular}




\subsection{Stickiness Test}

An evaluation of the stickiness of the samples was determined by the method described in Section 3.8. Table 8.1 summarizes the results from this test. The results indicate that the homogenized tank samples from Tanks T-204 and B-203 are stickier than the composite from Tank T-203. The composite from Tank T-110 was significantly drier than the waste as it was removed from the tank; therefore, this composite was not very sticky. The addition of a small amount of water to this composite resulted in a material that was much stickier than the original composite. Tests of the $1: 1$ and $4: 1$ dilutions of all of the tank composites resulted in minimal retention of material on the stainless steel cylinder. The 30 -wt $\%$ dilutions of the Tank B-203 and T-203 composites were less sticky than the original composites from these tanks, while the 30-wt $\%$ dilution of the Tank T-204 composite was approximately as sticky as the composite from this tank.

Table 8.1. Stickiness Test Results of Tank T-110, T-204, B-203, and T-203 Samples

\begin{tabular}{||c|c|c|}
\hline Tank No. & Dilution & $\begin{array}{c}\text { Stickiness } \\
\text { (g) }\end{array}$ \\
\hline \multirow{4}{*}{ T-110 } & Composite & Insignificant \\
\cline { 2 - 3 } & Initial & 0.32 \\
\cline { 2 - 3 } & $30-\mathrm{wt} \%$ & Insignificant \\
\cline { 2 - 3 } & $1: 1$ & Insignificant \\
\hline \multirow{4}{*}{ T-204 } & $4: 1$ & Insignificant \\
\cline { 2 - 3 } & Composite & 1.02 \\
\cline { 2 - 3 } & $30-\mathrm{wt} \%$ & 1.35 \\
\hline \multirow{5}{*}{ B-203 } & $1: 1$ & Insignificant \\
\cline { 2 - 3 } & $4: 1$ & Insignificant \\
\cline { 2 - 3 } & Composite & 1.01 \\
\cline { 2 - 3 } & $30-\mathrm{wt} \%$ & 0.42 \\
\hline \multirow{5}{*}{ T-203 } & $1: 1$ & Insignificant \\
\cline { 2 - 3 } & $4: 1$ & Insignificant \\
\cline { 2 - 3 } & Composite & 0.63 \\
\cline { 2 - 3 } & $30-\mathrm{wt} \%$ & Insignificant \\
\cline { 2 - 3 } & $1: 1$ & Insignificant \\
\hline
\end{tabular}




\subsection{References}

Anderson JD. 1990. History of the 200 Area Tank Farms. WHC-MR-0132, Westinghouse Hanford Company, Richland, WA.

Bell KE. 1993. Tank Waste Remediation System Tank Waste Characterization Plan. WHC-SD-WMPLN-047, Rev. 1, Westinghouse Hanford Company, Richland, WA.

Bird RB, WE Stewart, and EN Lightfoot. 1960. Transport Phenomena. John Wiley \& Sons, New York.

Cooke GA. 2003. Tanks 241-B-203, 241-T-110, 241-T-203, and T-204: MAI TRU Composite

Preparation and Analytical Results for the Final Report. HNF-15703 Rev. 0, Fluor Hanford Inc., Richland, WA.

EI DuPont de Nemours \& Company, Inc. 1944. Hanford Technical Manual. Section C. Separations. HW-10475-C, General Electric Hanford Atomic Products Operation, Richland, WA.

Gasper KA, KD Boomer, ME Johnson, GW Reddick Jr, AF Choho, and JS Garfield. 2002.

Recommendation for Supplemental Technologies for Potential Mission Acceleration. RPP-11261 Rev. 0, CH2M HILL Hanford Group, Inc., Richland, WA.

Gauglitz PA and JT Aikin. 1997. Waste Behavior During Horizontal Extrusion: Effect of Waste Strength for Bentonite and Kaolin/Ludox Simulants and Strength Estimates for Wastes from Hanford Tanks 241-SY-103, $A W$-101, $A N-103$, and S-102. PNNL-11706, Pacific Northwest National Laboratory, Richland, WA.

Heath WO. 1987. Development of an In-Situ Method to Define the Rheological Properties of Slurries and Sludges Stored in Underground Tanks. PNL-6083. Pacific Northwest Laboratory, Richland, WA.

Onishi Y, BE Wells, ST Yokuda, and G Terrones. 2003. Feasibility Study on Using a Single Mixer Pump for Tank 241-AN-101 Waste Retrieval. PNNL-14105, Pacific Northwest National Laboratory, Richland, WA.

Rassat SD, LM Bagaasen, LA Mahoney, RL Russell, DD Caldwell, and DP Mendoza. 2003b. Physical and Liquid Chemical Simulant Formulations for Transuranic Wastes in Hanford Single-Shell Tanks. PNNL-14333, Pacific Northwest National Laboratory, Richland, WA.

Rassat SD, LA Mahoney, BE Wells, DP Mendoza, and DD Caldwell. 2003a. Assessment of Physical Properties of Transuranic Waste in Hanford Single-Shell Tanks. PNNL-14221, Pacific Northwest National Laboratory, Richland, WA.

Rector DR, and BC Bunker. 1995. Sedimentation Models. PNL-10154, Pacific Northwest National Laboratory, Richland, WA. 
U.S. Environmental Protection Agency (EPA). 1994. Test Methods for Evaluating Solid Waste, Physical/Chemical Methods. SW-846, U.S. Government Printing Office, Washington, DC. 


\section{Appendix A}

\section{Rheology Results}




\section{Appendix A: Rheology Results}

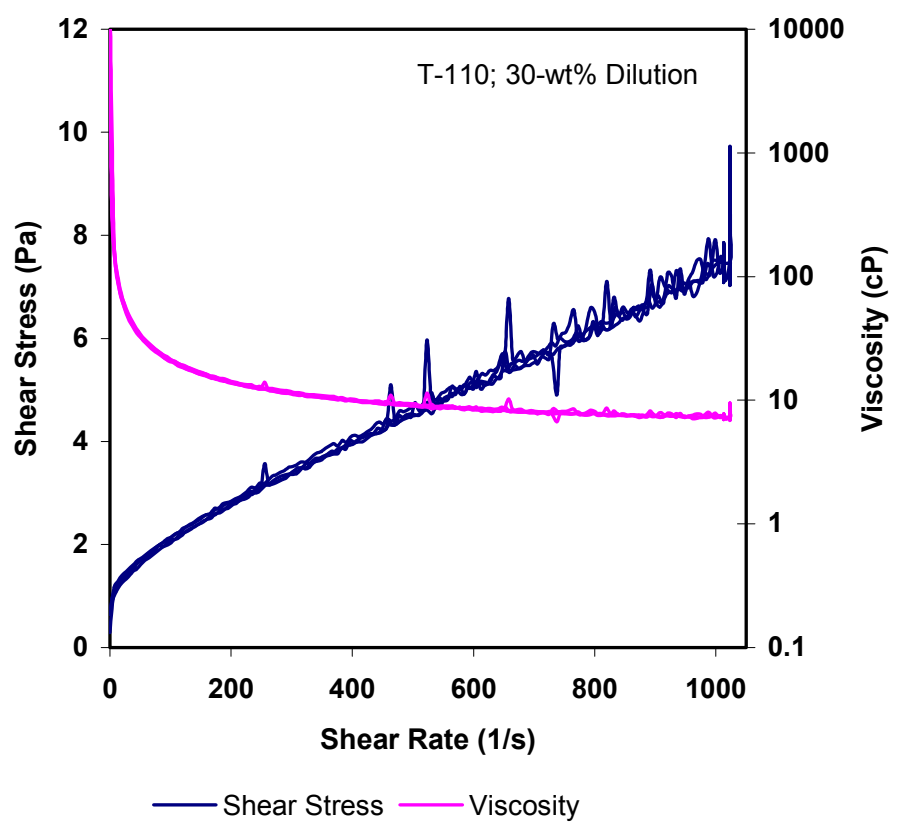

Figure A.1. Shear Stress and Viscosity vs. Shear Rate of the Tank T-110 30-wt\% Solids Dilution

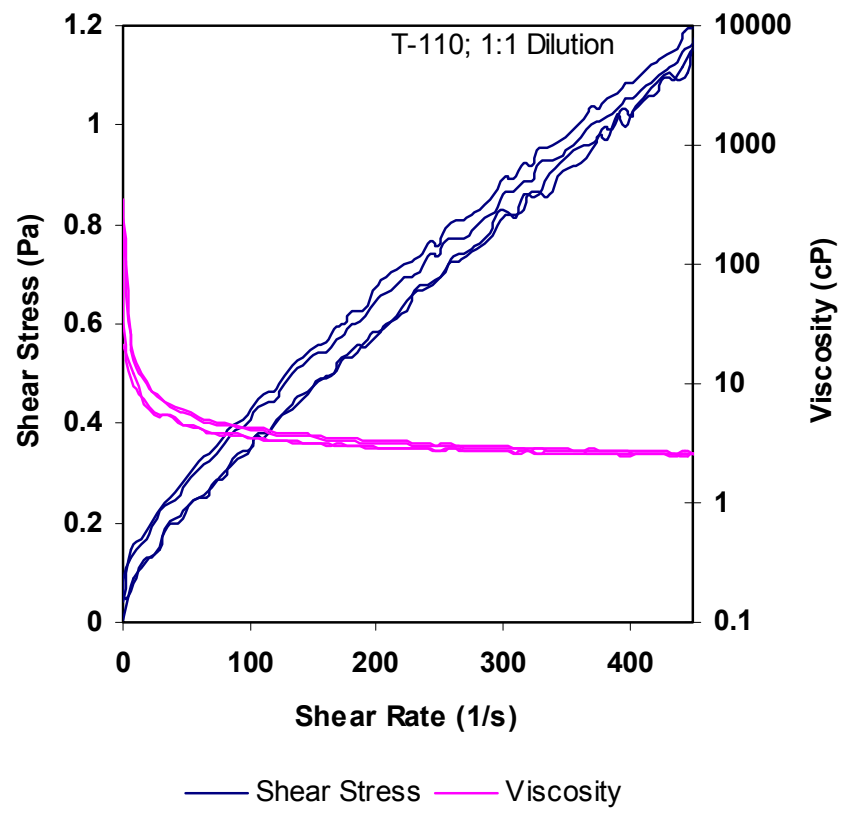

Figure A.2. Shear Stress and Viscosity vs. Shear Rate of the Tank T-110 1:1 Dilution 


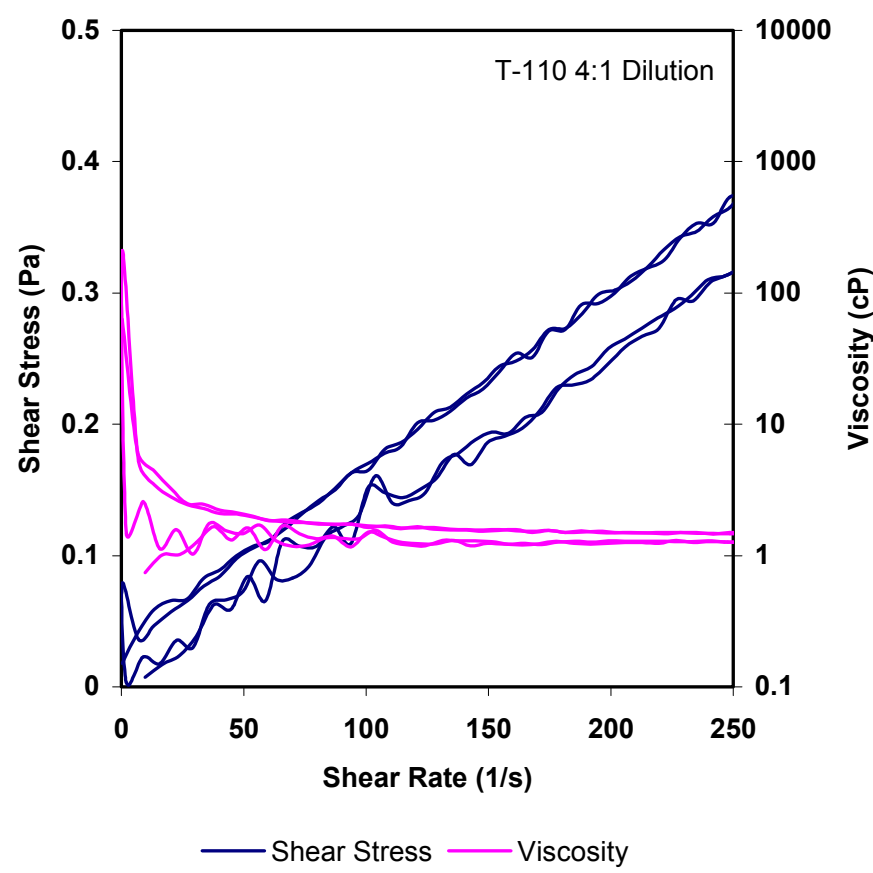

Figure A.3. Shear Stress and Viscosity vs. Shear Rate of the Tank T-110 4:1 Dilution

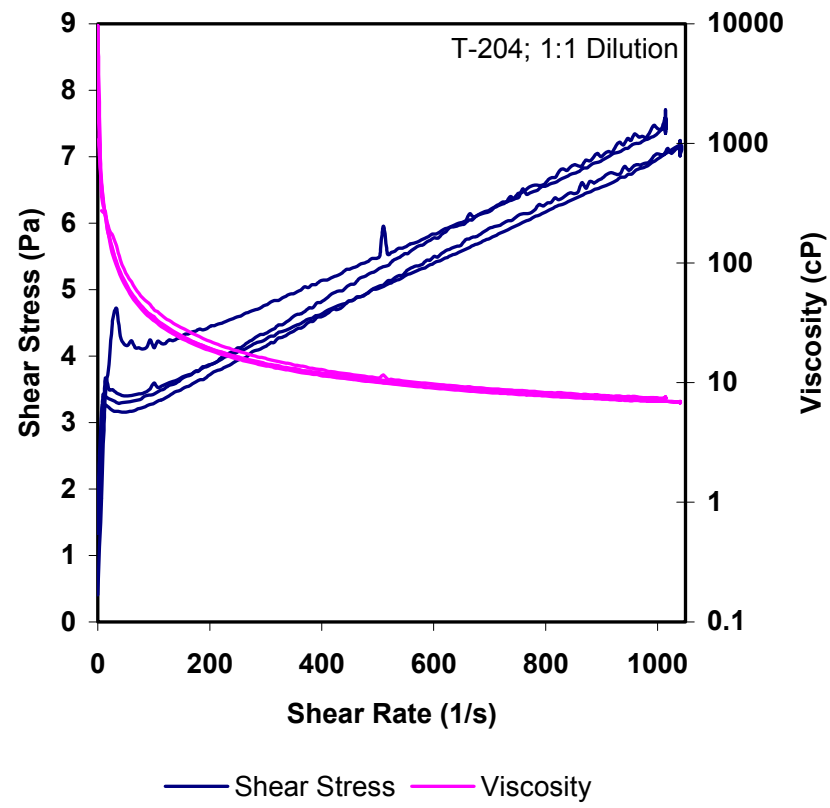

Figure A.4. Shear Stress and Viscosity vs. Shear Rate of the Tank T-204 1:1 Dilution 


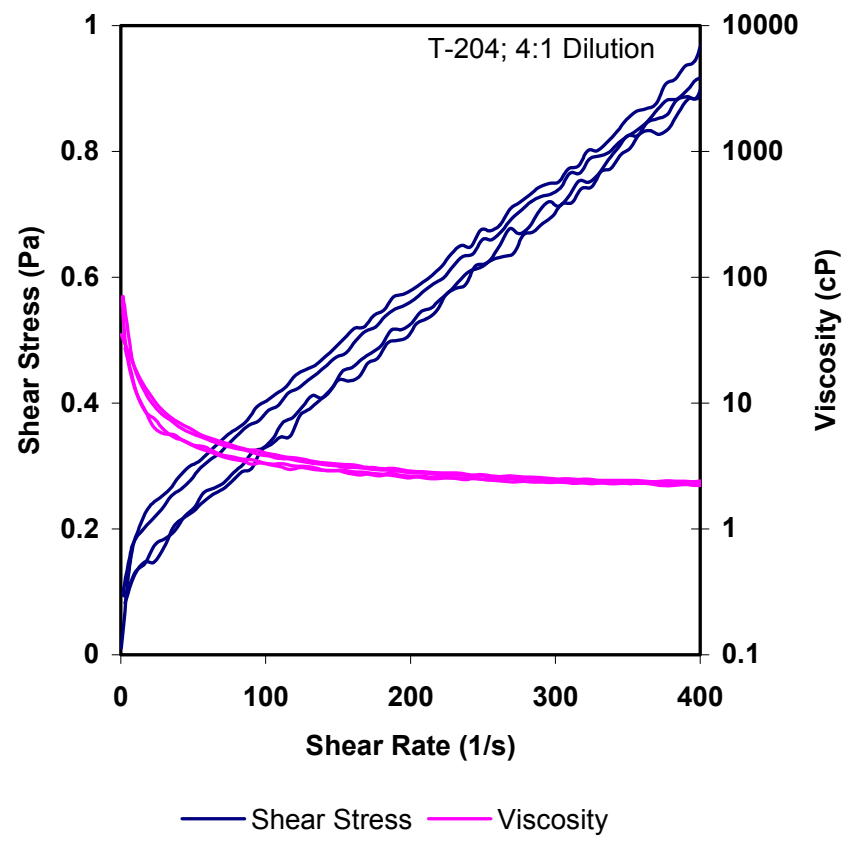

Figure A.5. Shear Stress and Viscosity vs. Shear Rate of the Tank T-204 4:1 Dilution

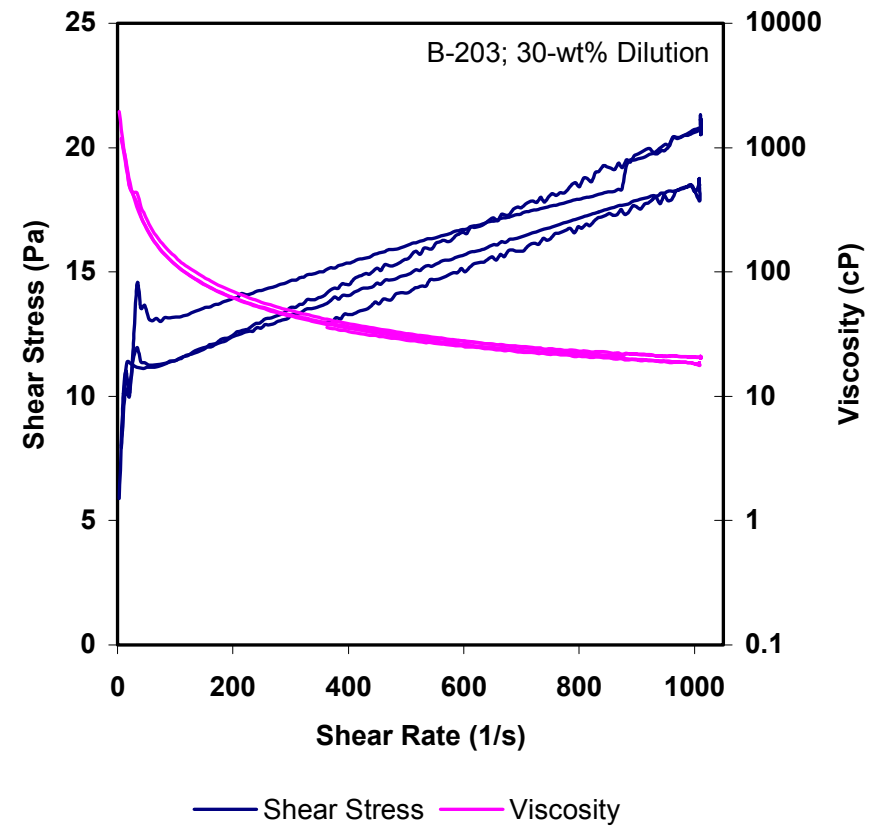

Figure A.6. Shear Stress and Viscosity vs. Shear Rate of the Tank B-203 30-wt\% Solids Dilution 


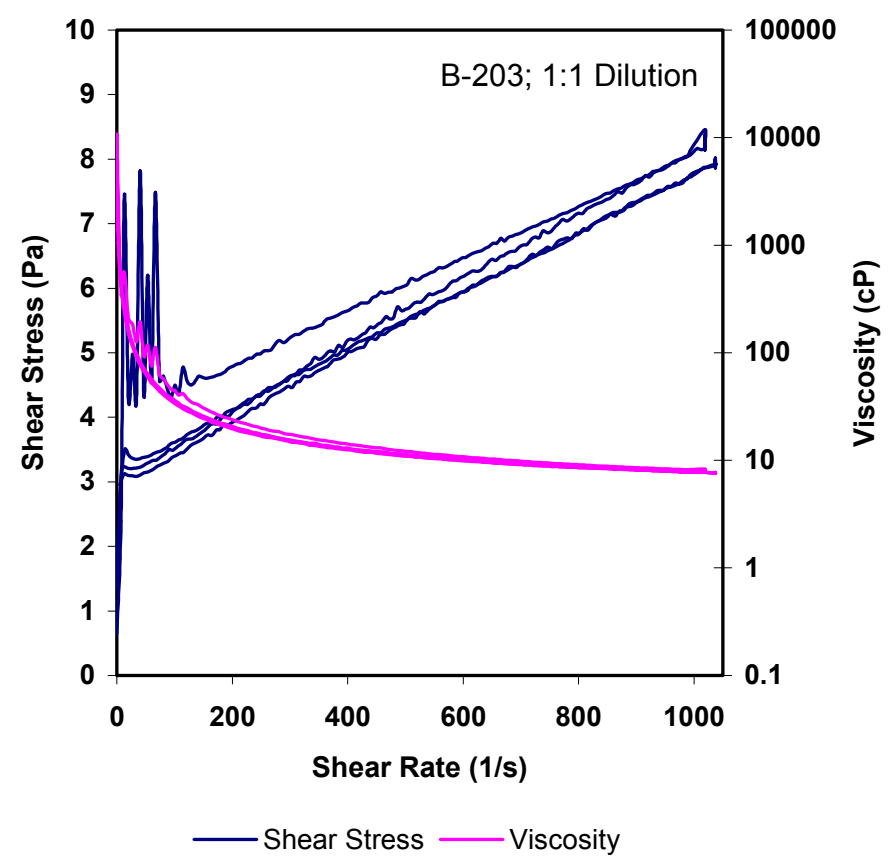

Figure A.7. Shear Stress and Viscosity vs. Shear Rate of the Tank B-203 1:1 Dilution

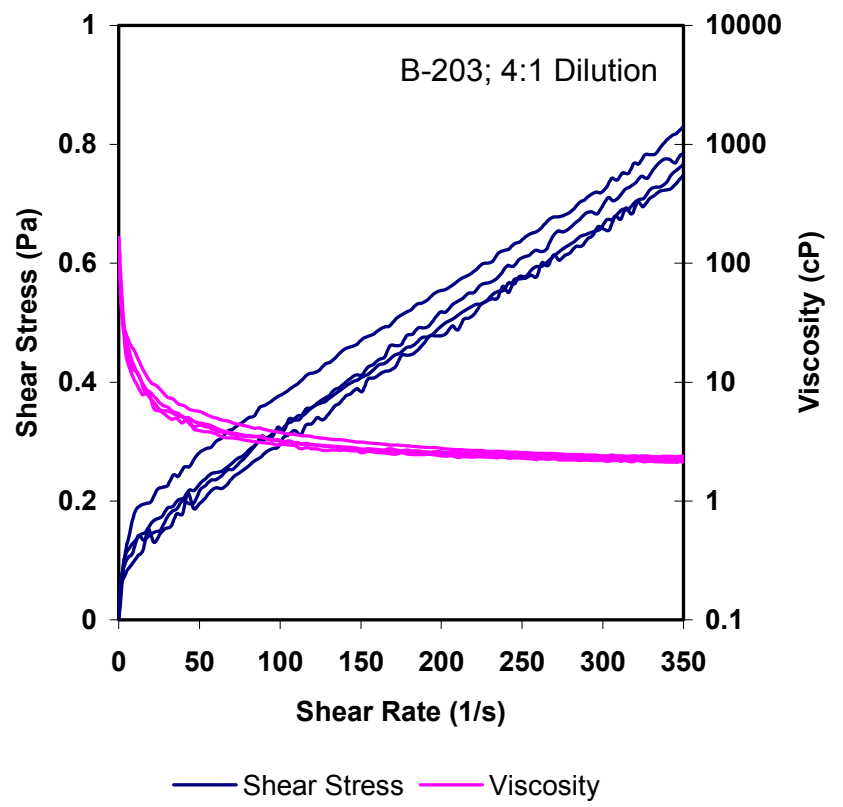

Figure A.8. Shear Stress and Viscosity vs. Shear Rate of the Tank B-203 4:1 Dilution 


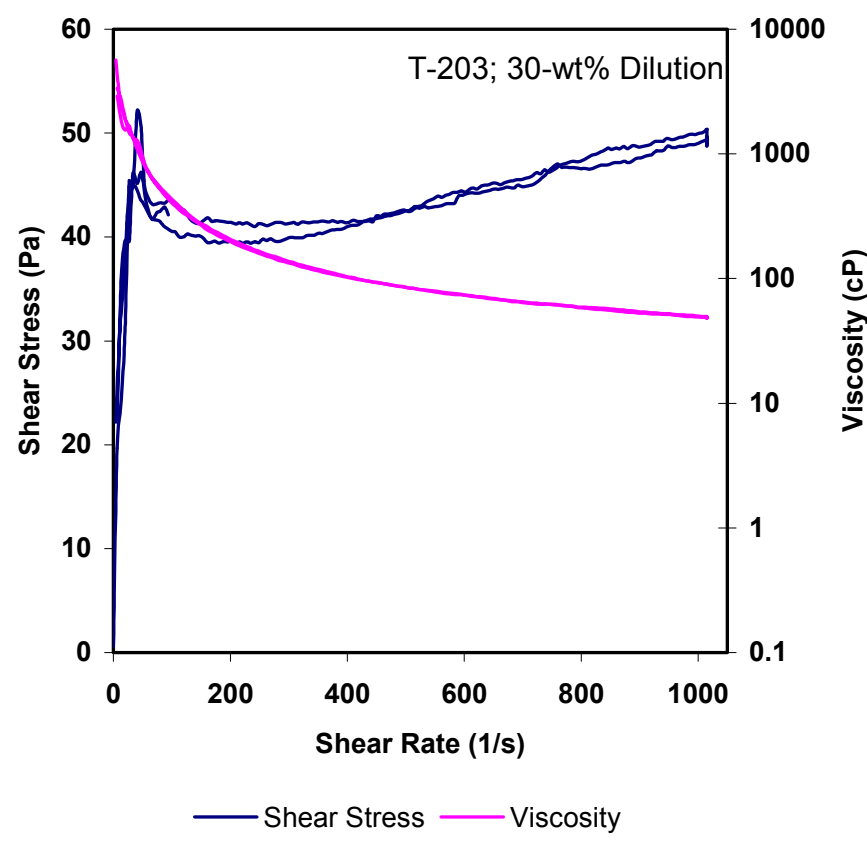

Figure A.9. Shear Stress and Viscosity vs. Shear Rate of the Tank T-203 30-wt\% Solids Dilution

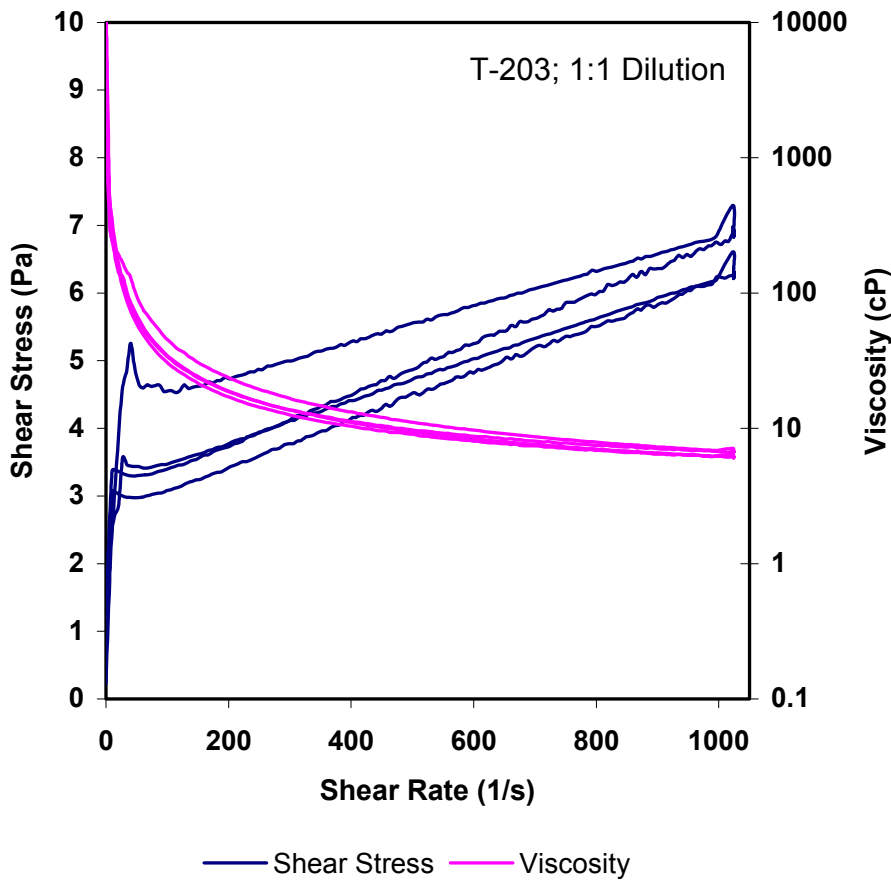

Figure A.10. Shear Stress and Viscosities vs. Shear Rate of the Tank T-203 1:1 Dilution 


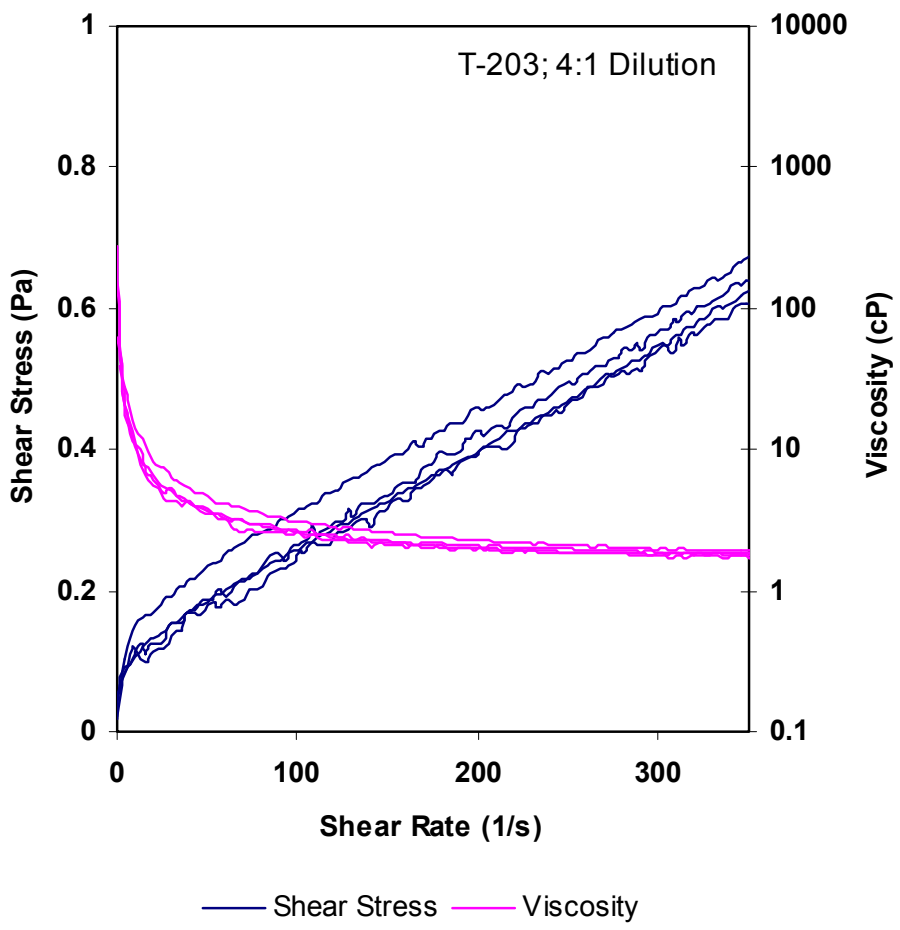

Figure A.11. Shear Stress and Viscosities vs. Shear Rate of the Tank T-203 4:1 Dilution 


\section{Distribution}

No. of

Copies

OFFSITE

1 Battelle-Dugway Proving Grounds

J. Gao

Life Sciences Test Facility

Battelle Dugway Operation

PO. Box 217

Bldg. 4329

Dugway, UT 84022

ONSITE

1 DOE Richland Operations Office

T. P. Pietrok

K8-50

1 DOE-Office of River Protection

B. M. Mauss

H6-60

19 CH2M HILL

K. D. Boomer

L4-07

P. M. Branson

S7-65

W. E. Bryan

D. W. Hamilton

M. E. Johnson

J. G. Kristofzski

M. W. Leonard

T. H. May

R. W. Powell (5)

R. E. Raymond

G. W. Reddick, Jr.

D. B. Smet

S7-70

H6-22

L4-07

H6-03

H6-19

H6-03

H6-64

H6-22

L4-07

S7-65

A. R. Tedeschi (3)

H6-22
No. of

Copies

\section{ONSITE}

31 Pacific Northwest National Laboratory

L. M. Bagaasen K6-28

S. Q. Bennett K7-90

J. W. Brothers K7-15

T. M. Brouns $\quad$ K9-69

D. D. Caldwell K6-28

W. C. Cosby K1-01

C. H. Delegard P7-25

P. A. Gauglitz (3) K6-28

G. B. Josephson K6-69

M. E. Lerchen K7-97

G. J. Lumetta P7-22

L. A. Mahoney K7-15

D. P. Mendoza K6-81

A. P. Poloski P7-25

S. D. Rassat K6-28

R. L. Russell K6-24

J. M. Tingey (10) P7-25

B. E. Wells K7-15

Information Release (2) K1-06

Distr. 1 